NATIONAL LABORATORY

MANAGED BY UT-BATTELLE

FOR THE DEPARTMENT OF ENERGY

\title{
FY 2000 Saltcake Dissolution and Feed Stability Workshop
}

\author{
R. D. Hunt \\ C. P. McGinnis \\ C. F. Weber \\ T. D. Welch \\ J.R. Jewett
}

Tanks

Focus

Area ${ }^{\circ}$

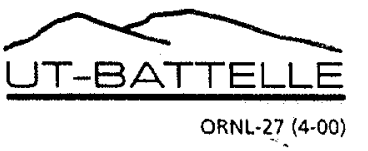


$\cdots \cdots$ 


\section{FY 2000 Saltcake Dissolution and Feed Stability Workshop}

Rodney D. Hunt, C. Phil McGinnis, Chuck F. Weber, and Timothy D. Welch

Oak Ridge National Laboratory

P.O. Box 2008

Oak Ridge, Tennessee 37831-6221

James R. Jewett

Retrieval Engineering

Numatec Hanford Corporation

P.O. Box 1300

Richland, Washington 99352

Letter Report presented to the

Pretreatment Technical Integration Manager of the Tanks Focus Area Office of Science and Technology

U.S. Department of Energy

in fulfillment of Milestone B.2-1 of TTP OR16WT41

July 31,2000

Prepared by the

OAK RIDGE NATIONAL LABORATORY

Oak Ridge, Tennessee 37831-6285

managed by

UT-BATTELLE, LLC

for the

U.S. DEPARTMENT OF ENERGY

under contract DE-AC05-00OR22725 



\section{LETTER REPORT}

To:

C. P. McGinnis

Subject of Document:

FY 2000 Saltcake Dissolution and Feed Stability Workshop

Type of Document:

Letter Report

Authors:

Rodney D. Hunt, C. Phil McGinnis, Chuck F. Weber, Timothy D. Welch, and James R. Jewett

Date of Document:

July 2000

\section{Internal Distribution}

1. Allen Croff, $4500 \mathrm{~N}, \mathrm{MS}-6178$

2-5. Rodney Hunt, 4501, MS-6221

6. Robert Jubin, 4501, MS- 6223

7. Phil McGinnis, $4500 \mathrm{~N}, \mathrm{MS}-6273$

8. Gene McNeese, $4500 \mathrm{~N}, \mathrm{MS}-6228$

9. Jack Watson, $4500 \mathrm{~N}$, MS-6178

10. Chuck Weber, 6011, MS-6370

11. Timothy Welch, $4500 \mathrm{~N}$, MS- 6273

12. ORNL Laboratory Records-RC

\section{External Distribution}

13. Hani Al Habbash, 205 Research Boulevard, Starkville, MS 39759-9734

14-15. Harry Babad, Babad Technical Services, 2540 Cordoba Court, Richland, WA 99352

16. Dennis Crass, Numatec Hanford Company, P.O. Box 1300, MSIN R3-47, Richland, WA 99352

17-18. Joe Cruz, Department of Energy, Office of River Protection, P.O. Box 550, MSIN H6-60, Richland, WA 99352

19. Andy Felmy, Pacific Northwest National Laboratory, MSIN K8-96, P.O. Box 999, Richland, WA 99352

20. John Garfield, Numatec Hanford Company, P.O. Box 1300, MSIN R3-73, Richland, WA 99352

21. Ken Gasper, CH2M Hill Hanford Group, P.O. Box 1500, MSIN H6-19, Richland, WA 99352 
22. Don Geniesse, COGEMA Engineering, 2425 Stevens Center, Richland, WA 99352

23. Pete Gibbons, Numatec Hanford Company, P.O. Box 1300, MSIN K9-91, Richland, WA 99352

24. Dan Herting, Fluor Daniel, P.O. Box 1970, MSIN T6-07, Richland, WA 99352

25. Jim Honeyman, CH2M Hill Hanford Group, P.O. Box 1500, MSIN H6-62, Richland, WA 99352

26. Albert Hu, CH2M Hill Hanford Group, P.O. Box 1300, MSIN R2-11, Richland, WA 99352

27. James Jewett, Numatec Hanford Company, P.O. Box 1300, MSIN R3-73, Richland, WA 99352

28. Randy Kirkbride, Numatec Hanford Company, P.O. Box 1300, MSIN R3-73, Richland, WA 99352

29. Bill Kuhn, Pacific Northwest National Laboratory, P.O. Box 999, MSIN K7-15, Richland, WA 99352

30. Jeff Lindner, DIAL, 205 Research Boulevard, Starkville, MS 39759-9734

31. Ruben Lopez, Florida International University, 10555 West Flagler Street, CEAS 2100, Miami, FL 33174

32. Graham MacLean, FFS, P.O. Box 1050, MSIN G3-10, Richland, WA 99352

33. Yasuo Onishi, Pacific Northwest National Laboratory, P.O. Box 999, MSIN K7-15, Richland, WA 99352

34. Eric Pacquet, Numatec Hanford Company, P.O. Box 1300, MSIN R3-47, Richland, WA 99352

35. Mike Rinker, Pacific Northwest National Laboratory, P.O. Box 999, MSIN K5-22, Richland, WA 99352

36. Wally Schultz, W2S Company, 12704 Sandia Ridge Place, NE, Albuquerque, NM 87111

37. Jenn Seidl, COGEMA Engineering, 2425 Stevens Center, Richland, WA 99352

38. Rajiv Srivastava, Florida International University, 10555 West Flagler Street, CEAS 2100, Miami, FL 33174

39. Tanks Focus Area Headquarters Program Lead, c/o Kurt Gerdes, DOE Office of Science and Technology, 19901 Germantown Road, 1154 CloverleafBuilding, Germantown, MD 208741290

40. Tanks Focus Area Program Manager, c/o T.P. Pietrok, U.S. Department of Energy, Richland Operations Office, P.O. Box 550, MSIN K8-50, Richland, WA 99352

41-48. Tanks Focus Area Technical Team, c/o B.J. Williams, Pacific Northwest National Laboratory, P.O. Box 999, MSIN K9-69, Richland, WA 99352

49. Becky Toghiani, Mississippi State University, School of Chemical Engineering, P.O. Box 9595, Mississippi State, MS 39762

50. Joe Westsik, Pacific Northwest National Laboratory, P.O. Box 999, MSIN K9-91, Richland, WA 99352

51. Rob Wilson, COGEMA Engineering, 2425 Stevens Center, Richland, WA 99352 


\section{CONTENTS}

PROGRAMMATIC OVERVIEW $\ldots \ldots \ldots \ldots \ldots \ldots \ldots \ldots \ldots \ldots \ldots \ldots \ldots \ldots \ldots$

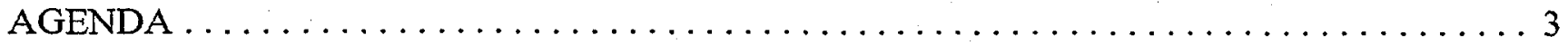

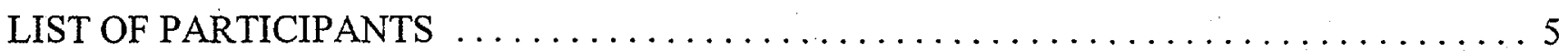

ADDITIONAL COMMENTS $\ldots \ldots \ldots \ldots \ldots \ldots \ldots \ldots \ldots \ldots \ldots \ldots \ldots \ldots \ldots \ldots$

Appendix A. TANKS FOCUS AREA PRESENTATIONS $\ldots \ldots \ldots \ldots \ldots \ldots \ldots \ldots \ldots$ A 1

Appendix B. OFFICE OF RIVER PROTECTION PRESENTATIONS $\ldots \ldots \ldots \ldots \ldots . .$. B-1 


\section{PROGRAMMATIC OVERVIEW}

The Tanks Focus Area (TFA) continues to work closely with the Office of River Protection (ORP) to better understand the chemistry involved with the retrieval, transport, and pretreatment of nuclear wastes at Hanford. Since a private contractor is currently responsible for the pretreatment and immobilization activities in this remediation effort, the TFA has concentrated on saltcake dissolution and waste transport at the request of the ORP. Researchers at Hanford have performed a series of dissolution experiments on actual saltcake samples. Staff members at Mississippi State University (MSU) continue to model the dissolution results with the Environmental Simulation Program (ESP), which is used extensively by ORP personnel. Several ways to improve the predictive capabilities of the ESP were identified. Since several transfer lines at Hanford have become plugged, TFA tasks at AEA Technologies, Florida International University (FIU), MSU, and Oak Ridge National Laboratory (ORNL) are investigating the behavior of the supernatants and slurries during transport. A combination

of experimental and theoretical techniques is used to study the transport chemistry. This effort is expected to develop process control tools for waste transfer. The results from these TFA tasks were presented to ORP personnel during the FY 2000 Saltcake Dissolution and Feed Stability Workshop, which was held on May 16-17 in Richland, Washington. The minutes from this workshop are provided in this report.

With the anticipated changes in the privatization effort at Hanford, the ORP is expected to rely more heavily on the TFA for technology development. In addition, discussions during and after the workshop confirmed the need for three new starts for FY 2001. The first initiative, which is already in the program plan for FY 2001, involves the development of methods to remove pipeline plugs. The other two initiatives will require modifications to the pretreatment plans for FY2001. These new starts are the radionuclide partitioning during saltcake dissolution and the addition of the Pitzer model to the ESP code.

The workshop also evaluated the ability of the TFA to respond to the needs and requirements of the ORP. During last year's workshop (FY 1999), participants identified several action items for the saltcake dissolution team. The status of each of these action items is listed below. Considerable progress has been made on nearly all of the action items. 
- Integration between the two pretreatment tasks (Saltcake Dissolution and Feed Preparation) and the retrieval task (Pipeline Plugs) is required.

Progress: The principal investigators for both pretreatment tasks participated in the same weekly conference calls, and a joint workshop was held. The Retrieval Technology Integration Manager also participated in the conference calls and in the workshop.

- The TFA researchers need to work more closely with the process engineers. The TFA products must be in a format that can be easily used by the process engineers.

Progress: Interaction between the ORP and TFA staff members has increased significantly through conference calls and kickoff meetings. TFA test plans were provided to the ORP personnel for their review and comment.

- The chemical forms that are selected by the ESP must be physically possible.

Progress: The TFA researchers continued to identify compounds and conditions that are problematic. In addition, several discrepancies in the ESP data bases were identified.

- When additional characterization information on a Hanford waste is needed for the modeling effort, the user should be contacted so that he or she can make the appropriate request to the Hanford Characterization Organization.

Progress: Due to limited funds, the Hanford Characterization Organization cannot respond to all of the requests. Whenever possible, the TFA staff performed the necessary chemical analyses.

- The data base for the double salts should be improved.

Progress: Solubility results for key double salts continued to be acquired.

- Input for the user guide on the ESP model and for the test cases to validate the new version of the ESP model was requested by ORP personnel.

Progress: Unfortunately, other ORP priorities severely limited progress on the user guide.

- Future ESP results should include the data base, the selected options, and the composition of the final feed.

Progress: The TFA researchers have been requested to include this information in their reports.

- Users should verify whether key assumptions in the TFA research are reasonable. Progress: ORP personnel were routinely asked to provide input on test conditions. 


\section{AGENDA}

\section{SALTCAKE DISSOLUTION AND FEED STABILITY WORKSHOP \\ The Conference Center in Richland, Washington \\ May $16-17,2000$}

Tuesday, May 16.2000

8:00 a.m. Introduction

Phil McGinnis and Joe Cruz

8:15 a.m. Review of FY 1999 Workshop (Path Forward and Action Items)

Chuck Weber

8:30 a.m. Single-Shell Tank Retrieval and Waste Feed Delivery Program

Warren Thompson and Randy Kirkbride

10:00 a.m. Saltcake Dissolution Tests and Modeling

Dan Herting and Becky Toghiani

1:00 p.m. Solubility Tests to Improve the ESP Data Base

Becky Toghiani and Jeff Lindner

1:30 p.m. Comparison of Calculations by ESP, SOLGASMLX, and Moonis Ally's Model

Becky Toghiani and Chuck Weber

2:00 p.m. Status and Planning of Hanford Data Base Reconstruction and Hanford Waste Speciation Prediction Code Using OLI Software

Albert Hu

2:30 p.m. Identification of Future Tests and Benefits

Becky Toghiani

3:00 p.m. River Protection Project: Status of Waste Transfers, Criteria, and Plugs

Dan Reynolds

3:45 p.m. Retrieval Tasks on Waste Transfers and Plugs

Pete Gibbons

4:30 p.m. Overview of the Feed Stability Tasks

Tim Welch 
Wednesday, May 17,2000

8:00 a.m. Saltwell Pumping/Pipeline Plugging

Jeff Lindner

8:45 a.m. Model Development for the Waste Transfers

Hani Al Habbash and Jeff Lindner

9:45 a.m. Pipeline Transfers at Florida International University

Ruben Lopez and Rajiv Srivastava

10:45 a.m. Identification of Future Tests and Benefits

Tim Welch

11:00 a.m. Program Outlook and Path Forward for Saltcake Dissolution and Feed Stability

Phil McGinnis and Randy Kirkbride 


\section{LIST OF PARTICIPANTS}

Name

Hani Al Habbash

Harry Babad

Dennis Crass

Joe Cruz

Andy Felmy

John Garfield

Ken Gasper

Don Geniesse

Pete Gibbons

Roger Gilchrist

Dan Herting

Kent Hodgson

Albert Hu

Rodney Hunt

Jim Jewett

Randy Kirkbride

Bill Kuhn

Jeff Lindner

Ruben Lopez

Graham MacLean

Phil McGinnis

Yasuo Onishi

Eric Pacquet

Dan Reynolds

Mike Rinker

Wally Schultz

\section{Organization}

Mississippi State University

Babad Technical Services

Numatec Hanford Corporation

Department of Energy

Pacific Northwest National Laboratory

Numatec Hanford Corporation/CH2M Hill Hanford Group

CH2M Hill Hanford Group

COGEMA Engineering

Numatec Hanford Corporation

Pacific Northwest National Laboratory

Fluor Hanford

CH2M Hill Hanford Group

Lockheed Martin Hanford Corporation

Oak Ridge National Laboratory

Numatec Hanford Corporation

Numatec Hanford Corporation/CH2M Hill Hanford Group

Pacific Northwest National Laboratory

Mississippi State University

Florida International University

Fluor Daniel Northwest

Oak Ridge National Laboratory

Pacific Northwest National Laboratory

Numatec Hanford Corporation

CH2M Hill Hanford Group

Pacific Northwest National Laboratory

W2S Company 
Name

Jenn Seidl

Rajiv Srivastava

Becky Toghiani

Chuck Weber

Tim Welch

Joe Westsik

Rob Wilson
Organization

COGEMA Engineering

Florida International University

Mississippi State University

Oak Ridge National Laboratory

Oak Ridge National Laboratory

Pacific Northwest National Laboratory

COGEMA Engineering 


\section{ADDITIONAL COMMENTS}

\section{Introduction}

\section{Phil McGinnis}

- Due to problems with the privatization contract, the TFA and the ORP will explore the need for additional technology development tasks to treat the nuclear waste at Hanford.

- The TFA and the ORP must take an integrated approach to solving the waste remediation problems at Hanford. Randy Kirkbride and Jim Jewett of the ORP continue to play key roles in the development and implementation of the TFA pretreatment tasks for Hanford.

- The TFA has considerable experimental and theoretical resources, which continue to support the needs of the ORP.

- The TFA is currently scheduled to fund several research tasks for FY 2001. These tasks can be divided into three groups: saltcake dissolution, feed stability, and sludge processing.

\section{Joe Cruz}

- While the problems with the privatization plan clearly indicate that changes are needed, the design effort for the pretreatment and vitrification facilities will continue as originally planned.

- A new milestone will be added to the salt well pumping task. This milestone will involve the development of a request for proposal to replace the current privatization contract.

- The remediation effort at the Hanford site is now under a consent decree. Therefore, a court will be involved with any missed milestones.

\section{Review of Saltcake Dissolution Workshop Held May 18-19, 1999}

\section{Chuck Weber}

- The Saltcake Dissolution Workshop focused on the following five major areas: the Hanford requirements, the use of the ESP code, the experimental efforts, the need for more communication between the TFA and the ORP, and the TFA program status.

- The Hanford Tank Waste Operations Simulator (HTWOS) and the ESP are the primary models used by ORP personnel. The HTWOS model is used to predict the effects of the waste transfer and to determine if the new waste meets the contract specification. 
- At the moment, the ORP is more concerned with physical constraints such as space and equipment availability than with waste compatibility.

- The ESP is used to determine if the proposed transfer will cause a problem based on the chemistries of the wastes.

- During FYs 1998 and 1999, the initial remediation of Tank SY-101 became a high priority. After this effort was completed, the ESP was used to model the results from the saltcake dissolution experiments on Tanks A-101, BY-102, and S-102.

- Unresolved issues may impact confidence in the ESP predictions. These issues include the various methods for charge reconciliation, the discrepancies in predictions between different versions of ESP, and the lack of solubility data for key chemical systems.

- Experimental results and other code calculations continue to be obtained in an effort to validate the ESP.

\section{Single-Shell Tank Retrieval and Waste Feed Delivery Program \\ Randy Kirkbride}

- The ORP has the details on the BNFL, Inc., flow sheets and has received some of the flow sheets, which contain a limited amount of experimental results.

- The HTWOS is a dynamic model for waste transfers. The model includes a mass balance and takes approximately $2 \mathrm{~h}$ per simulation.

- Experimental results and model predictions are used to develop tank-specific flow sheets.

- Due to the changes in privatization, the ORP needs to develop an integrated model for waste transfers and pretreatment, and operating envelopes for waste transfers may change.

- The ORP also needs a model that can predict the physical properties of slurries.

- The models are needed to support the limited experimental results.

- Tank AN-104 will be retrieved first due to concerns with flammable gases. The salts in Tank AN-104 contain high concentrations of sulfate, so several transfers may be needed.

- Tanks AN-102 and AN-107 may be caustic deficient, which can lead to corrosion.

- During saltcake dissolution, the ORP needs to know if precipitation will occur after the wash solutions are combined and if preferential dissolution will take place. 
- The entrained solids from saltcake dissolution will be sent to a double-shell tank.

- The latest version of the Tank Waste Remediation System's Operations and Utilization Plan (TWRSO\&UP II) is now available.

\section{Warren Thompson}

- The cost of retrieving the waste in Tank C-106 was over $\$ 1$ million. It may be possible to close Tank C-106. Data collection to support "operational closure" was initiated.

- FY 2000 plans include a 3-year acceleration of the retrieval schedule for the sludge in Tank C-104. Preliminary engineering will be initiated this year.

- Alternative retrieval technologies will be evaluated as appropriate. The crawler technology will be tested after the operators have been trained.

- Fifty-eight of the 149 single-shell tanks contain $90 \%$ of the long-term radionuclides, which do not include cesium. Forty-two of the 58 tanks are considered to be sound.

- One possible processing scenario is to demonstrate the retrieval process in a sound tank and then proceed to a leaking tank.

\section{Saltcake Dissolution Tests and Modeling}

\section{Dan Herting .}

- Dissolution experiments were performed on five saltcake samples, and the chemical composition of the saltcakes varied considerably.

- The saltcake sample from Tank S-102, which will be the first saltcake tank to be retrieved, was almost pure sodium nitrate and contained very little water.

- The dissolution results at 25 and $50^{\circ} \mathrm{C}$ were comparable.

- When the water washes were combined in the receiver jar, solids formed due to reduced solubility of certain components as the ionic strength was increased.

- The initial saltcake sample from Tank A-101 contains the sodium sulfate carbonate double salt. After the saltcake dissolution process, undissolved solids were primarily sodium carbonate.

- For Tank AN-104, ESP predicts that the sulfate will not reprecipitate when the supernatant and dissolved saltcake are recombined. 
- The saltcake from Tank TX-113 contained the sodium nitrate sulfate double salt, and no sodium nitrate was observed. The needle crystals were due to sodium phosphate or sodium carbonate.

- A compilation of optical data on all potentially relevant salts is under way to assist in the identification process. This information will be made available to TFA and ORP staff members.

- The sludge in the saltcake hinders the identification of the solids in the initial samples.

Becky Toghiani

- ESP calculations on the saltcakes from Tanks BY-102 and TX-113 indicated the need for special data bases. For Tank BY-102, the TRONA data base was needed for the high carbonate. The $\mathrm{Na} 2 \mathrm{SNaCl}$ data base was required for the high sulfate in Tank TX-113.

- The recommended practices for the ESP include the proration method of charge balancing and the preprocessing of important data. The ESP code encounters significant problems with saltcake samples that contain very little water.

- The ESP predictions encountered a problem with fluoride and sulfate. This difficulty may be due to the presence of a sodium fluoride sulfate double salt, which is not included in any of the ESP data bases.

- The ESP was used to predict solids that would form when the different wash solutions from a saltcake dissolution experiment were combined. The ESP predictions and the experimental results were in reasonable agreement. The ESP predicts the formation of gibbsite, which was not observed in the actual tests. However, the kinetics for gibbsite formation can be very slow.

- ESP also overestimates the formation of dawsonite, which is not stable at a pH above 9. Andy Felmy

- The modeling of dilution experiments is a trivial exercise. A rigorous validation of the ESP code requires chemical conditions where species are in two different phases.

- A systematic approach is needed to validate ESP. The phase diagrams for small groups of key constituents should be compared with ESP predictions.

\section{Dan Reynolds}

- Problems with ESP increase as the temperature of the chemical system increases. Improvements to the data bases may reduce these problems. 


\section{Solubility Tests to Improve the ESP Data Base}

\section{Jeff Lindner}

- The solubility tests on the fluoride and phosphate system were conducted in water, $1 \mathrm{~m}$ sodium hydroxide, and $3 \mathrm{~m}$ sodium hydroxide. Temperatures of 25,35 , and $50^{\circ} \mathrm{C}$ were used, and the minimum equilibration period was 2 weeks.

- ESP can use a temperature fit expression (KFIT) or the Gibbs free energy of formation to predict the equilibrium species distributions.

- The ESP consistently underestimated the solubility of sodium fluoride as compared with the SOLGASMIX code.

- For natrophosphate, the solubility increased slightly as the temperature was raised from 25 to $35^{\circ} \mathrm{C}$.

- With the current arrangement, OLI Corporation is able to fit the solubility results.

- A study on the solubility on the sodium fluoride sulfate double salt was initiated.

- Very limited information on the extent of hydrate formation for sodium carbonate, sodium phosphate, and sodium sulfate at elevated ionic strength is available.

- The solubility of sodium carbonate decreases as the ionic strength increases.

Randy Kirkbride

- The maximum processing temperatures for the saltcakes are the temperatures in the tanks. In contrast, the temperature of the sludges may be increased during sludge processing.

\section{Comparison of Calculations by ESP, SOLGASMIX, and Moonis Ally's Model}

\section{Becky Toghiani}

- The SOLGASMIX code models equilibria using Gibbs energy minimization and the Pitzer model, while Moonis Ally's model is a lattice model.

- The ESP predictions for sodium fluoride are dependent on the mode of calculation, which can be either KFIT or Gibbs free energy of formation.

- Solubility data from Hanford on the sodium, fluoride, and phosphate system was incorporated into the data base for ESP.

- The discrepancies between the ESP predictions and the experimental results for the sodium, fluoride, and sulfate system increase as the $\mathrm{pH}$ increases. 
- The predictions of the ESP and Moonis Ally's model are in good agreement at $25^{\circ} \mathrm{C}$. Deviations between ESP and the model increase at 100 and $125^{\circ} \mathrm{C}$.

\section{$\underline{\text { Randy Kirkbride }}$}

- When ESP was selected, it was the only commercially available software that provided a robust engineering tool. The ESP is not just a program to calculate chemical equilibria.

\section{Graham MacLean}

- At the time of the selection of ESP, CHEMSAGE, which is a commercial version of the SOLGASMIX code, was the only alternative. Although ASPEN can handle Pitzer parameter, this ability is not one of its strengths.

\section{Status and Planning of Hanford Data Base Reconstruction and Hanford Waste Speciation Prediction Code Using OLI Software}

\section{Albert Hu}

- Inconsistencies between ESP predictions and analytical results increase as the concentrations in the waste increase. The limitations of the ESP for extreme waste conditions must be validated.

- It would normally take a day for ESP to complete its waste speciation predictions for a single tank.

- The stream analyzer in ESP is not robust enough for the Hanford waste. Development of a windowbased code is needed to automate the modeling efforts and to increase the speed of the calculations.

- Water, nitrate, sodium, hydroxide, and nitrite account for nearly $88 \%$ of the Hanford waste. The ORP should establish the parameters of the binary electrolyte in this multicomponent system. Then, secondary components such as sodium carbonate, sodium fluoride, sodium phosphate, and sodium sulfate should be added.

- Equilibrium constant, ESP parameters, and solubility of sodium nitrate were determined using the OLI-modified Bromley electrolyte model of ESP.

- At temperatures below $50^{\circ} \mathrm{C}$, the new $\mathrm{K}_{\text {eq }}(\mathrm{ppt})$ agreed better with the public data base; above $50^{\circ} \mathrm{C}$, the new $\mathrm{K}_{\mathrm{eq}}(\mathrm{ppt})$ was closer to the Hanford data base.

- Errors in the $\mathrm{K}_{\mathrm{eq}}(\mathrm{aq})$ can lead to errors in the ionic strength, which can change all of the speciation calculations.

- The public data base for the ESP needs to be customized systematically to meet the ORP requirements. 


\section{Additional ESP Studies at the Hanford Site}

\section{Don Geniesse}

- A sensitivity study using the ESP is under way to determine the solubility of solids as a function of temperature and dilution. The results of this effort will be used by the ORP in flow sheet development.

- The ESP is known to have a problem with chromium chemistry.

\section{Identification of Future Tests and Benefits for Saltcake Dissolution}

Becky Toghiani

- The deficiencies in the ESP data bases should be addressed.

- The best way to treat saltcake with low water content needs to be determined.

- Sludge processing should be added to the current modeling effort on saltcake dissolution.

- Aluminum and chromium chemistry must be analyzed, and the results must be added to the ESP data bases.

\section{Andy Felmy}

- The ESP should be modified so it can accept Pitzer parameters.

\section{River Protection Project: Status of Waste Transfers, Criteria, and Plugs \\ Dan Reynolds}

- ESP has been used at the Hanford site since 1982.

- The maximum specific gravity for liquids and slurries to be transferred is $1.41 \mathrm{~g} / \mathrm{mL}$. Currently, the ORP is transferring 1 million gal of liquid waste per year from the single-shell tanks.

- The criteria for the transfers can be found in several semiofficial documents.

- In the past five years, three pipeline plugs have occurred during transfers from saltcake tanks. In each case, the transfer of the waste was suspended, and the pipeline was not flushed with water. The line from Tank BY-103 was abandoned. A hot water flush broke the plug from Tank SX-104, while a jumper was pulled to break the U-103 plug.

- Temperature can dramatically affect the weight percent of solids. For Tank SY-101, a sample contained $70 \%$ liquid at $65^{\circ} \mathrm{C}$. However, when the sample was cooled to $25^{\circ} \mathrm{C}$, it contained no free liquid. 
- No plug has ever been recovered and analyzed. Most plugs were probably due to sodium phosphate. The length of a sodium phosphate crystal and its density cannot be measured.

- During transfers, the needle crystals of sodium phosphate present a more significant problem than the round crystals of natrophosphate.

- Carbonate may have been responsible for the plug from Tank BY-103. No evidence for a plugged pipeline due to aluminum has been observed.

- The diameters of the slurry and supernatant transfer lines are 2 and 3 in., respectively. The new transfer lines are not heat traced and are designed for very high pressures.

$\underline{\text { Jim Jewett }}$

- The cost of replacing a transfer line depends on length, location, and many other factors.

\section{Retrieval Tasks on Waste Transfers and Plugs}

\section{Pete Gibbons}

- At the Savannah River Site (SRS), the heel in Tank 19 is an equal mixture of sludge and zeolites.

- In the retrieval task for the SRS, the particle size ranged from 5 to $20 \mu \mathrm{m}$.

- Potentially high-level waste sludges were discovered at Idaho.

\section{Overview of the Feed Stability Tasks}

\section{Tim Welch}

- The retrieval program of the TFA has focused on physical aspects of waste transfers, while the pretreatment program will examine fluid dynamics, thermodynamics, viscosity, precipitation, and crystallization.

- An on-line viscometer will be added to the pipeline system at FIU.

- One of the objectives is to define and validate better waste transfer criteria.

Harry Babad

- The sum of limitations for pipeline transfers can be found in the authorization basis.

- Future transfer tests should focus on waste that can lead to pipeline plugs.

- A transfer could encounter three phases: gas, liquid, and solid.

- Aging may influence the morphology of the solids. 


\section{$\underline{\text { Jim Jewett }}$}

- The document for the authorization basis covers the hazards to workers, the public, and the environment; it does not cover hazards to the program or to the equipment. The consequences of plugging generally fall into the latter category.

\section{Wally Schultz}

- Future pipeline tests need to examine recovery methods.

Randy Kirkbride

- Hanford engineers have limited process controls over the transfers. Options include the temperature, pump rate, and amount of dilution water.

\section{Don Geniesse}

- OLI Corporation has a kinetics program for precipitation and crystallization.

\section{Yasuo Onishi}

- The only requirement for the chemical portion of the transport model is to accurately predict the viscosity of the waste.

\section{Saltwell Pumping/Pipeline Plugging}

\section{Jeff Lindner}

- Variation in the chemical compositions in the simulant for Tank SX-104 can lead to gel formation, solid deposition, or both. Different plug mechanisms may be possible.

- Plugging from gel formation should result in a pressure drop different from plugging due to gradual particle deposition.

- For the waste transfer from Tank C-104, approximately 260,000 gal of diluent must be added to achieve a solids loading of 20 weight percent. The retrieved waste should conform to the storage criteria requirements.

- The gel is not covalently bonded.

Randy Kirkbride

- A thorough understanding of past problems can be used to prevent future problems.

- The results from saltwell pumping can be used during the retrieval of the saltcake tanks. 


\section{Model Development for the Waste Transfers}

\section{Hani Al Habbash}

- The current plan is to use the ESP and a commercial computational fluid dynamics (CFD) code.

- The CFD code must have multiphase capability. Fluid properties such as flow rates, pressure, and viscosity and particle properties such as size, shape, and growth kinetics are expected to be key variables.

- Four commercial CFD codes-CFD 2000, Fluent, Pheonics, and Tempest-were evaluated. Pheonics was selected due to its open source code, its pre- and post-processing capabilities, and its comprehensive physical models.

\section{Yasuo Onishi}

- It is very difficult to model a pipeline transfer. Empirical models usually provide better predictions. Any transfer model must emphasize the chemistry of the waste.

- In Tempest simulations, nearly $90 \%$ of the computational time may be used by the chemistry module.

\section{$\underline{\text { Randy Kirkbride }}$}

- The pipeline plugs occur when the temperature of a saturated solution drops. The ORP needs a tool to identify potential problems.

\section{Harry Babad}

- Models for the transfers of brine solutions may be useful in this effort.

Jim Jewett

- The cost of removing the most recent plug was between $\$ 700,000$ and $\$ 800,000$.

\section{Pipeline Transfers at Florida International University}

\section{Rajiv Srivastava}

- The ORP has proposed the transfer of slurries from Tanks AN-103 and C-104.

- The pipeline system at FIU will be used to simulate these proposed transfers. If a plug occurs, recovery methods will be tested.

- The flow rates in the FIU system will range from 2 to $8 \mathrm{ft} / \mathrm{s}$, while the typical flow rate of a slurry transfer at Hanford is $6 \mathrm{ft} / \mathrm{s}$.

- The pressure drop will be determined as a function of bulk viscosity and solids formation. 


\section{Dan Reynolds}

- The addition of fluoride to prevent the formation of sodium phosphate crystals is not an option.

- The use of steam will interfere with leak detection. However, the line can be preheated with hot water.

$\underline{\text { Joe Cruz }}$

- Two major concerns for the ORP are pipeline plugs and tank space. Efforts to reduce the potential for pipeline plugs must be balanced with the limited amount of tank space.

\section{Identification of Future Tests and Benefits}

\section{$\underline{\text { Randy Kirkbride }}$}

- Pipeline plugs during the Phase I transfers are unlikely. The FIU tests should confirm this conclusion.

Dan Reynolds

- Future tests should focus on recovery methods from full and partial plugs.

- The conditions that lead to phosphate or carbonate plugs should be evaluated further. The waste that was responsible for the last cross-site line plug contained very little phosphate and a considerable amount of carbonate.

- A chemical analysis of a sample before it is transferred is critical.

- In addition to pipeline plugs, feed stability should also focus on waste compatibility, criticality, and flammable gases.

Jim Jewett

- The chemical composition of the waste should be included in the transfer criteria.

\section{Program Outlook and Path Forward for Saltcake Dissolution and Feed Stability}

\section{Phil McGinnis}

- This workshop has identified two additional needs that should be addressed by the TFA. These needs are the partitioning of radionuclides during saltcake dissolution and the addition of Pitzer parameters to the ESP. The effort to include these new tasks in the TFA program plan for FY 2001 was initiated. 


\section{Randy Kirkbride}

- ESP in its current form is important and heavily used.

- The TFA should continue to improve the ESP model and its data bases.

- The TFA should support Onishi's need for chemistry during waste transfers.

- The ORP supports the proposed modifications to the TFA work scopes for FY 2001.

- The ORP should decide on the best way to handle the various ESP data bases.

- The ORP should determine if the preferential dissolution of salts offers any significant advantages.

- Potential users of the TFA results need to make themselves known and be identified. 
Appendix A

TANKS FOCUS AREA PRESENTATIONS 


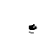




\section{Review of FY 1999 Workshop}

Charles F. Weber

Presented at the FY 2000

Saltcake Dissolution and Feed

Stability Workshop

May $16-17,2000$

\section{Review of FY 1999 Workshop}

- Hanford requirements

- Use of ESP code

- Experimental efforts

- Communication

- TFA Program Status

\section{Hanford Processing Operations} Require Modeling Support

- Modeling and simulation tools

- Hanford Tank Waste Operations Simulator (HTWOS)

$\bullet$ ESP

- Problem areas

- Remediation of tank SY-101

- Evaluations of other tanks (S-102, A-101, BY-102)

- Ability to match dissolution experiments

\section{ESP Is an Important} Analytical Tool

- Minimize need for actual experiments

- Establish parameters for tank farm operations

- Improvements needed

- Avoid excess conservatism in operations

- Match all experiments

\section{Unresolved Issues May Affect Confidence in ESP Predictions}

- Method of charge reconciliation

- Discrepancies with certain experimental results

- Validation needed

- Previous versions of ESP

- Other code calculations

- Experimental data

- Need for improvement in OLI data bases

\section{Experiments in Support of Code Validation and Modeling}

- Effects of dilution, viscosity

- Saltcake dissolution tests (Herting)

- Solubility of $\mathrm{Na}-\mathrm{F}-\mathrm{PO}_{4}$ and other double salts

- Isopiestic measurements 


\section{Communication Is Essential}

- TFA researchers and users

- Integration between different tasks

- Validation of ESP

- Test cases relevant to users

- Comparison with other code calculations

- Better explanations of input and data sets

- Collaboration with OLI to improve data sets 


\section{Saltcake Workshop 2000}

Richland, May 16, 2000

Hanford Laboratory Program

TTP No. RL-08-WT-41

D. L. Herting, PI

\section{Hanford FY2000 Tasks}

- Task A - Feed Stability (5 tanks)

- stepwise dissolution to model retrieval

- Task B - Batch Dissolution (TX-113)

- sequential dissolution to determine composition

- series dissolution to measure trends

- Task C - Solids Analysis/Identification

- PLM, SEM/EDS, XRD 


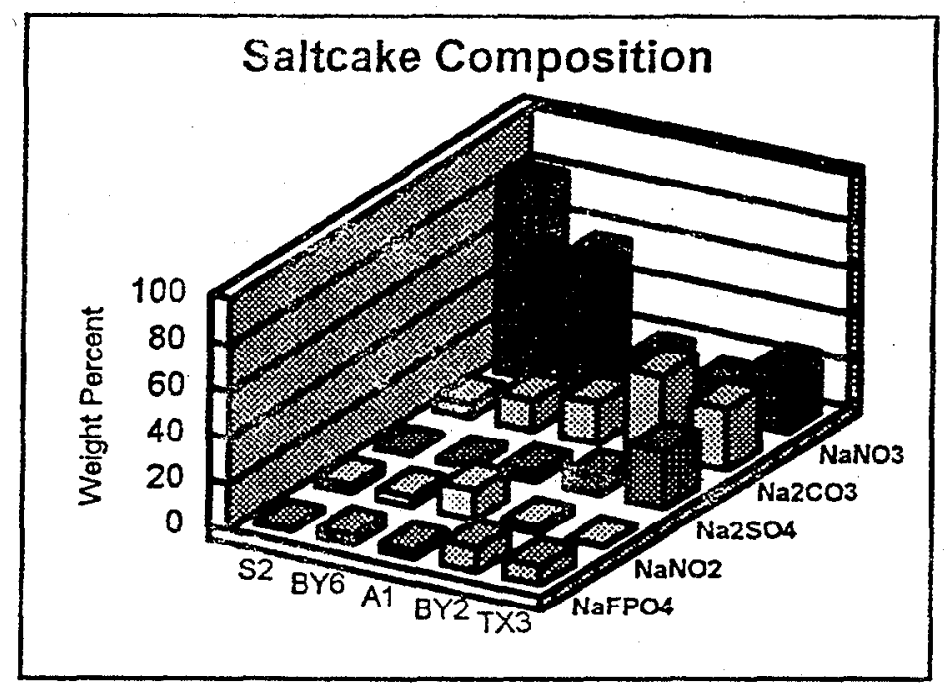

\section{Feed Stability Procedure}

1. Start with "source tank" and "receiver"

2. Add 30 g saltcake to "source tank"

3. Add 15 g H2O, mix, centrifuge

4. Decant liquid to "receiver", weigh solids

5. Repeat steps $3 \& 4$ total of 10 contacts

6. Identify solids that form in "receiver" 


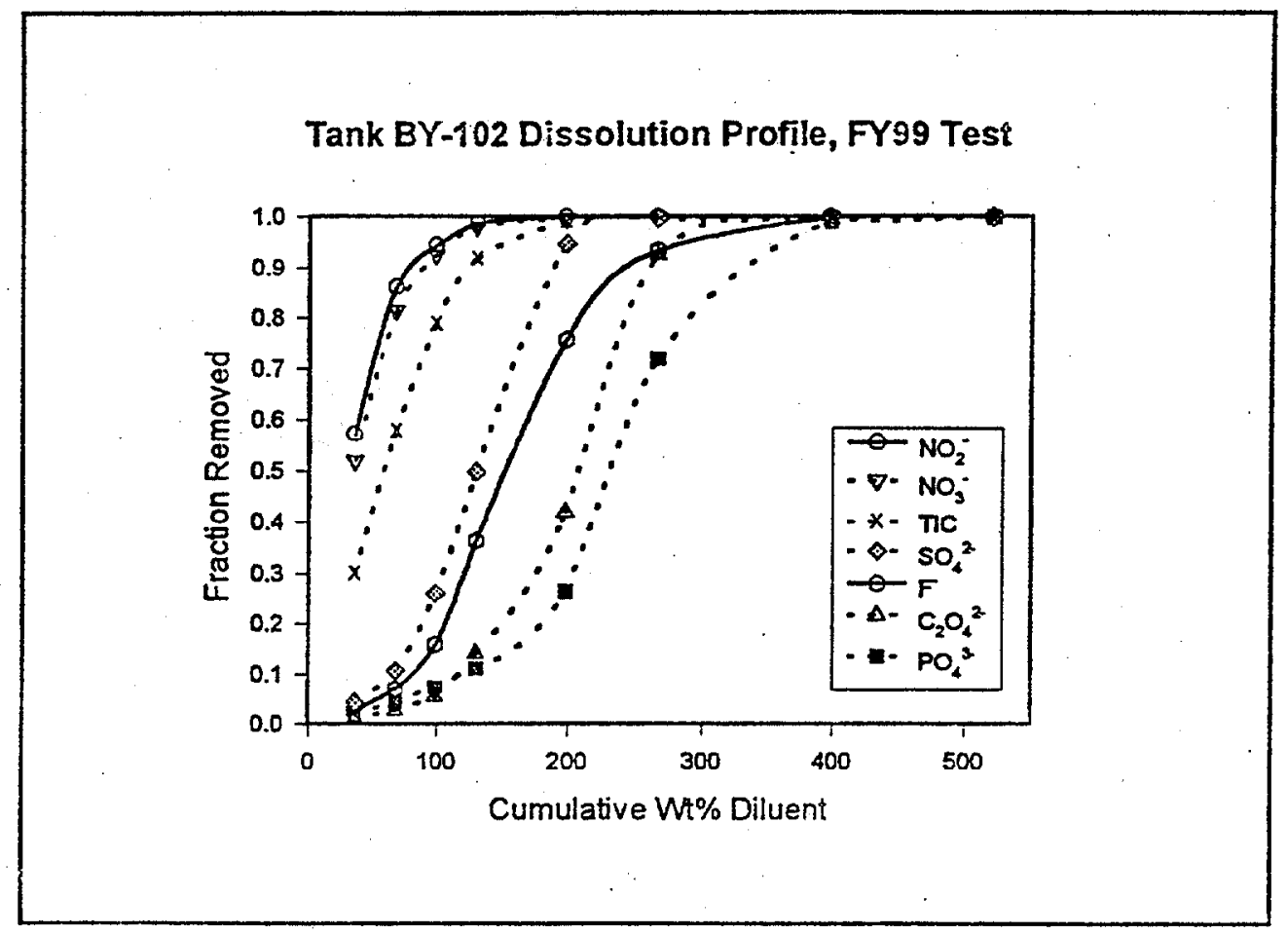

\section{Saltcake Dissolution Progress}

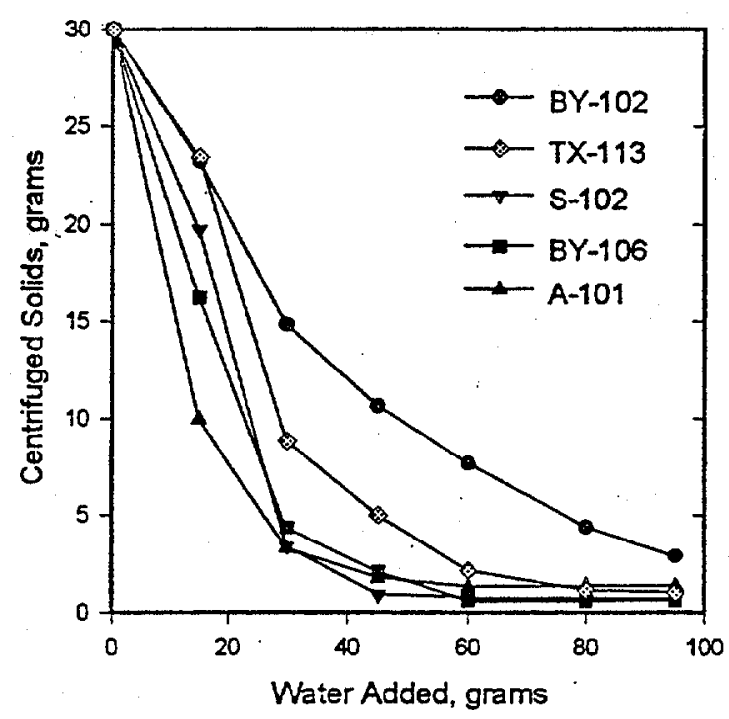




\section{Solids Formed in Receiver}

(no solids formed in S-102)

\begin{tabular}{|c|c|c|c|c|}
\hline Contact & BY2 & BY6 & A101 & TX3 \\
\hline 2 & S, FS, FP & & & S, FS \\
\hline 3 & FS, Ox, FP & Ox & Ox & FP \\
\hline 4 & & Ox & & FP \\
\hline 5 & FP & & & \\
\hline 6 & FP, Ox & & & \\
\hline
\end{tabular}

\section{Conclusions}

- Salts dissolved in tank A re-form in tank B

- Quickly reach point of diminishing return

- Plan retrieval carefully 


\section{Task B - Batch Dissolution, TX-113}

- Sequential Dissolution (ESP Input)

$-30 \mathrm{~g}$ saltcake $+30 \mathrm{~g} \mathrm{H}_{2} \mathrm{O}$, mix, decant Wash \#1

- Add 30 g H$_{2} \mathrm{O}$, mix, decant Wash \#2

- Analyze Washes $1 \& 2$ + residual solids

- Series Dissolution (ESP Output)

- $\mathrm{X}$ g saltcake $+\mathrm{nX} \mathrm{g} \mathrm{H}_{2} \mathrm{O}$, where $\mathrm{n}=0.5,1.0,1.5,2.0,2.5,3.0$

- Analyze liquid phase

\section{Tank TX-113 Composite Sample}

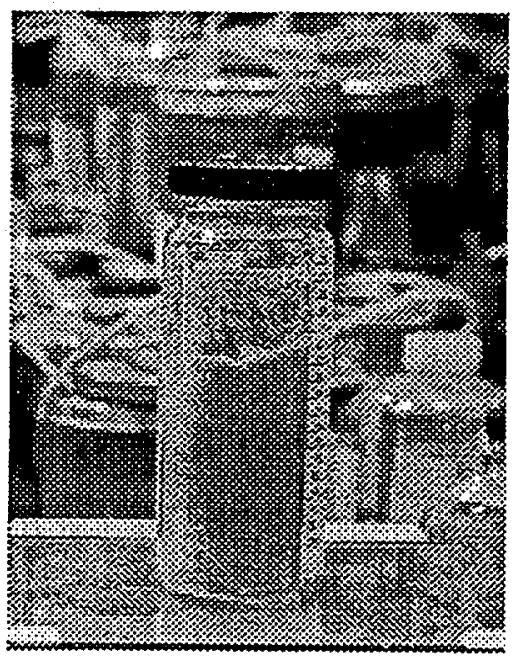




\section{TX-113 PLM, Original Sample}

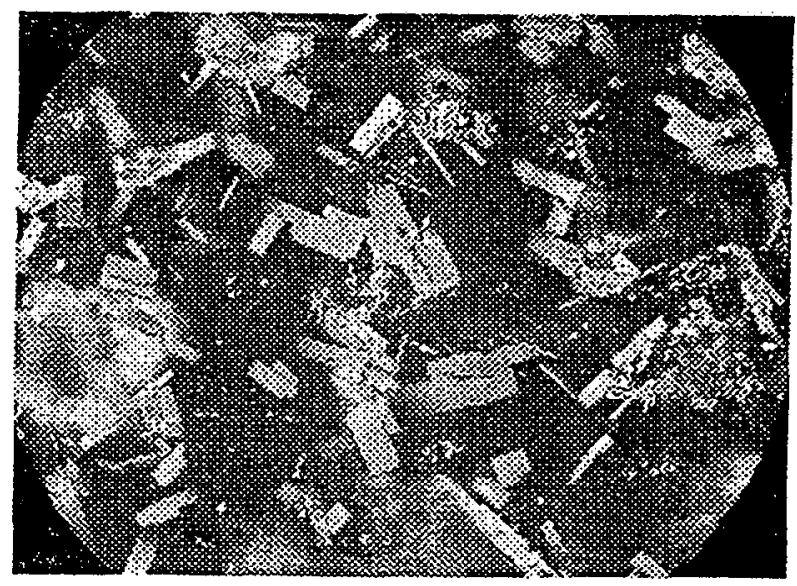

\section{Types of Double Salts}

- Congruent:

$$
\mathrm{Na}_{7} \mathrm{~F}\left(\mathrm{PO}_{4}\right)_{2} \cdot 19 \mathrm{H}_{2} \mathrm{O}(\mathrm{s})+\mathrm{H}_{2} \mathrm{O} \rightarrow 7 \mathrm{Na}^{+}+\mathrm{F}^{-}+2 \mathrm{PO}_{4}{ }^{3-}
$$

- Incongruent:

$$
\mathrm{Na}_{3} \mathrm{NO}_{3} \mathrm{SO}_{4} \cdot \mathrm{H}_{2} \mathrm{O}(\mathrm{s})+\mathrm{H}_{2} \mathrm{O} \rightarrow \mathrm{Na}_{2} \mathrm{SO}_{4}(\mathrm{~s})+\mathrm{Na}^{+}+\mathrm{NO}_{3}^{-}
$$


TX-1 13 Series Dissolution

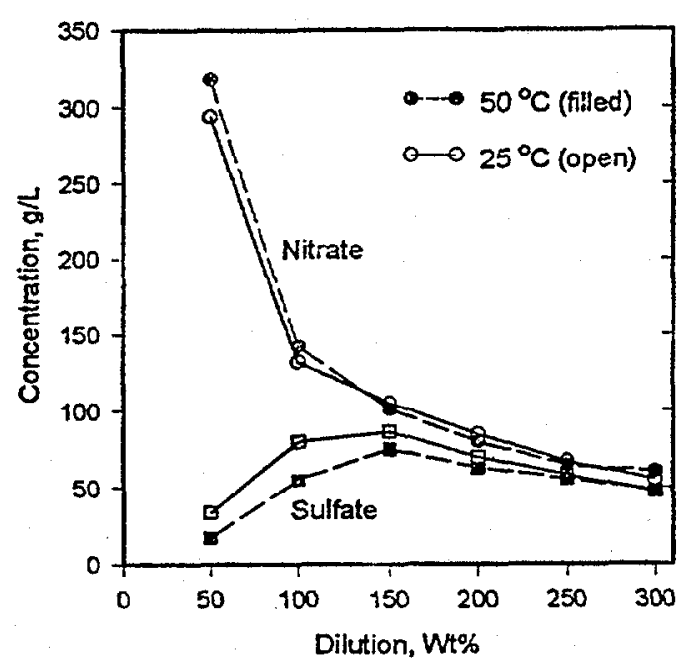

\section{Task C - Solids Identification}

- PLM - polarized light microscopy

- SEM/EDS - scanning electron microscopy $+\mathrm{x}$-ray fluorescence

- XRD - x-ray diffraction

- Example: $\mathrm{Na}_{3} \mathrm{FSO}_{4}$ 


\section{$\mathrm{Na}_{3} \mathrm{FSO}_{4}$ Optical Data}

- Crystal system: hexagonal

- Habit: basal tablets or rhombohedra

- Polarization info: uniaxial positive birefringence $=0.003$ (very low) $\mathrm{n}_{\mathrm{o}}=1.426 ; \mathrm{n}_{\mathrm{e}}=1.429$

\section{PLM Photo of $\mathrm{Na}_{3} \mathrm{FSO}_{4}$}

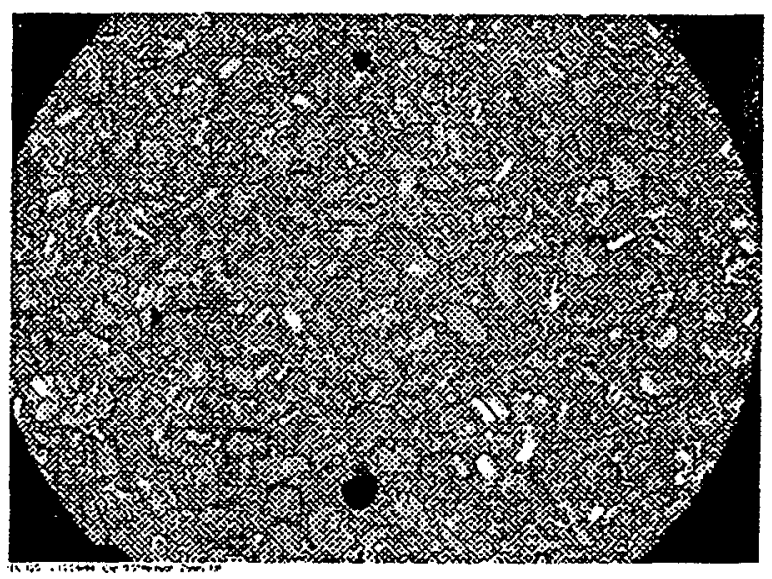



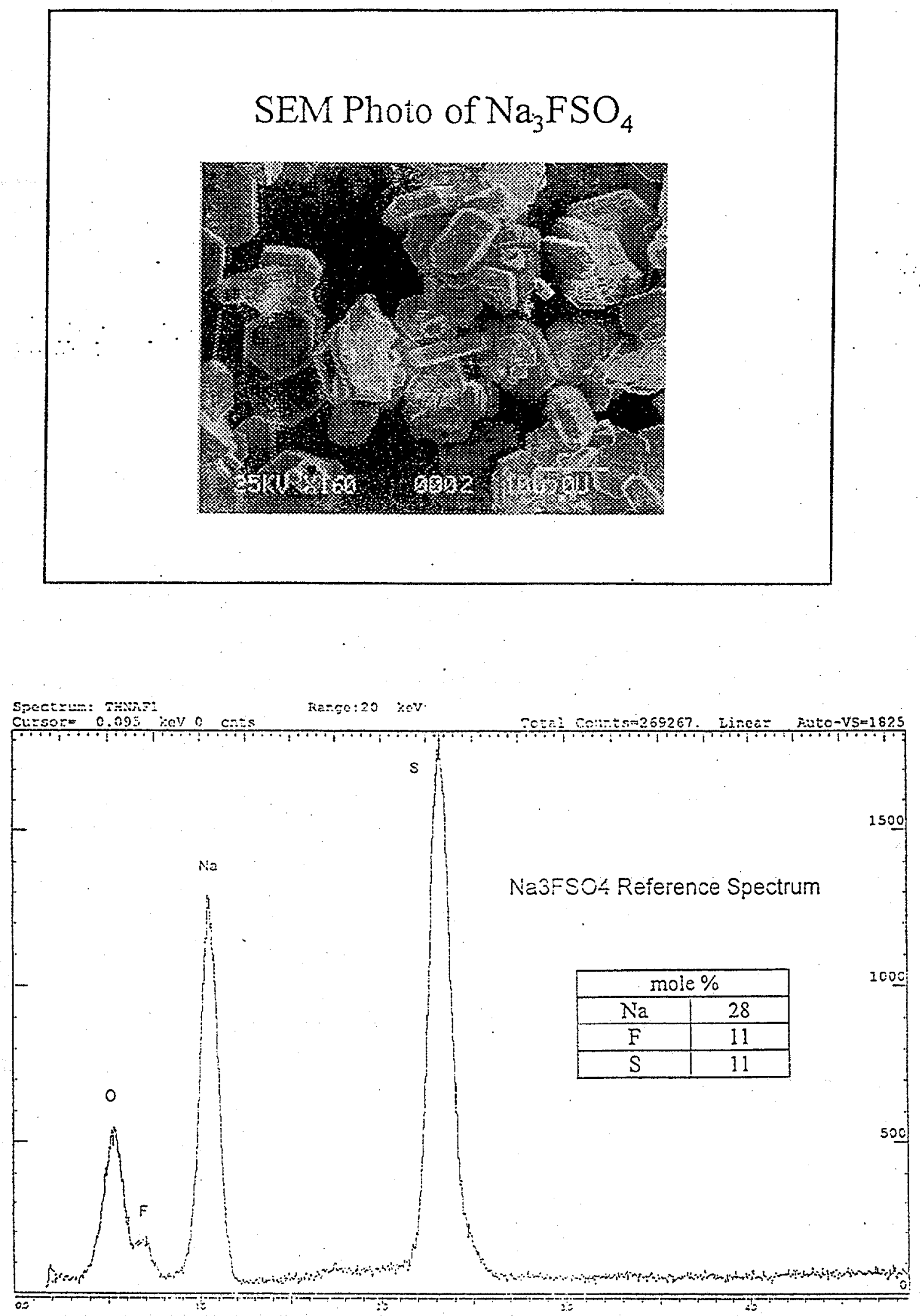

A-13 


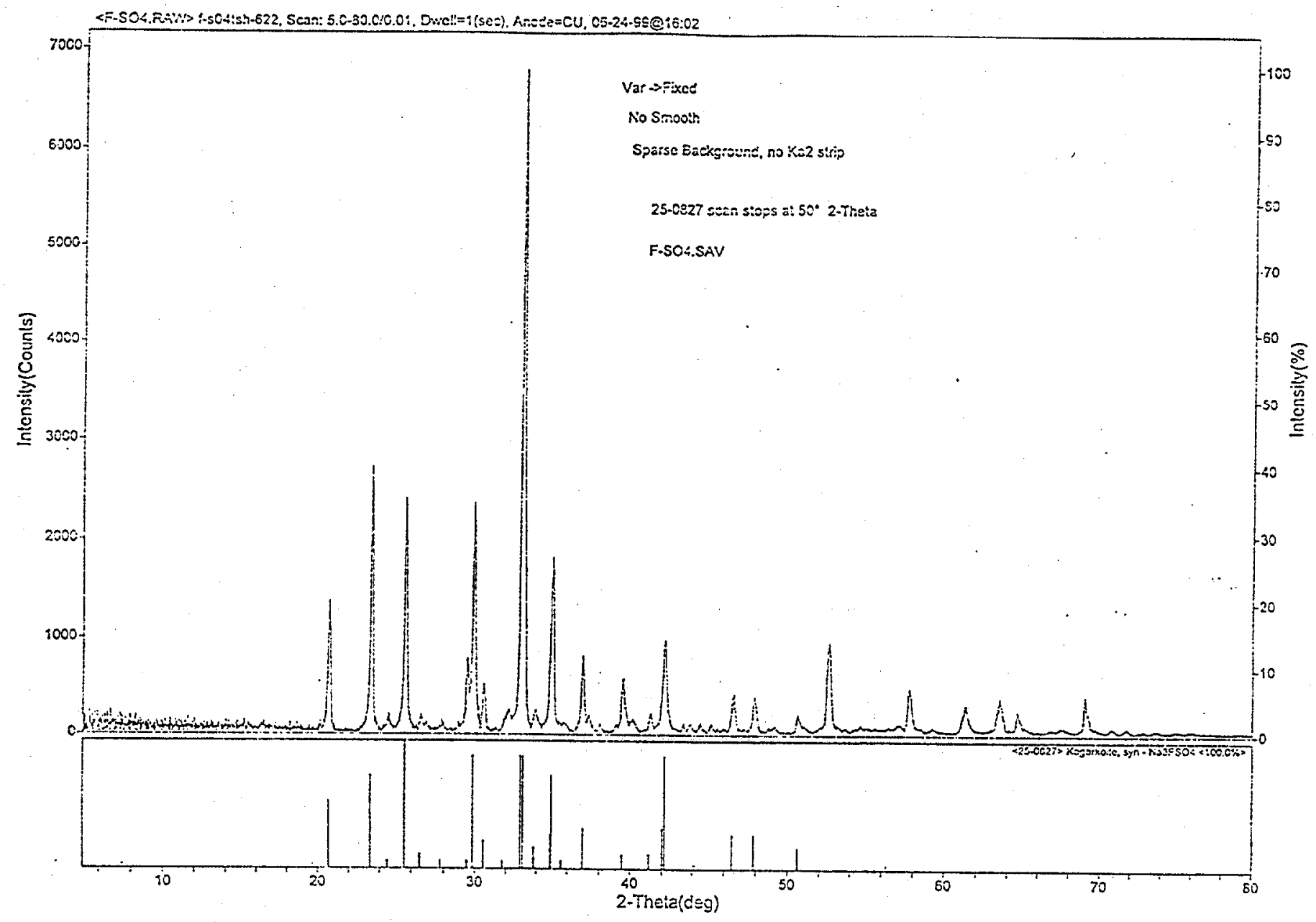

\section{Plans for FY2001}

- one more tank (tbd) for ESP

- continue solids analysis development

- expand feed stability to mixed tanks?

- identify solids that don't dissolve?

- determine ${ }^{99}$ Tc distribution?

- expand and dovetail simulant testing for "physical" parameters 


\section{Saltcake Dissolution Modeling}

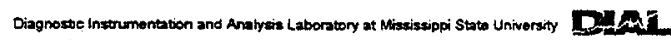

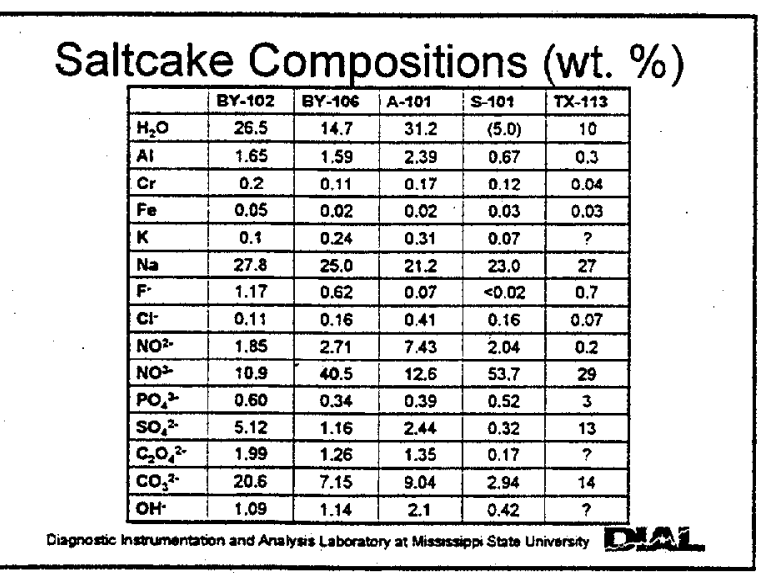

FYOO Workscope - ESP Efforts

- ESP Prediction of TX-113

- Feed Stability Studies

- ESP Predictions - Comparison with Other Models

- NaNO3/H2O at high ionic strength

- Na-F-SO4 double salt as function of ionic strength and temperature

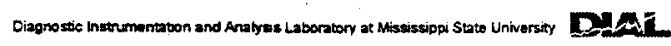

\section{Progress to Date}

- Modeling of Saltcake Dissolution Experiments

-5 tanks; diverse saltcake compositions

- Identified need for proper database selection

- Examination of supernate composition; solids speciation

- Modeling of Feed Stability Experiments

- Staged retrieval

- Examination of cumulative supernate to identify potential solids formation

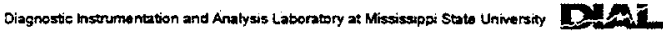

\section{Summary of FY99 Tasks}

- ESP Input Data Pre-processing Issues

- Processing of experimental data

- Charge reconciliation method

- Adjustment of input density

- Comparison with Experimental Data

- Revised ESP predications for BY-102, BY-106

- Solids Identification for BY-102

- ESP Predictions for A-101, S-102

Diagnosie Insoumention and Analysis Laboratory at Mississipai Stato University

\section{Charge Reconciliation - Recommended Practices}

- Proration method

- Pre-processing of data important

- Tuning of density to provide experimentally measured \% water

- Practices implemented for all 5 tanks examined

- Difficulties encountered for low-water content saltcakes (S-102, TX-113)

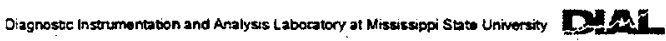




\section{ESP Public Database}

- Deficiencies in the database identified through saltcake dissolution simulations

- Representation of carbonate behavior

- Representation of sulfate behavior

- Deficiencies in the database identified through comparative calculations with other codes

- Representation of double salts

- Pure component solubility for NaF

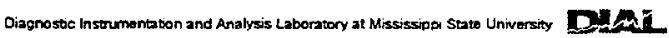

\section{Carbonate \& Nitrate Behavior} Public Database

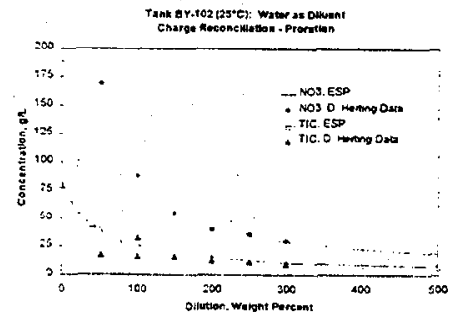

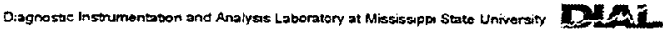

Carbonate \& Nitrate Behavior

\section{Trona Database}

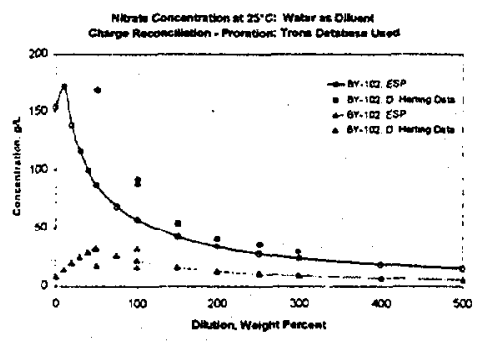

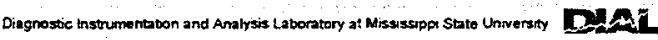

\section{Sulfate Behavior - TX113}

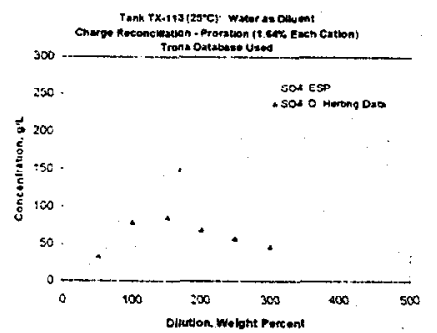

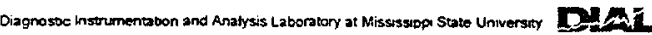

Sulfate Behavior - TX113

Special Sulfate Database

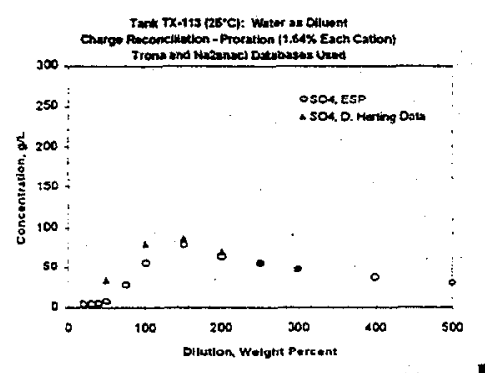

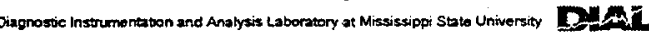

\section{Database Selection}

- Critical in development of ESP as a routine process operations tool

- Database(s) used must properly model known behavior of species at high ionic strength

- Identified need for specialized databases only through comparison with saltcake dissolution experiments 


\section{TX113 Saltcake Dissolution}

- Recommended practices for data preprocessing and charge reconciliation used

- Water input was adjusted so that generated molecular stream contained sufficient water for equilibration calculations $(20 \mathrm{~g} \mathrm{H} 2 \mathrm{O} / 100 \mathrm{~g}$ saltcake added)

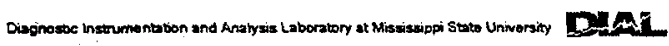

\section{.TX113 Saltcake Dissolution}

- Trona \& Special Sulfate databases used

- Inhibited water as diluent

- Dilution level range: 20 to $500 \%$ dilution by weight

- Temperatures of $25^{\circ} \mathrm{C}$ and $50^{\circ} \mathrm{C}$
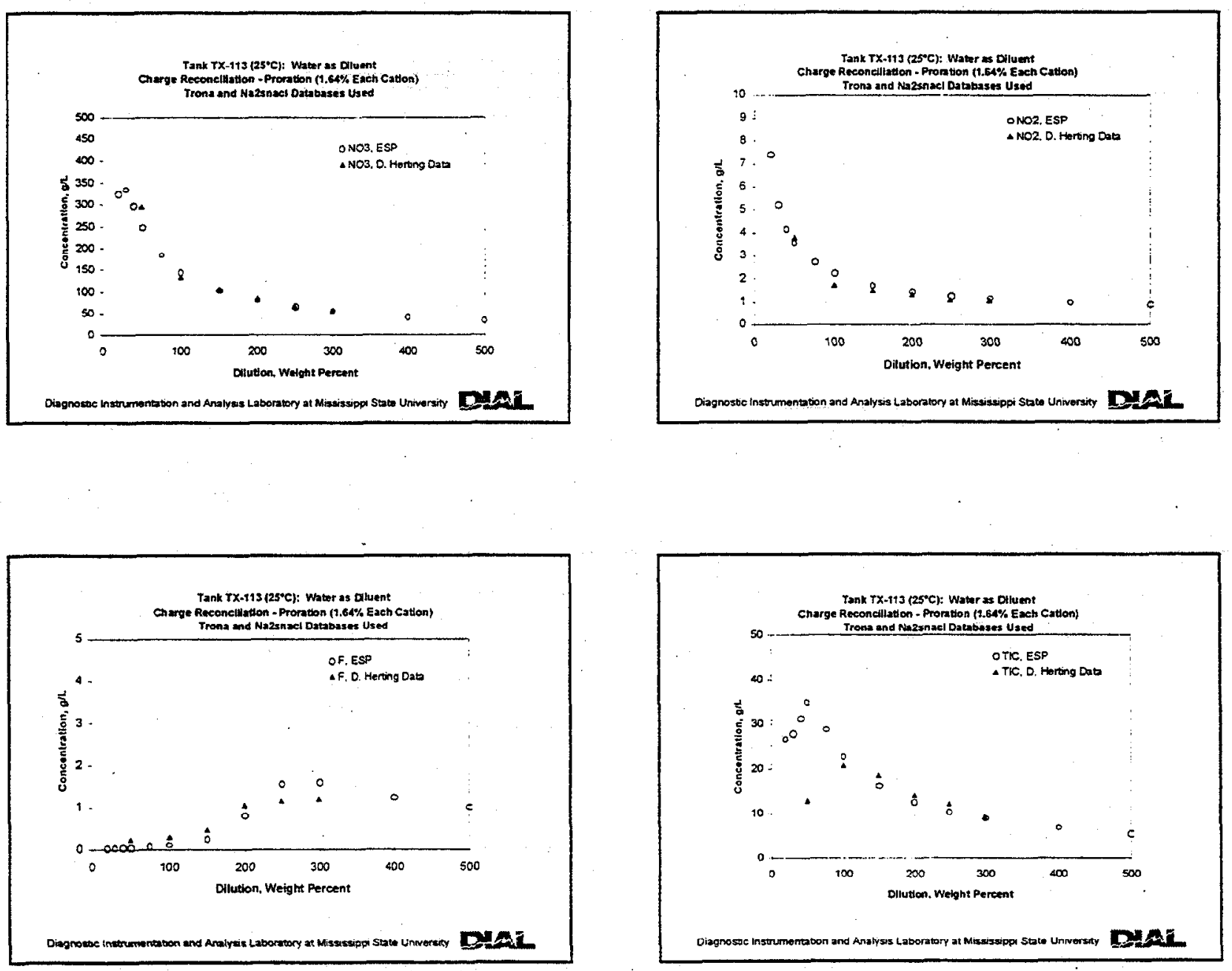

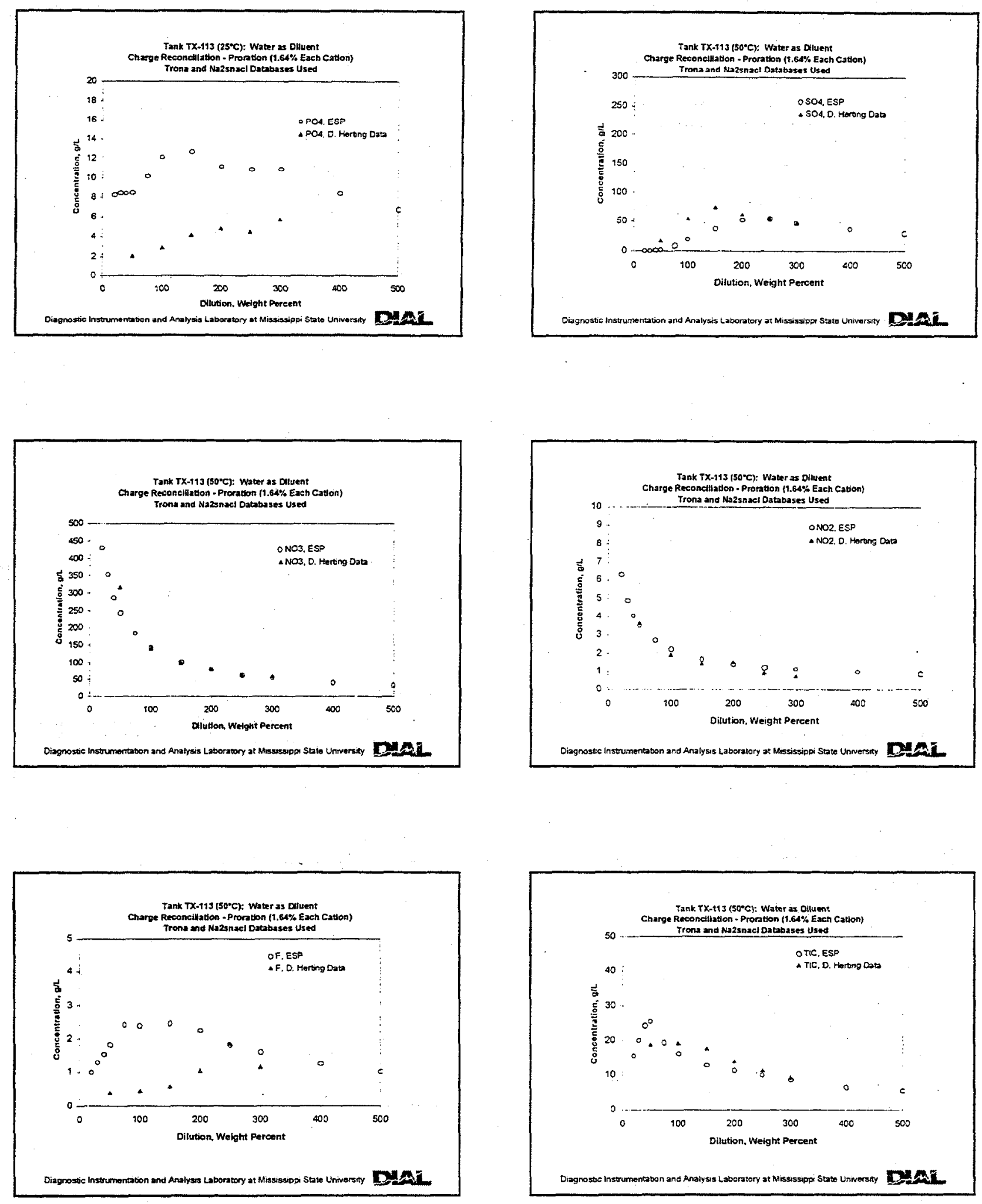


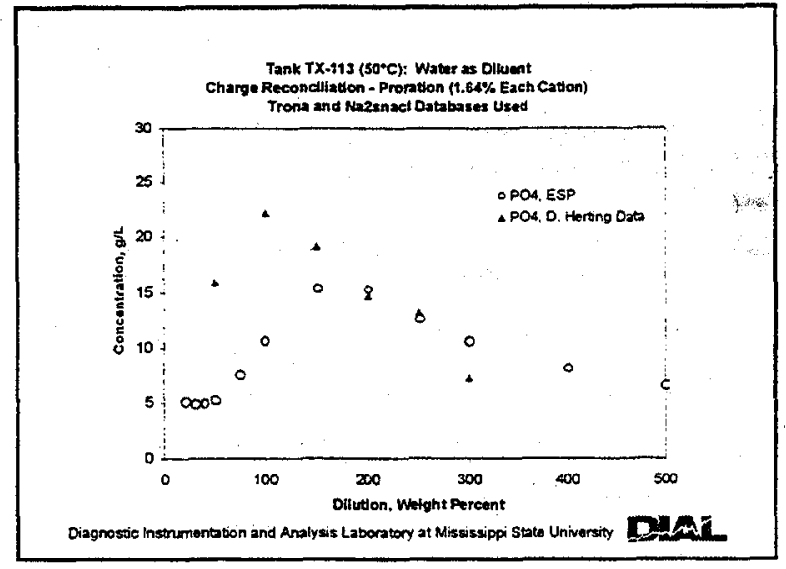

\section{Feed Stability Studies}

- Simulate experimental test plan

- Purpose - examine potential solids formation when supernates obtained at different stages of retrieval are remixed

- Molecular streams generated during FY99 used as input for ESP model calculations

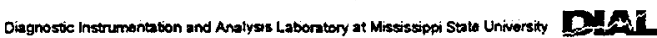

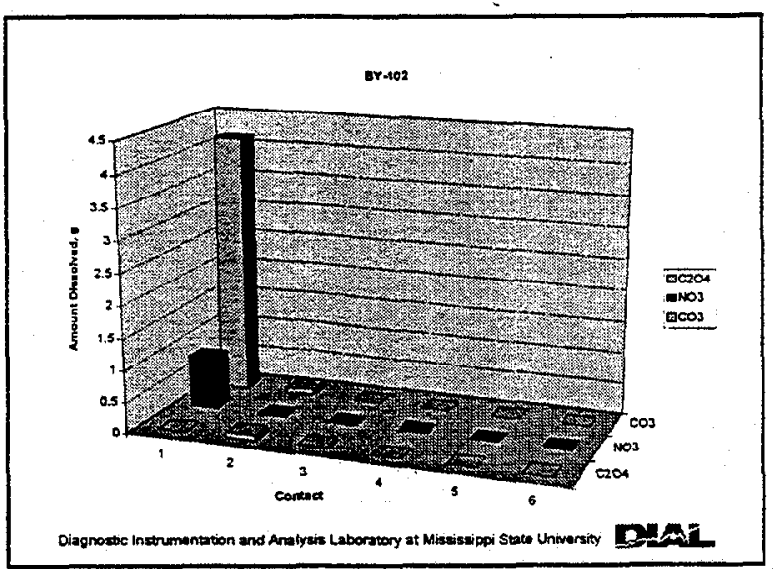

\section{ESP Predictions of TX113}

- Major trends exhibited by experimental data are reproduced

- Discrepancies at low dilution levels still apparent for select anions

- Results reinforce the need for solubility data for sulfate-(carbonate, fluoride, nitrate) double salts

- Double salts are predicted to be present until high levels of dilution

Diagnossie Instrumentabion and Analysis Laboratory-at Missizscipei State Univorsity DUAT.
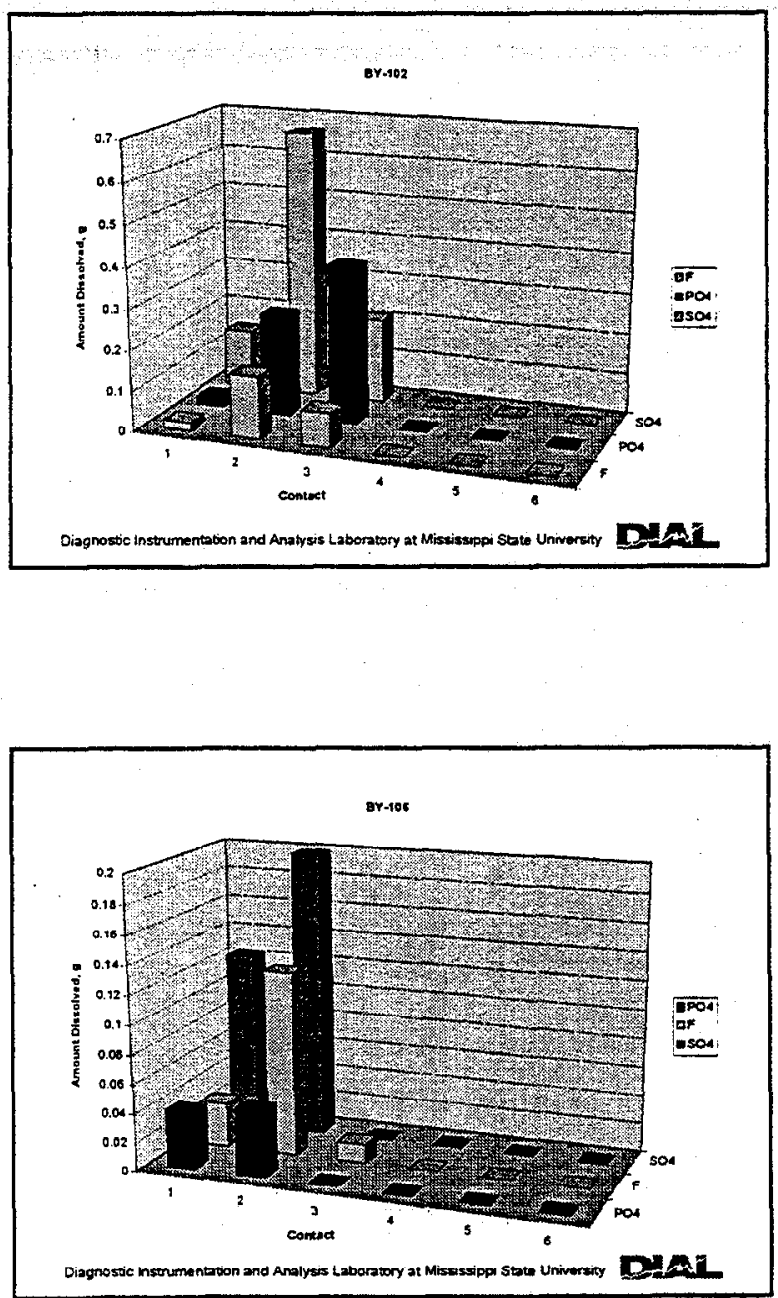

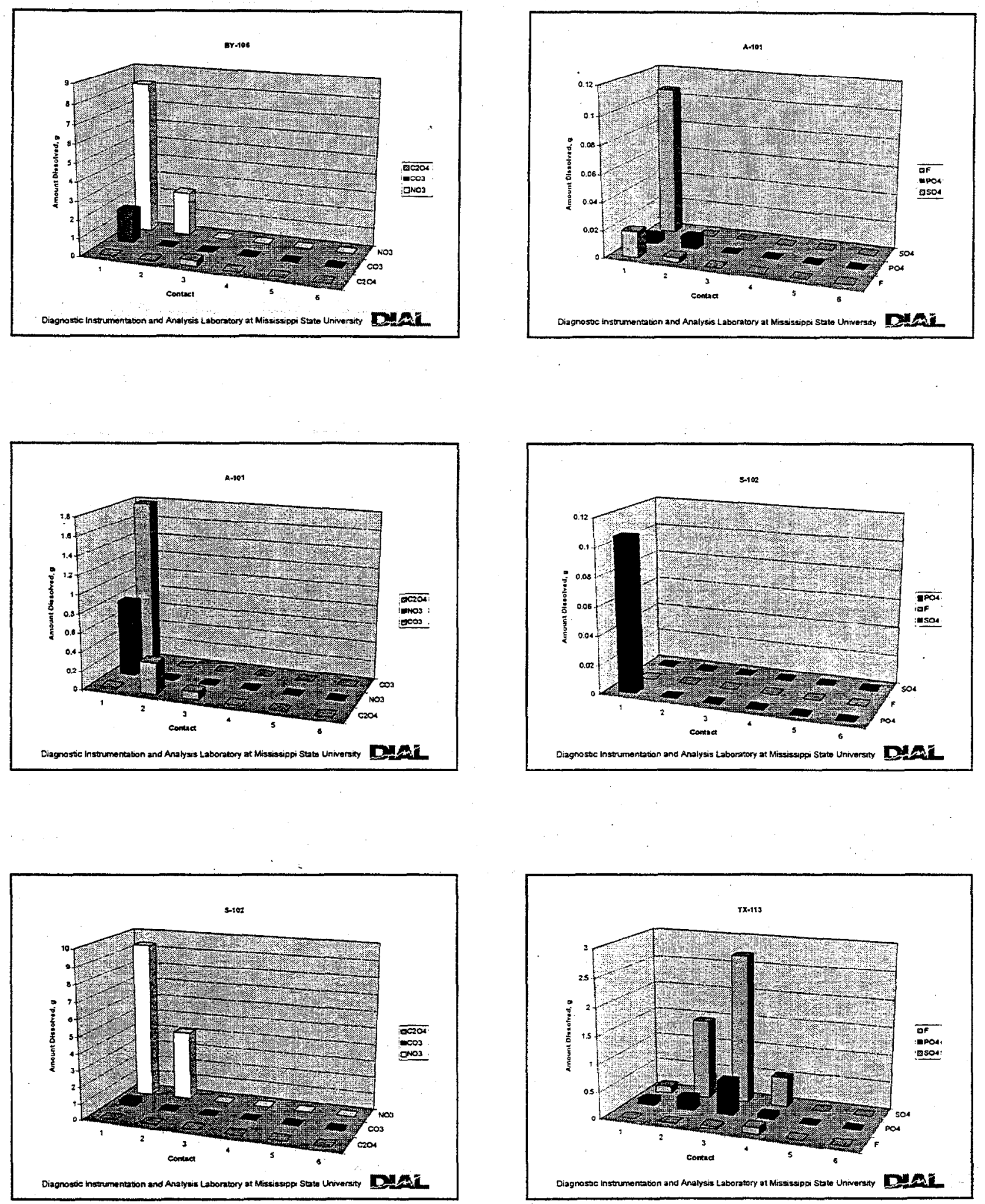


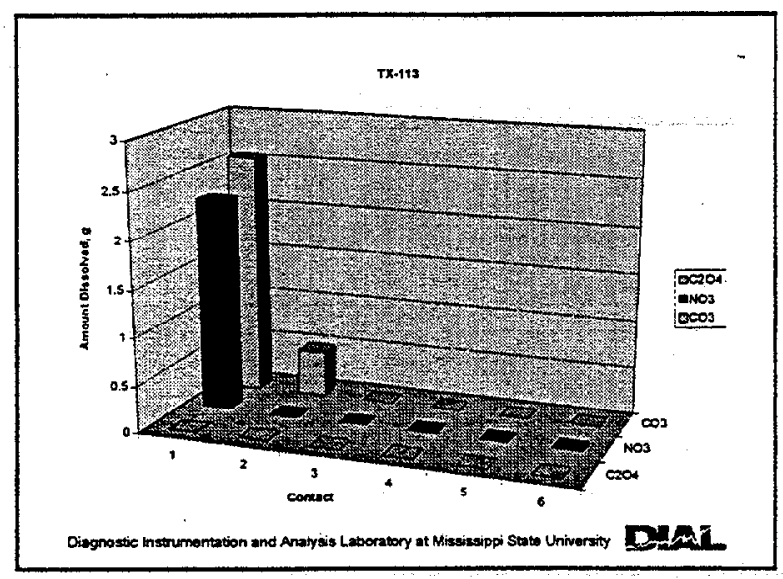

\section{Solids Formation in Cumulative Supernate}

- As supernate obtained from different contacts is accumulated, potential for solids formation exists

- Double salts will reprecipitate and then go into solution as more supernate is accumulated and ionic strength of the cumulative supernate drops

- Major trends found in experimental data exhibited by model predictions

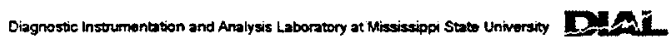

\begin{tabular}{|l}
\begin{tabular}{|l|l|}
\hline Solids Predicted to Form in \\
Receiver
\end{tabular} \\
\begin{tabular}{|l|l|l|l|l|l|}
\hline Contact & BY-102 & BY-106 & A-101 & S-102 & TX-113 \\
\hline 2 & $\begin{array}{l}\text { FP,FS, } \\
\text { Ox }\end{array}$ & $\begin{array}{l}\text { F,Ox, } \\
\text { FP }\end{array}$ & $\begin{array}{l}\text { FP,FS, } \\
\text { Ox }\end{array}$ & OX & $\begin{array}{l}\text { S, FP, } \\
\text { FS }\end{array}$ \\
\hline 3 & $\begin{array}{l}\text { FP,FS, } \\
\text { Ox }\end{array}$ & Ox & $\begin{array}{l}\text { FP,FS, } \\
\text { Ox }\end{array}$ & & FP,FS \\
\hline 4 & FP & Ox & FP & & FP,FS \\
\hline 5 & FP & Ox & FP & & FP,FS \\
\hline 6 & & Ox & & & \\
\hline
\end{tabular}
\end{tabular}
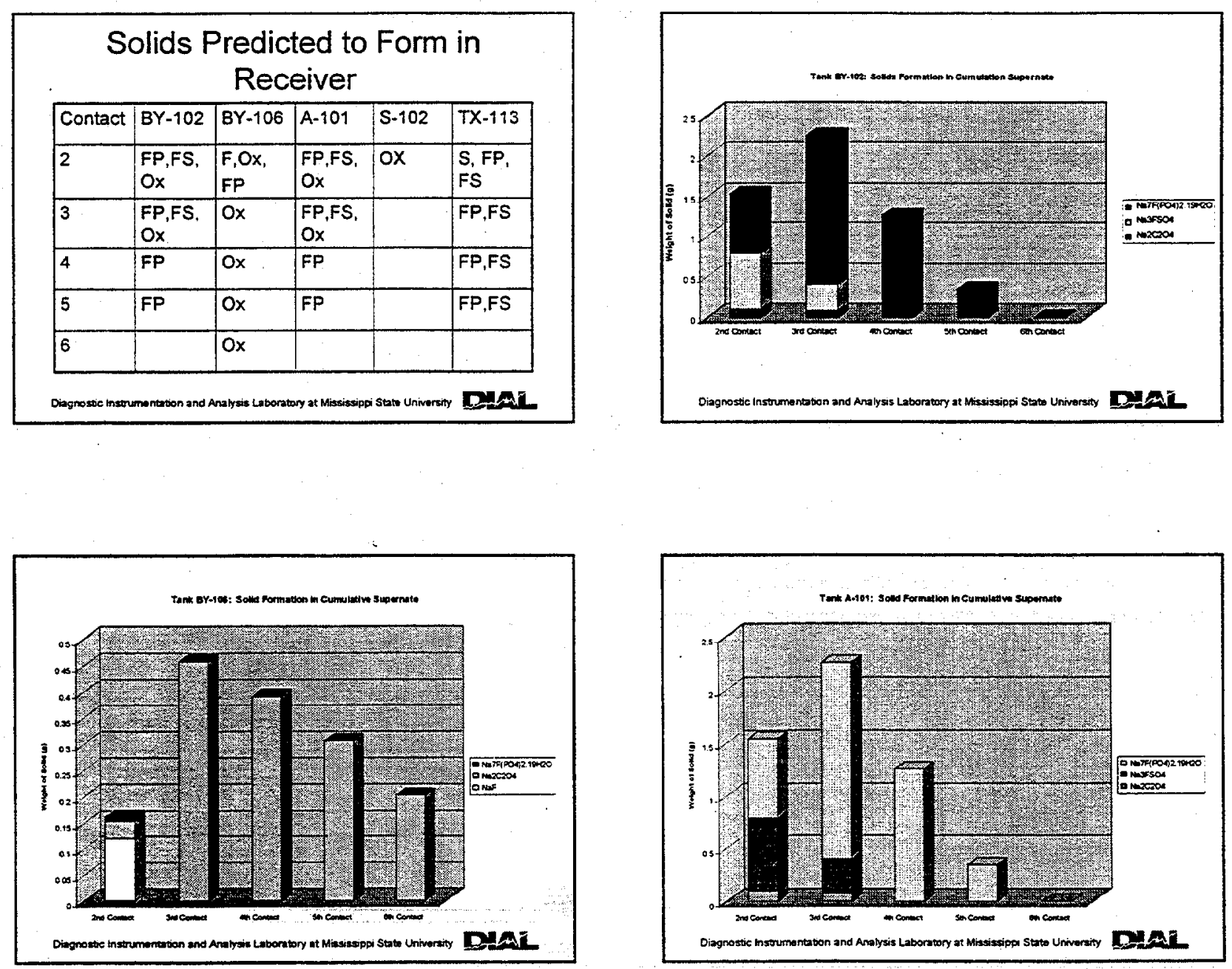




\section{ESP Comparison Studies}

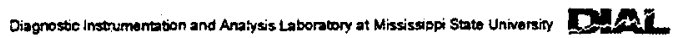

\section{Na-F-PO4 System}

- Discrepancies noted between ESP and SOLGASMIX

- Pure component solubility for sodium fluoride

- Solubility dependence on $\left[\mathrm{OH}^{-}\right]$different between ESP and SOLGASMIX models

$\mathrm{Na}-\mathrm{F}$-PO4 System at $25^{\circ} \mathrm{C}$

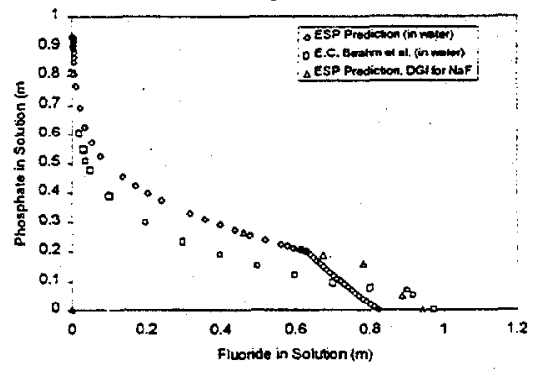

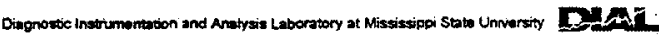

\section{Progress to Date}

- Sodium/Fluoride/Phosphate System

- comparison with SOLGASMIX calculations

- behavior as function of ionic strength at $25 \mathrm{C}$

- Sodium/Fluoride/Sulfate System

- comparison with SOLGASMIX calculations

- behavior as function of ionic strength at $25 \mathrm{C}$

- ESP database combinations examined

- Sodium NitrateNater System

- comparison with M. Ally model

Diagnostic instrumentabon and Analysis Laboratory ai: Mississippt State University DSAT.

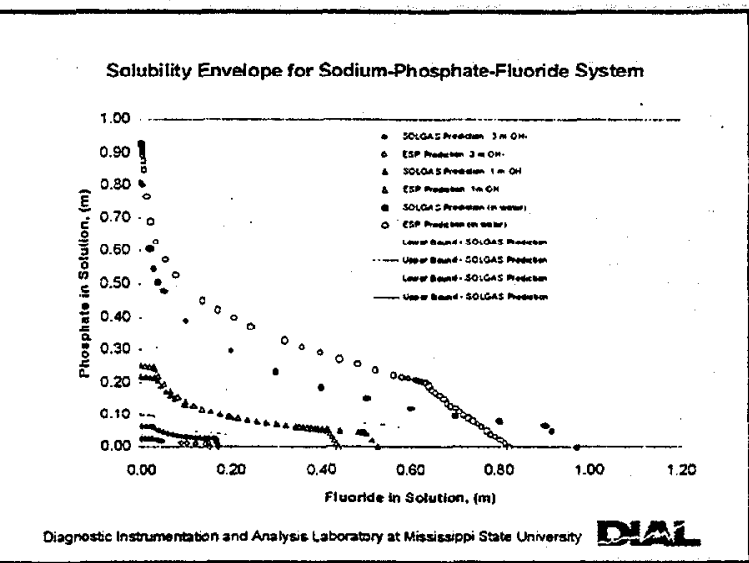

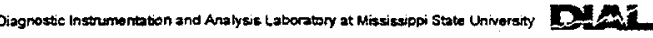

\section{Na-F-SO4 System}

- Preliminary examination of ESP predictions for sodium-fluoride-sulfate double salt

- Examined at $25^{\circ} \mathrm{C}$ as function of $\left[\mathrm{OH}^{-}\right]$

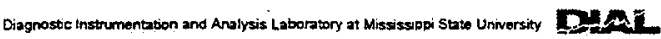



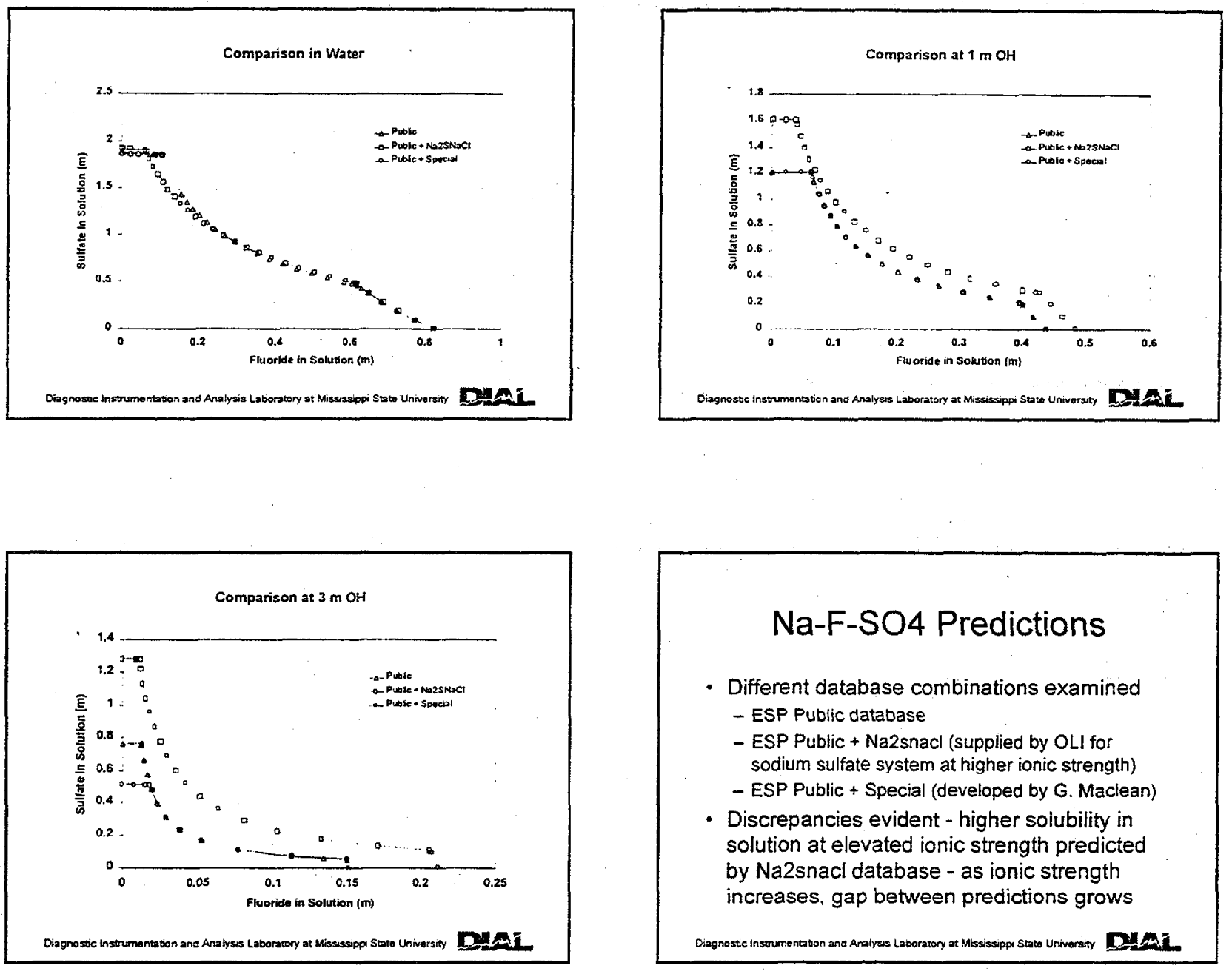

\section{Na-F-SO4 Predictions}

- Different database combinations examined

- ESP Public database

- ESP Public + Na2snacl (supplied by OLI for sodium sulfate system at higher ionic strength) - ESP Public + Special (developed by G. Maclean)

- Discrepancies evident - higher solubility in solution at elevated ionic strength predicted by Na2snacl database - as ionic strength increases, gap between predictions grows

\section{ESP and SOLGASMIX}

- Comparison in water at $25^{\circ} \mathrm{C}$

- ESP Public + Na2snacl database used

- SOLGASMIX predicts higher solubility compared to ESP

- Comparisons as function of $\left[\mathrm{OH}^{-}\right]$and temperature are planned

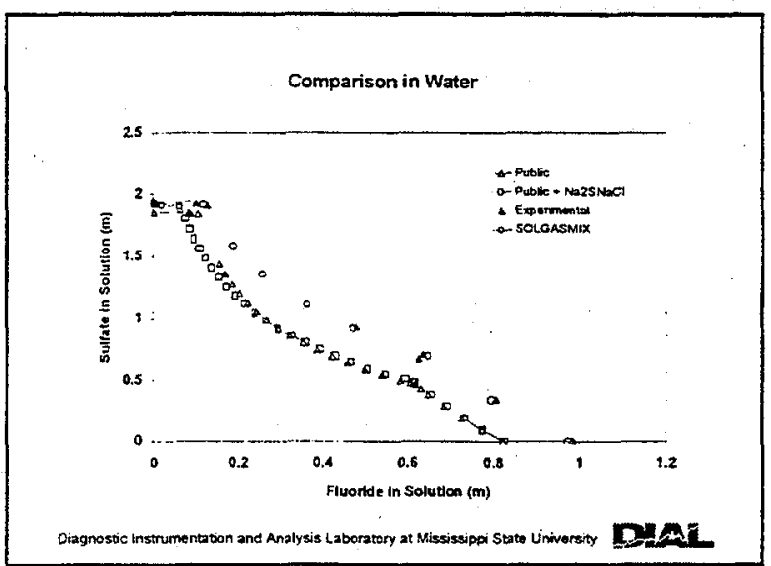




\section{Comparison with Work of Ally}

- Objective - to investigate validity of ESP and models of electrolyte solution behavior at high ionic strength

- Reasonable agreement at $25^{\circ} \mathrm{C}$

- Deviations between ESP predictions and Ally's predictions at $100^{\circ} \mathrm{C}$ and $125^{\circ} \mathrm{C}$

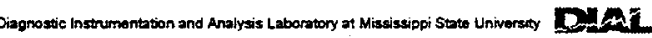

\section{Sodium Nitrate Water System $-25^{\circ} \mathrm{C}$}

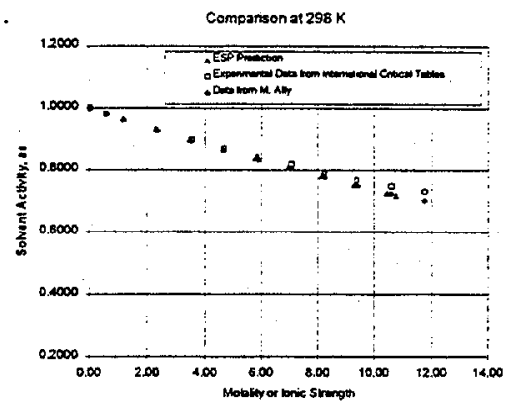

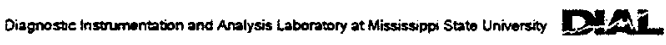

Sodium Nitrate/Water System at $100^{\circ} \mathrm{C}$

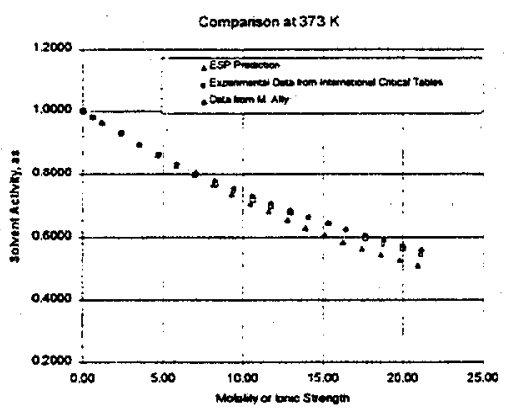

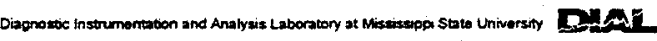

Sodium Nitrate $/$ Water System at $125^{\circ} \mathrm{C}$

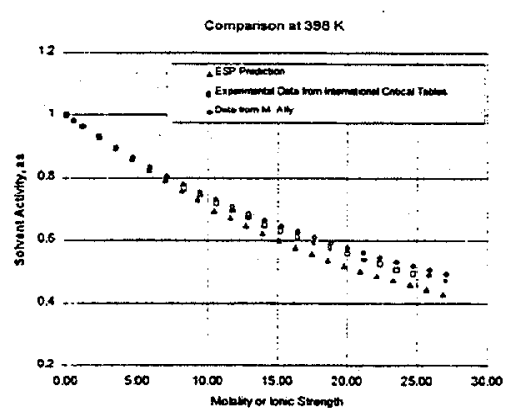

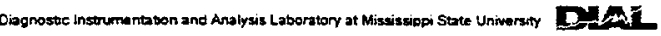

\section{Conclusions}

- ESP models/methods appear to provide good prediction at elevated ionic strength for simple single salt system (sodium nitrate)

- Comparisons for double salts validate need for experimental effort measuring SLE as function of ionic strength and temperature

- Discrepancy for NaF pure component solubility should be discussed with $\mathrm{OLI}$ personnel to determine a means of resolution

Diagnostic instrumartation ant Aralywis Laborztory at Misscissopan Suto University

Dint. 
- 
Solubility Tests to Improve the ESP Database

- Craig Barfield, Mong Tan

- MS Students Chemical Engineering

- Sam Nicholoson

- BS Chemical Engineering (MSU Dec'99)

Med School (Aug'O0)

- Valerie Phillips

- MS Analytical Chemistry (MSU 1988)

- Becky Toghiani, Jeff Lindner

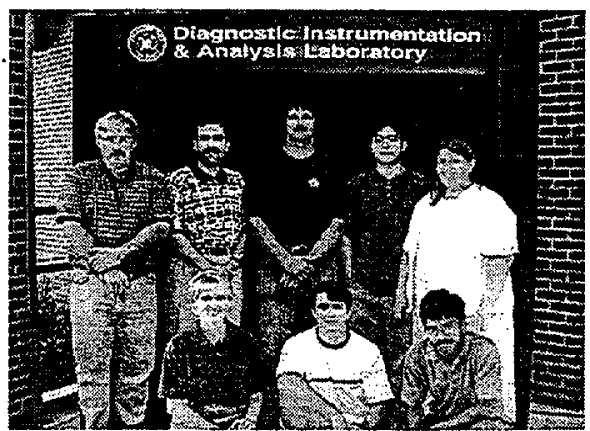

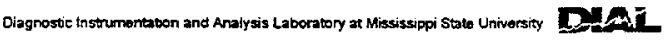

Acknowledgements

- Tanks Focus Area

- Phil McGinnis (TIM) Tim Welch (ORNL)

- Tom Brouns (visit to DIAL)

- DOE University Programs

- DIAL Cooperative Agreement

- Tom Brown, Contract manager

- Rodney Hunt, Chuck Weber (ORNL)

- Dan Herting.

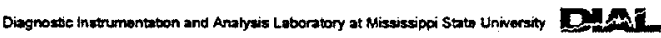

Accomplishments FY'98

- Comparison of thermodynamic parameters in ESP Public Database with Compilations form NIST and NEA

- Simulations on Saltcakes from 2 tanks

- Calculations for Remediation Operations for 241-SY-101

- Equilibrium Comparison calculations for the Na-F- $\mathrm{PO}_{4}-\mathrm{OH}$ System

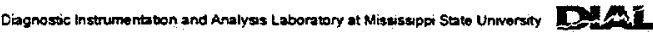

Accomplishments FY'99

- Completion of SY-101 calculations

- Studies on electroneutrality reconciliation

- Dissolution Modeling extended to Saltcakes from 4 Tanks

- $\mathrm{Na}-\mathrm{F}-\mathrm{PO}_{4}-\mathrm{OH}$ Solubility Experiments
Work in Progress FY'00

- Revised dissolution calculations and predictions for TX-113

- Feed Stability simulations

- ESP Calculations for NaNO3 at high ionic strength

- Continued Solubility Experiments

$$
\begin{aligned}
& -\mathrm{Na}-\mathrm{F}-\mathrm{SO}_{4}-\mathrm{OH} \\
& -\mathrm{Na}_{2} \mathrm{CO}_{3} \times \mathrm{H}_{2} \mathrm{O} \\
& -\mathrm{Na}_{3} \mathrm{PO}_{4} \times \mathrm{H}_{2} \mathrm{O}
\end{aligned}
$$

Dar 
Equilibrium Chemistry Experiments

- A number of double salts are predicted by ESP to exist and have been observed in Hanford waste

- Data for these systems is sparse and improvement of model predictions is only possible through improved and additional measurements

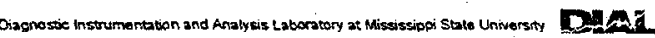

Solubility Studies on the Na-F-PO4-OH System ESP and SOLGASMIX Model Predictions

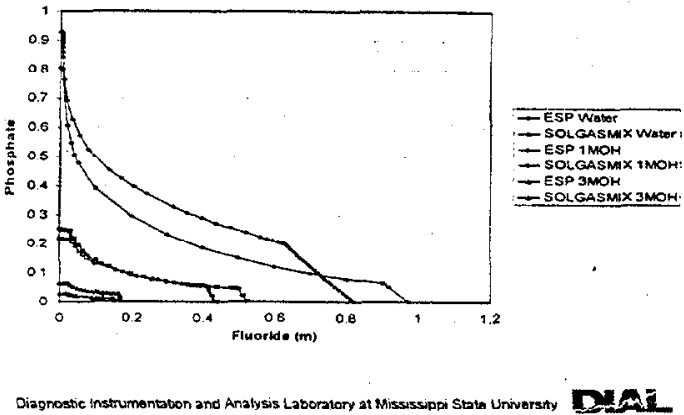

Experimental Summary

- Solutions prepared in water, $1 \mathrm{~m}$ and $3 \mathrm{~m} \mathrm{OH}$

- Temperatures of 25,35 , and $50^{\circ} \mathrm{C}$

- Allowed to dissolve at elevated temperature

- Equilibrated with occasional shaking for a period of not less than two weeks

- Liquid phase characterization using IC

- Solids by PLM

Diagrostic instrumentation and Analysss Laboratory at Mississippi Ste University DIT
Typical IC Calibration for Fluoride Anion

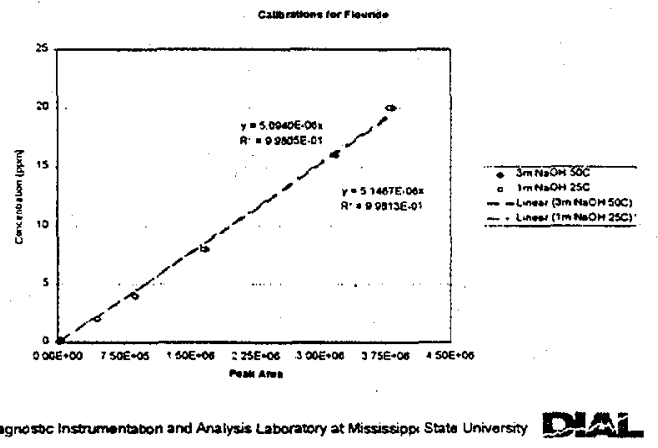

Data and Predictions for $1 \mathrm{~m} \mathrm{OH}$ at $25^{\circ} \mathrm{C}$

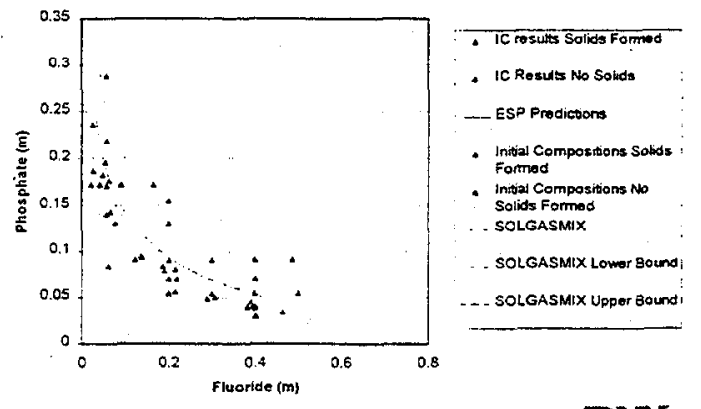

Diagnoste instrumentabon and Anolyssis Laboratory at Missssippi State Unwersty Dity 


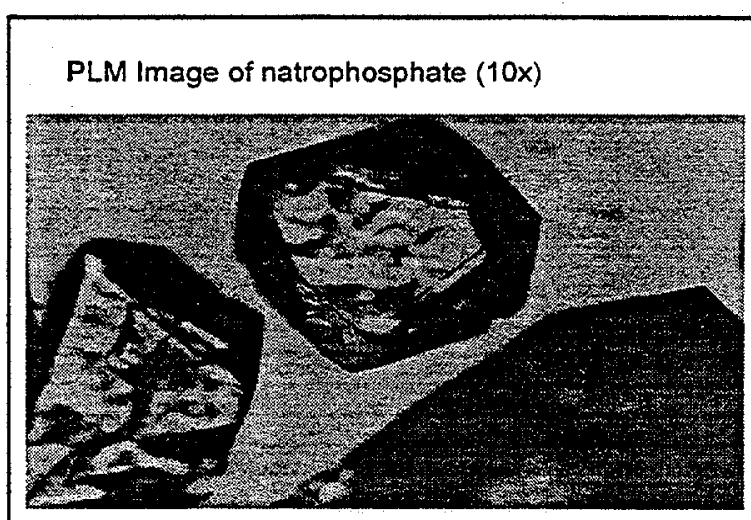

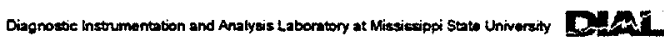

Solids ID with Conservative IC Errors

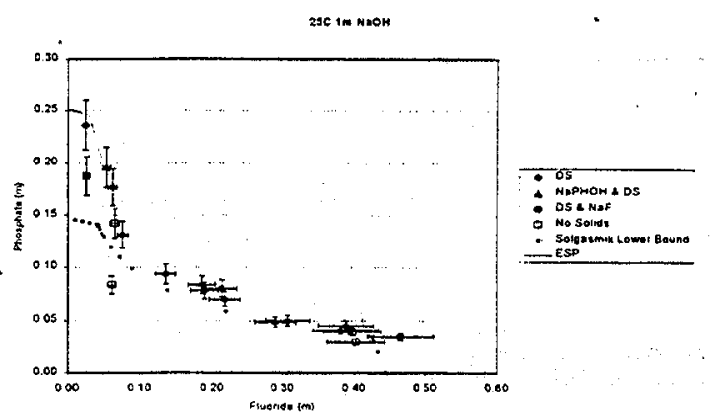

Diagnostc Instrumentation and Analysis Laboratory at Mississippi State Universaty DPAT.
Solubility Data for $25^{\circ} \mathrm{C}$

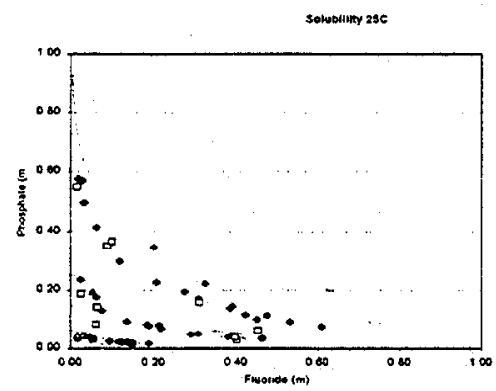

Diegnostec instrumentation and Analysis Laboratory at Miscriscippi Strete Universaty

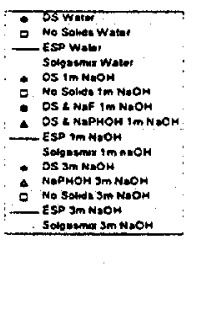

Dyar
Results for $1 \mathrm{mOH}$ at Different Temperatures
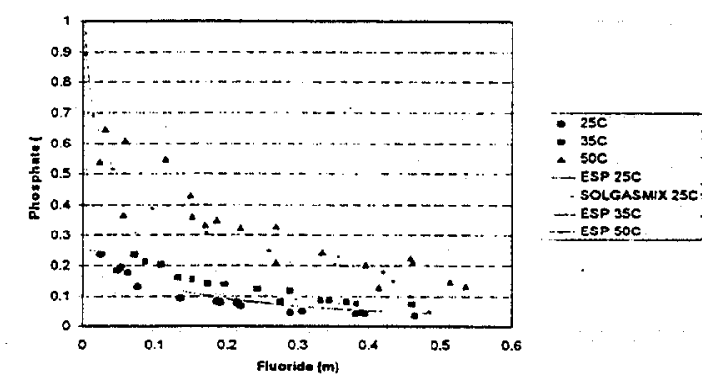

SOLGASM
- ESP $35 C$
EST

-. ESP SOOC

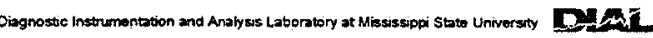

\section{ESP Calculations for Pure Components}

- ESP predictions consistently underestimate $\mathrm{NaF}$ solubility as compared to SOLGASMIX

- ESP employs a temperature fit expression (KFIT) to predict the equilibrium constant

- If a KFIT expression is not available ESP will revert to the Gibbs energy of formation

- Becky requested a special database for $\mathrm{NaF}$ and $\mathrm{Na}_{3} \mathrm{PO}_{4} \cdot 12 \mathrm{H}_{2} \mathrm{O} 0.25 \mathrm{NaOH}$ containing the free energies then compared the results to the KFIT expression and to the SOLGASMIX results

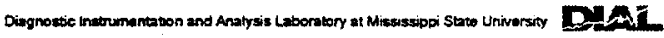

Pure Component Solubilities from ESP ( 2 calculation options) and SOLGASMIX

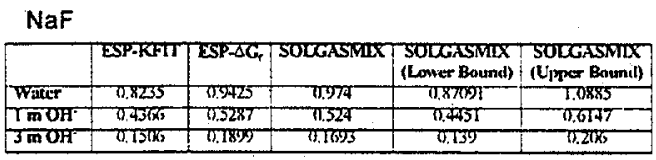

$\mathrm{Na}_{3} \mathrm{PO}_{4}-12 \mathrm{H}_{2} \mathrm{O} \cdot 0.25 \mathrm{NaOH}$

\begin{tabular}{|c|c|c|c|c|c|}
\hline & ESP-KFIT & ESPQG & SOLCESWLX & $\begin{array}{l}\text { SOLCASSIIX } \\
\text { (Lower Bound) }\end{array}$ & $\begin{array}{l}\text { SOCGSSYIX } \\
\text { (Cppor Bourd) }\end{array}$ \\
\hline Whiter & $0.98 \times 4$ & 0.9159 & 0.8067 & 0.0005 & 1.165 \\
\hline TmOF & 0.2520 & 0.2405 & 0.2184 & $014 \pi$ & 0.3215 \\
\hline $3 \mathrm{mor}$ & 0.0503 & 0.0246 & 0.0624 & 0.0394 & $009 \pi$ \\
\hline
\end{tabular}

Oiagnosse instrumeneson ans Aralysis Laboratory at Mississippi Staw University 
Summary of Pure Component Solubility Modeling

- In water and $1 \mathrm{~m} \mathrm{OH}$ the differnece between the ESP and SOLGASMIX predictions are within the range of the SOLGASMIX calculation bounds

- In $3 \mathrm{~m} \mathrm{OH}$ the pure component solubility predicted by ESP is approximately $1 / 3$ that calculated from SOLGASMIX

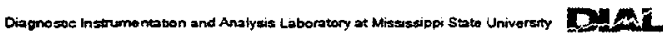

Initial Studies on $\mathrm{Na}_{3} \mathrm{FSO}_{4}$

- ESP and SOLGASMIX calculations at $25^{\circ} \mathrm{C}$

- Preparation of Solutions

- Work Planned at 25 and $50^{\circ} \mathrm{C}$ in water and $1 \mathrm{~m}, 3 \mathrm{~m} \mathrm{OH}$

- Previous experimental data

- Foote, H. W., and Schairer, J. F., JACS $\underline{52}, 4202(1930)$

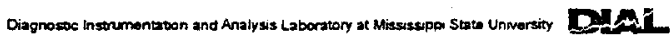

Equilibrium Experiments - Hydrates

- Proposed by Dan Herting

- Little Information is available on the extent of hydrate formation for $\mathrm{Na}_{2} \mathrm{CO}_{3}$, $\mathrm{Na}_{3} \mathrm{PO}_{4}$, and $\mathrm{Na}_{2} \mathrm{SO}_{4}$ at elevated ionic strength

- Initial focus on $\mathrm{Na}_{2} \mathrm{CO}_{3}$
Summary of Solubility. Experiments for natrophosphate

- Experimental results are in qualitative prediction with model calculations

- Only a small increase in solubility is observed in going from 25 to $35^{\circ} \mathrm{C}$

- Model Prediction in $1 \mathrm{~m}$ OH are in good agreement with the SOLGASMIX calculations

- Pure component solubility can depend on the calculation mode in ESP

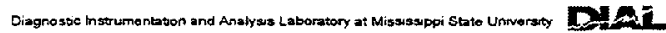

Model Calculations and Solution Preparation for $\mathrm{Na}-\mathrm{F}-\mathrm{SO}_{4}$

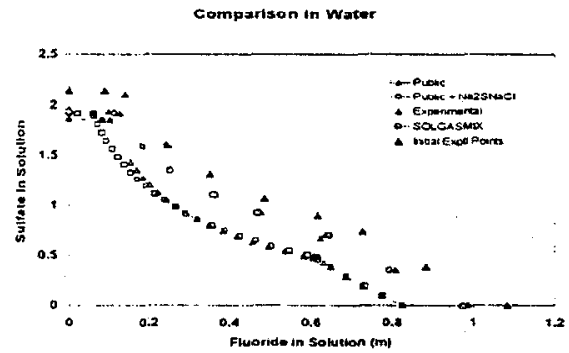

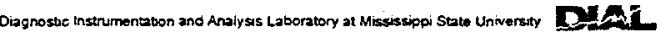

ESP Equilibrium Calculations for $\mathrm{Na}_{2} \mathrm{CO}_{3} \times \mathrm{H}_{2} \mathrm{O}$

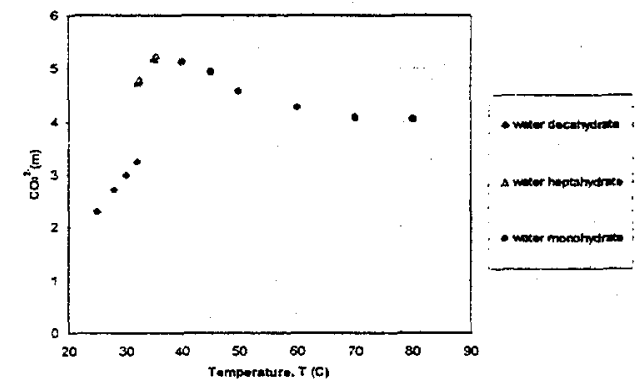

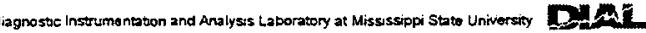


ESP Predicted Solubility for $\mathrm{NA}_{2} \mathrm{CO}_{3} \times \mathrm{H}_{2} \mathrm{O} 1 \mathrm{~m} \mathrm{OH}$

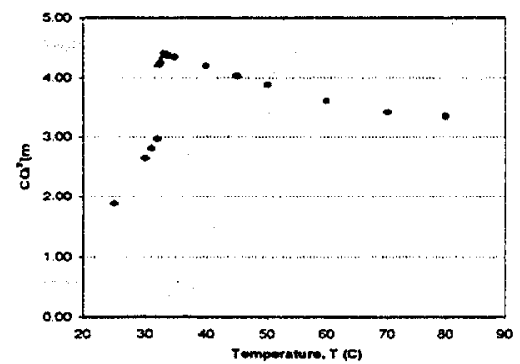

Diagnosbe Instrumentabion and Analyzis Laboratory at Misssissippi Sente Unveraty
PLM Images for $\mathrm{Na}_{2} \mathrm{CO}_{3} \times \mathrm{H}_{2} \mathrm{O}$

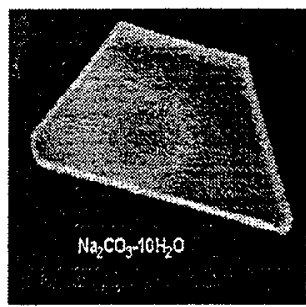

$40 x$

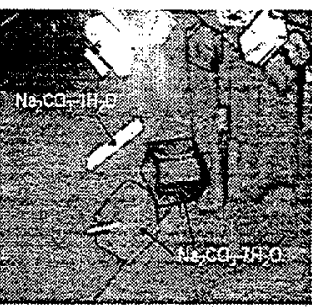

$20 x$

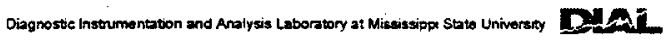

\section{Path Fonward}

Experiments

- Solubility decreases with increasing ionic strength

- Formation of the heptahydrate occurs over a narrow temperature range, crystal form not predicted in $7 \mathrm{~m} \mathrm{OH}$

- Preliminary PLM images predict that the monohydrate and heptahydrate can coexist in contrast to the ESP calculations

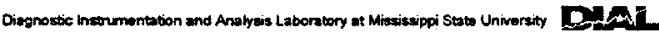

- Data for the natrophosphate system will be transferred to OLI Inc. to develop a revised database, equilibrium calculations will be redata

- Equilibrium Calculations (SOLGASMIX and ESP) have been performed on the $\mathrm{Na}-\mathrm{F}-\mathrm{SO} 4-$ $\mathrm{OH}$ system and experiments have commenced

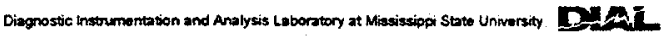
run to confirm with the existing experimental

\section{Path Forward}

- Calculations and experiments are in progress for the $\mathrm{Na}_{2} \mathrm{CO}_{3}$ system. ESP predicts distinct crystal types whereas PLM images indicate that different crystal forms can coexist

- Studies on $\mathrm{Na}-\mathrm{SO}_{4}-\mathrm{NO}_{3}-\mathrm{OH}$ are planned 
 


\section{Overview Of The TFA Feed Stability Tasks}

Tim Welch

Oak Ridge National Laboratory

Salt Dissolution and Feed Stability Workshop

Richland, Washington

May $16-17,2000$
Some Recent and Ongoing Work Related To Feed Preparation and Transport

- Defining waste acceptance criteria ano technical risk for feed delivery (PNNL et al)

- Modeling of tank mixing (with chemical reaction) for retrieval (Onishi et al, PNNL)

- Retrieval and pipeline unplugging demonstrations (TFA retrieval)

- Waste phase equilibrium, solubility, ESP (Hanford Herting, Maclean, Hu, Felmy, et al; MSU: Lindner, Toghiani; ORNL: Beanm, Hunt, Weber)

- Viscosity (RPP, ORNL, PNNL)

- Precipitation kinetics and precipitate properties (AEA)

- Saltcake dissolution (RPP, MSU)

\section{Why address waste stability?}

- To prevent pipeline plugging and maintain stable waste flow

- Cross-site transfer lines plugged

- Plugging during saltwell pumping of SX-104 and U-103

- To prevent process disruptions (e.g., evaporator shutdown at SRS)

- To deliver feed within specifications (solids content)

- To improve processes

- Minimize water additions during saltwell pumping

- Increase availability

- To understand and prevent catastrophic events-Avoid those changes in conditions that can result in dramatic change in chemical state, physical properties, or flow patterns
Factors That Effect Pipeline Plugging

$$
\begin{array}{ll}
\text { - Slurry fluid dynamics } \\
\text { - Velocity to maintain } \\
\text { particle in suspension } \\
\text { - Viscosity }
\end{array}
$$

The objectives of the feed stability tasks include:

- To model waste transfer operations coupling chemical reaction/precipitation and flow.

- To conduct tests to validate models and determine parameters for transfer without plugging

\section{Waste Transfer Stability Tasks}

- Slurry transport tests

- AN-103, C-104

- Precipitation kinetics and precipitate properties - \$X-104, AN-103

- Modeling of pipeline flow with precipitation

- Saltwell pumping tests

- SX-104, U-103 


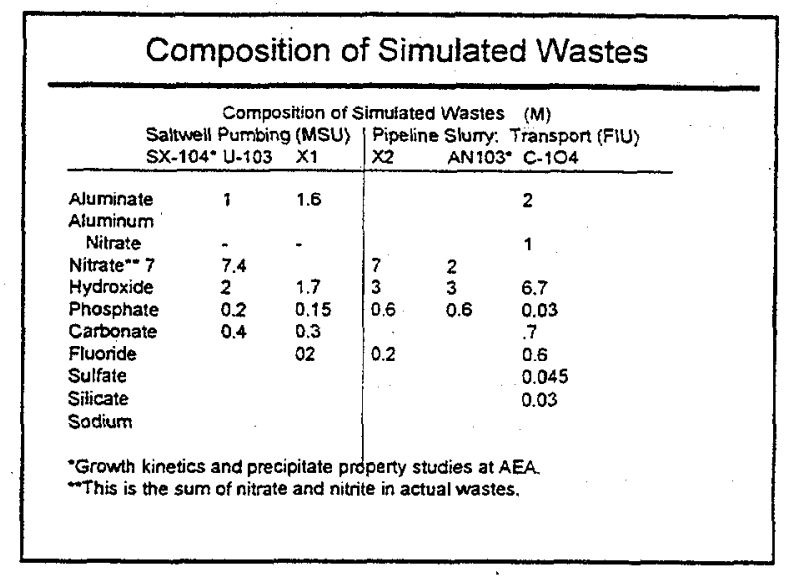

Objectives of the Saltwell Pumping Tests

- Identify plugging potential of specific wastes

- Provide data and model to evaluate saltwell pumping operations

- Improve saltwell pumping operations

Salt Well Pumping System Test Matrix

\begin{tabular}{|c|c|c|c|c|c|}
\hline \multirow{2}{*}{$\begin{array}{l}\text { Shathen } \\
\text { Whar }\end{array}$} & 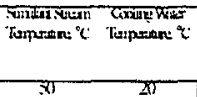 & \multirow{2}{*}{ 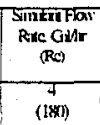 } & \multicolumn{3}{|c|}{ 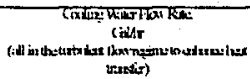 } \\
\hline & & & का & 4531 & 5 \\
\hline $\begin{array}{l}\text { FrरEक्ता } \\
\text { SX-1144 }\end{array}$ & त्र & (IX) & का & का & $\boldsymbol{x}$ \\
\hline 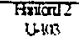 & 20 & $(1 \mathrm{k})$ & का & 45 & 5 \\
\hline \multicolumn{6}{|c|}{ 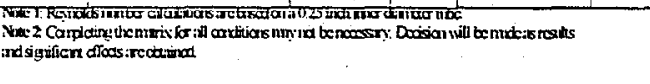 } \\
\hline
\end{tabular}

0

PLM Image of Solids at Room Temperature (10x)

Rodney 2

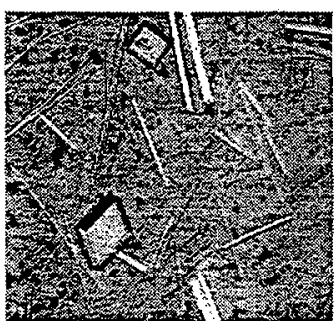

Sample 8

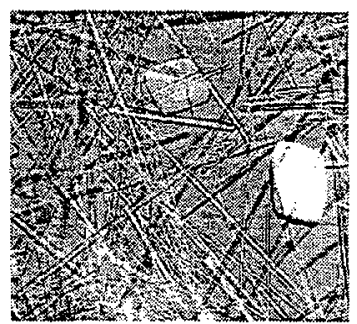

\section{Objectives of the Slurry Transport Tests}

- Evaluate the pipeline transport of specific waste slurries

- Provide data to support slurry transport modelling

- Develop a better understanding of plugging mechanisms

- Physical

- Chemical

- Flow 

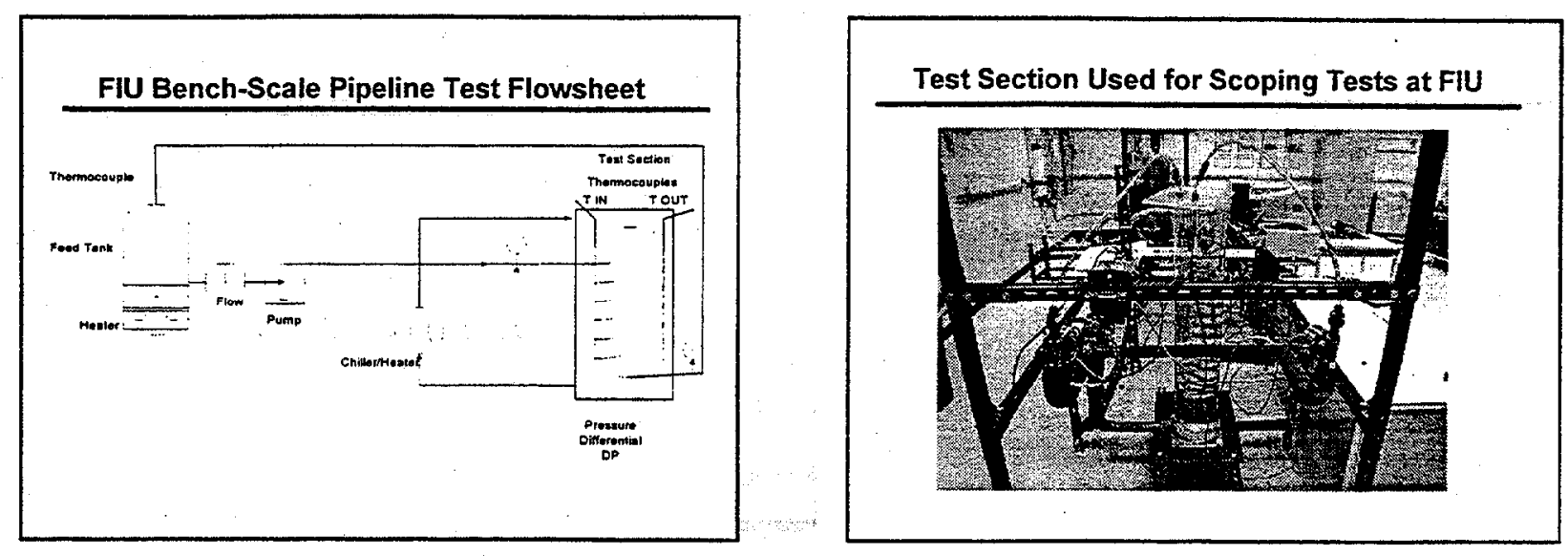

\section{Test Matrix}

- Feed tank temperature: $-50^{\circ} \mathrm{C}$

- Test section temperatures:

$-15^{\circ} \mathrm{C}, 40^{\circ} \mathrm{C}, 50^{\circ} \mathrm{C}$

- Flow rates

- Laminar, Re<2,300

- Transition, $\operatorname{Re}<10,000$

- Turbulent, Re>10,000

FIU Test Section Partially Plugged by Hydroxide-Phosphate-Fluoride Simulant

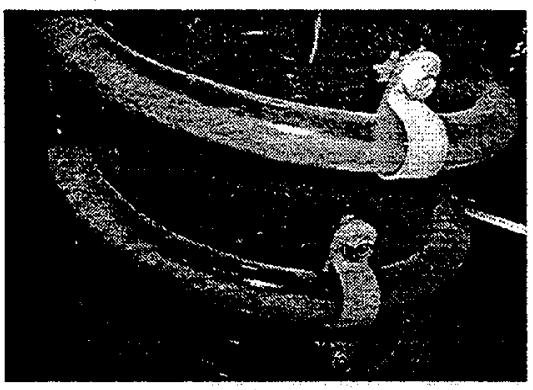

FIU Test Section Tubing Plugged by Hydroxide-Phosphate-Fluoride Simulant

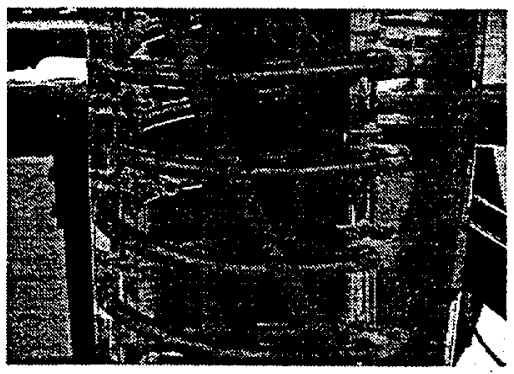

Objectives and Requirements of Waste Transport Model

Develop practical engineering tools to support data evaluation, waste transfer planning and waste transfer operations

- Must predict operating parameters (pressure, flowrate) during waste transfers

- Must predict plug formation, time to plug, and location

- Must be in terms of measurable and controllable variables 


\section{Initial Transport Modeling Approach}

- 3D fluid mechanics

- Solid-liquid flow, solids suspension

- Chemical reaction / precipitation

- Solids population balance

- Nucleation and growth

- Particle agglomeration and breakup

- Viscosity (chemistry, volume fraction, particle shape, temperature)

- Temperature effects (heat transfer)

\section{Waste Transport Model Development Phases}

- Build complete model

- Start with CFD-Shurries

- Cherrical reactions.

- Population balance.

- Crystal nucleation and grown kinetics.

- Particle aggiomeration and breakup

- Viscosity (chemistry, solids fraction, shape, PSD)

- Heat transfer. conductivity

- Validate with data from simulated waste tests

- Test and reduce

- Simplify where appropriate

- Valicate with data from simulated waste and actual waste tests

Apply

- Validate with pilot tests

- Apply to operations

Tomorrow's Feed Stability Presentations

- Saltwell pumping tests (MSU)

- Slurry transport modeling (MSU)

- ESP (equilibrium) modeling of simulated tanik wastes to be used at FIU and MSU

- Slurry transport tests (FIU) 
Salt Well Pumping/Pipeline Plugging

Model Development for Waste Transfers

- Vijay Kumar

- MS Student, Chemical Engineering

- Sam Nicholson

- BS Chemical Engineering (MSU Dec'99) Med School (Aug'00)

- Johri Andol, Research Assistant I

- Hani Al Habbash, Jeff Lindner, Becky Toghiani

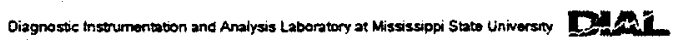

Salt Well Pumping

- Recent plugs from SX-104 and U-103 supernates

- Need for Laboratory Test Loop

- evaluate plug mechanisms

- support model development

- confirm and/or enhance operations, dilution, flushing

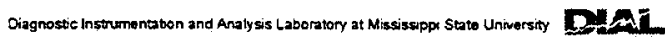

Pipeline Plugging

- New CSTL only available route for delivery of waste to the vitrification contractor

- Other CSTL's are plugged, leak or do not meet current environmental regulations

- Development of a validated Engineering Tool will allow Farm Operators to confirm existing models and criteria

Din
DIAL Program Activities

- Development of a Salt Well Pumping Test Loop and Testing with Waste Simulants

- Engineering Tool Development and Validation

- slurry transfers and salt well pumping

- ORNL surrogate compositions, viscosities

- FIU slurry transport experiments

- AEA surrogate particle growth, size

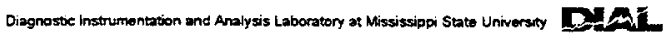

\section{Gantt Charts (2)}

ESP Supporting Calculations

- Obtain insight into phase equilibrium behavior and surrogate chemistry and properties

- Salt Well Pumping Experiments

$-\mathrm{SX}-104$

$-U-103$

- Support of FIU Slurry Transport Experiments - AZ-101 AN-103 C-104

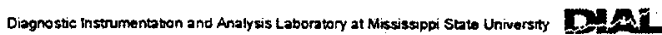


SX-104 Surrogate Studies

Anion ORNL(a) Sample 5 Sample 8

$\begin{array}{llll}\text { Aluminate } & 1 & 1 & 1 \\ \text { Nitrate } & 7 & 7 & 7 \\ \text { Hydroxide } & 2 & 2 & 2 \\ \text { Phosphate } & 0.2 & 0.3 & 0.3 \\ \text { Carbonate } & 0.4 & 0.4 & 0.1\end{array}$

Sodium cation

(a) recipe revised in an attempt to separate plug formation mechanisms

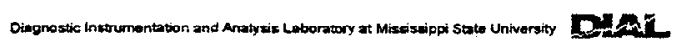

SX-104 Surrogates following Initial Prep at $70^{\circ} \mathrm{C}$ and Cooling to $50^{\circ} \mathrm{C}$

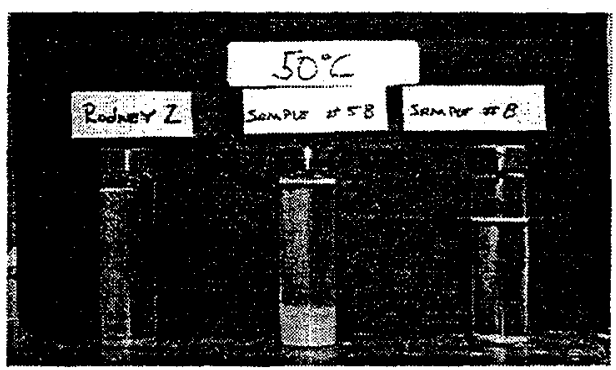

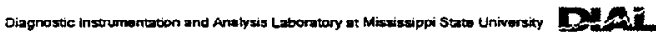

SX-104 Surrogate on Cooling to $25^{\circ} \mathrm{C}$ after 3 days

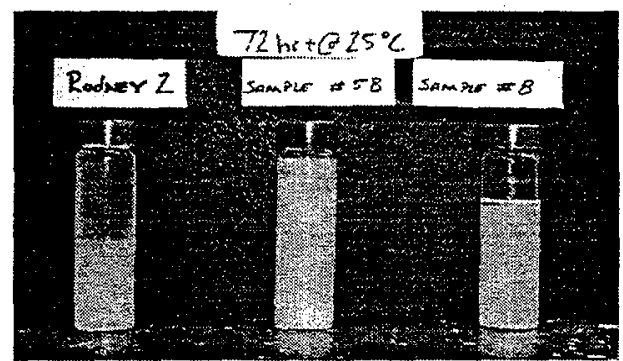

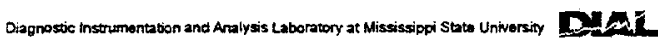

PLM Image of Solids at Room Temperature (10x)

Rodney 2

Sample 8
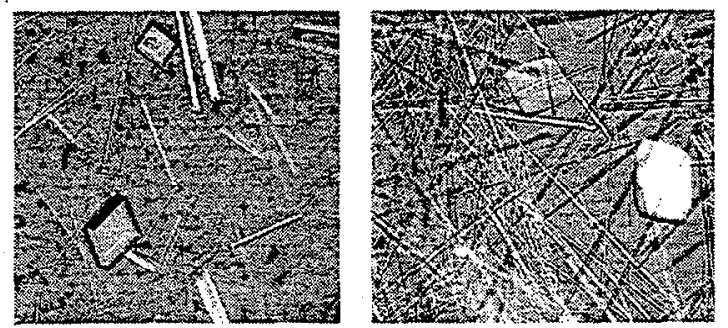

Inar 
Predicted Solids Loading at Different Temperatures

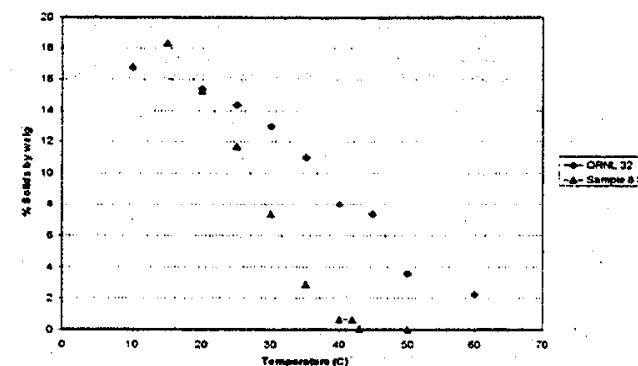

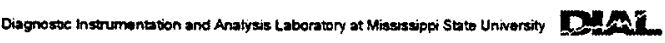

Weight Fraction of $\mathrm{Na}_{3} \mathrm{PO}_{4} \cdot 12 \mathrm{H}_{2} 0 \cdot 0.25 \mathrm{NaOH}$ in Surrogate Predicted by ESP

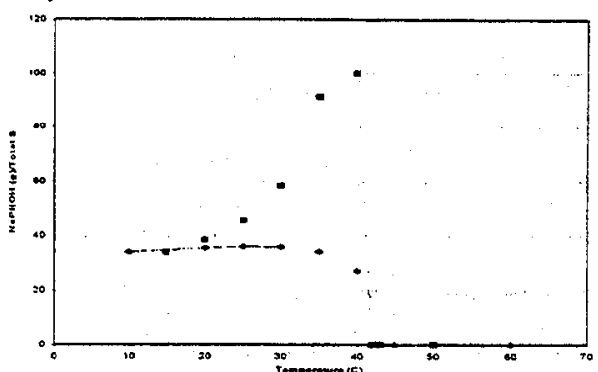

Demi
Heat Capacity Calculation Based on ESP Results

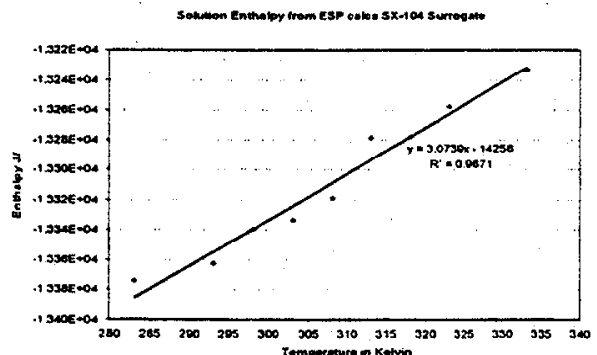

Din

\section{Summary of Surrogate Studies}

- Different plug mechanism may be possible

- Gel formation is from $\mathrm{Na}_{3} \mathrm{PO}_{4} \cdot 12 \mathrm{H}_{2} \mathrm{O} \cdot 0.25 \mathrm{NaOH}$

- Separation of Plug Formation due to gelation can be accomplished using the sample 8 formulation

- The $80 \%$ of non-gel forming solids predicted with the ORNL surrogate can be used to isolate particle deposition mechanisms

- It is anticipated that plugging from gel formation will result in a different pressure drop than from gradual particle deposition

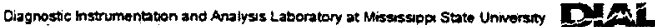

Salt Well Pumping Test Loop

- Heat transfer calculations

- Scoping Experiments

- Component Selection

- Acquisition

- Construction

- Testing

- Surrogate experiments

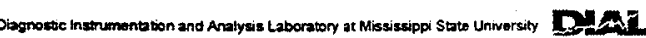

Laboratory-Scale Salt Well Pumping Apparatus

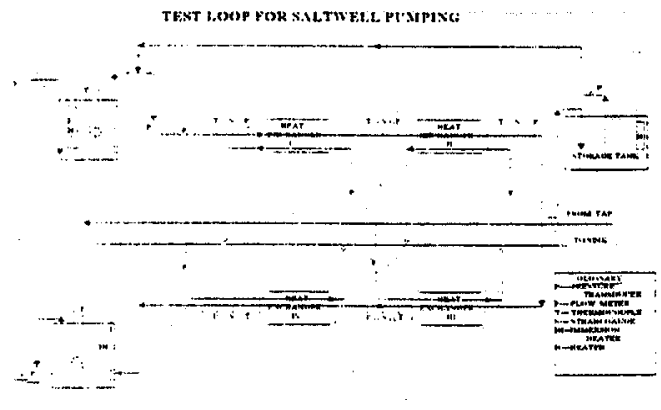

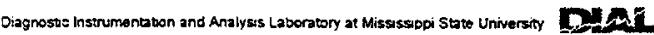


Salt Well Pumping System Test Matrix

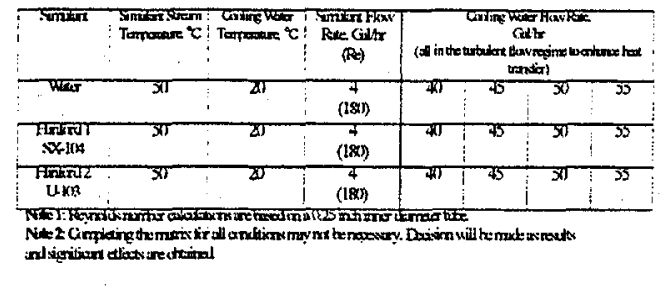

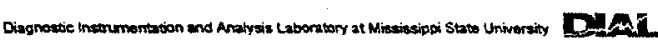

ESP Simulations for Slurry Transport

- ORNL Surrogates for AZ-101 and AN103

- AN-103 siurry measurements have been performed by FIU

- AZ-101 solids loading $<<5 \%$ wt. few problems expected

- Search for a second surrogate, $\mathrm{C}-104$ recommended by $\mathrm{J}$. Jewett, et al.

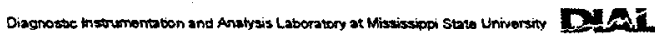

ESP Predictions of Particle Volumes ORNL AN-103 Surrogate

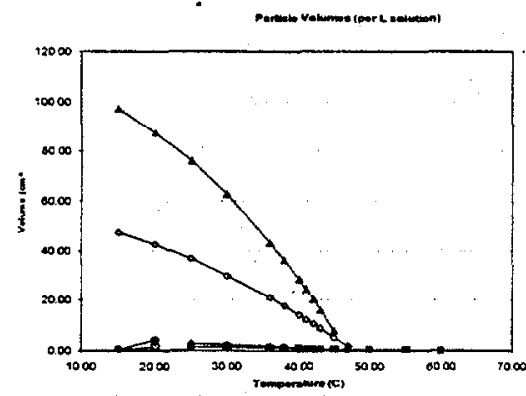

Diagroste instrumantabion and Analysis Laboratory at Missiassppi Stat University

Din
Model Input Correlations for AN-103 Surrogate

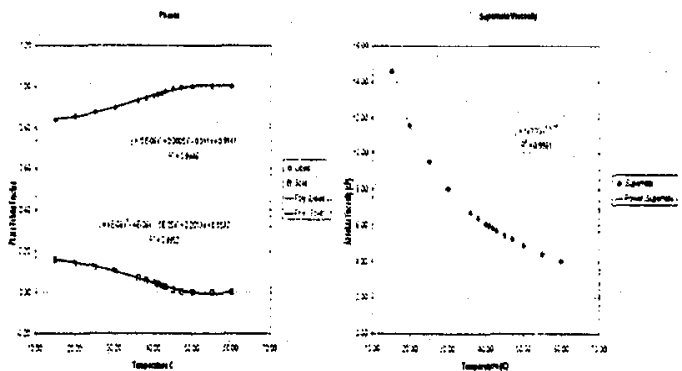

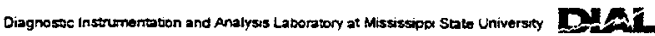

Stream Compositions Predicted for the AN-103 Surrogate ( $1-L$ basis)

\begin{tabular}{|c|c|c|c|c|c|c|c|c|}
\hline Temperature, C: & 15.00 & 20.00 & 30.00 & 36.00 & 40.00 & 45.00 & 50.00 & 00.00 \\
\hline & & & & & & & & \\
\hline \multicolumn{9}{|l|}{ Total Sirean } \\
\hline Total $g$ & 1415.39 & 1415.31 & 1415.30 & 1415.30 & 1445.30 & 1475.32 & 1415.30 & 1415.31 \\
\hline Volume, L & 0.91 & 0.92 & 0.94 & 0.96 & 0.96 & 0.98 & 0.00 & 1.00 \\
\hline Dersidy. of & 1561.36 & 1544.18 & 1506.96 & 1488.87 & 1467.65 & 1445,00 & 1430.45 & 1415.30 \\
\hline$\%$ Solids by $\mathrm{m}$ & 24.42 & 21.90 & 15.68 & 10.94 & 7.30 & 211 & 0.03 & 0.02 \\
\hline \% Solids by wol & 15.98 & 14.19 & 10.24 & 7.08 & 4.53 & 1.31 & 0.02 & 0.01 \\
\hline$\%$ Water by wt: & 4368 & 43.88 & 43.90 & 43.95 & 44.01 & 44.06 & 4.06 & 4.06 \\
\hline
\end{tabular}

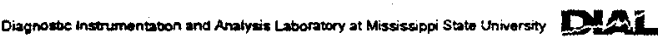

ESP Simulations for C-104 \& AY-101, Development of Surrogate (ORNL) to Replace AZ-101

- Jewett, J. R. personal comm. 4/21/00

- Phase 1 HLW

- O'Rourke, J. F., "Results of Retrieval Studies with Waste from Tank 241-C104,"RPP-5798, Fluor Hanford, Feb 8, 2000

- High Solids Loading $\sim 37 \%$ by wt.

- Tom Crawford, C-104 fails to meet tank farm storage requirements

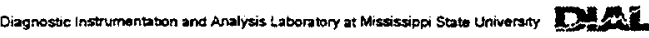




\section{Tank Farm Storage Requirements}

- For Temperatures less than or equal to $100^{\circ} \mathrm{C}$ and for $\left[\mathrm{NO}_{3}{ }^{-1}\right]<1.0$
$\left[\mathrm{OH}^{-1}\right]$
$0.010 \mathrm{M}<\left[\mathrm{OH}^{-1}\right]<5.0 \mathrm{M}$
$\left[\mathrm{NO}_{2}^{-1}\right]$
$0.011 \mathrm{M}<\left[\mathrm{NO}_{2}^{-1}\right]<5.5 \mathrm{M}$

$\left[\mathrm{NO}_{3}{ }^{-1}\right] /\left(\left[\mathrm{OH}^{-1}\right]+\left[\mathrm{NO}_{2}{ }^{-1}\right]\right)<2.5$ for DST

\section{Equilibrium Simulation Goals}

- Determination of diluent required to achieve $20 \%$ solids by weight

- What Diluent composition (caustic addition) is required to make $\mathrm{C}-104$ or AY-101 correspond to storage requirements

\section{ESP Parameters}

- BBI

- ESP Lab, Trona, Public Databases

- Proration in Water Analyzer

- Large Model oyar
Stream Totals Predicted for $\mathrm{C}-104$, dilution of C-104, AY-101 and addition of diluted C-104 stream to $A Y-101$

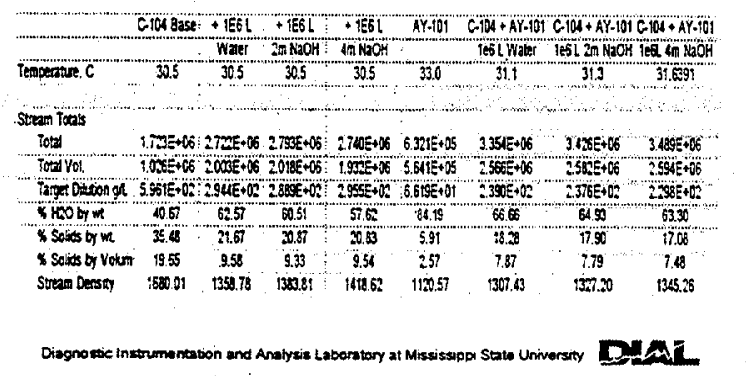

Anion Molarities

\begin{tabular}{|c|c|c|c|c|c|c|c|c|}
\hline \multirow[b]{3}{*}{ Tempentate $C$} & CikBase & \multirow{3}{*}{ 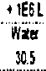 } & \multirow{3}{*}{ 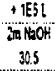 } & \multirow{3}{*}{$\begin{array}{c}1860 \\
400 \mathrm{H} \\
30.5\end{array}$} & \multirow{3}{*}{$\begin{array}{l}A Y .101 \\
330\end{array}$} & \multicolumn{3}{|c|}{ 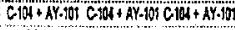 } \\
\hline & \multirow{2}{*}{ Ginatise } & & & & & 1e6l Whet & $60120 \mathrm{~kg}$ & 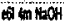 \\
\hline & & & & & & mi & $\mathrm{jt} 3$ & 31.091 \\
\hline 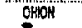 & 214 & 1.34 & 213 & $3 i$ & 106 & 1.20 & 1.62 & 2,4 \\
\hline Nozon & 0.84 & 0.13 & Q63 & Q.4) & 0.37 & 1.13 & 1.12 & 1.2 \\
\hline Horsion & 033 & 017 & 017 & bie. & 31 & 0.02 & 0.61 & 0.51 \\
\hline
\end{tabular}

[NO3-1] $<1.0 \mathrm{M} \mathrm{T}<100^{\circ} \mathrm{C}$

$[\mathrm{OH}-1]>0.010 \mathrm{M}<5.0 \mathrm{M}$

$\left[\mathrm{NO}_{2}^{-1}\right]>0.011 \mathrm{M}<5.5 \mathrm{M}$

$\left[\mathrm{NO}_{3}{ }^{-1}\right] /\left(\left[\mathrm{OH}^{-1}\right]+\left[\mathrm{NO}_{2}^{-1}\right]\right)$ is $<2.5$ for DST

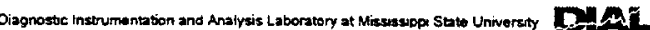


Preliminary Results C-104 Calculations

- Around $1 \times 10^{6} \mathrm{~L}(260 \mathrm{kgal}$.) of diluent will be required to achieve a $20 \%$ solids loading by weight

- Initial results indicate that the waste conforms to the storage criteria requirements

Modeling Requirements: Initial Starting Point

- Number of species and concentrations

- Conservation (mass, momentum, energy)

- Fluid properties (flow rates, pressure, density, viscosity)

- Particle size, shape, density, growth kinetics

- Population balance

- Chemical reactions

- Phase equilibria

- Sedimentation and deposition behavior

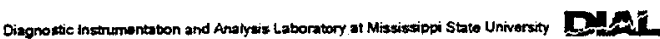

Model Flowchart

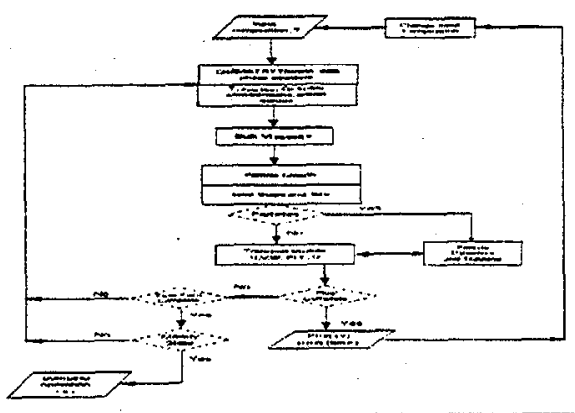

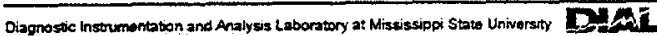

Slurry Transport and Salt Well Pumping Model

Objectives

- Capable of predicting plug formation in a waste transfer line

- Location and time needed to form the plug

- Values of variables that are used by the Tank Farm Operators (Pressures, Flow Rates..)

- Ultimate Model must be practical, easy to use, reliable, validated

- Modular Approach

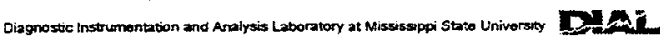

Modeling Approach

- General Purpose CFD Code

- Multi-phase formalism

- Chemistry

- correlations

- calls to existing existing models

- Particle growth, dynamics,

- Bulk viscosity

- Pre and post-processing capabilities

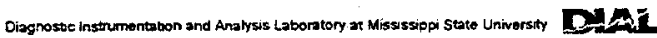

Down-Selection of Transport Module Criteria for Selection

- Cost, User Support

- Open Source Coding

- Built-in Capabilities

- Availability

- Ease of Use 
Commercial/Available CFD Codes Evaluated

- Fluent (25K/yr, comprehensive capabilities

- CFD 2000 (low cost, limited capabilities, company undergoing mergers)

- Pheonics (3.5K/yr software and support, open source code, pre and post processing capabilities, comprehensive physical models)

- Tempest (2 versions, good capabilities, public version limited model)

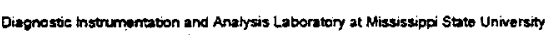

Demar.
Initial Simulations

- Water w/wo particles

- Drift Flux Multi-Phase Flow Model

- Turbulence

- Simulation Objectives

- Evaluate Code

- grid generation

- initial and boundary condition specifications

- conversion criteria

- post-processing capabilities

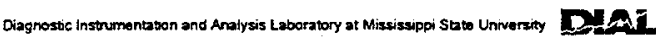

\section{Initial Simulation Parameters}

- Carrier fluid $20^{\circ} \mathrm{C}, 70 \%$ by volume

- Particles

- 200 micron, 400 Micron, $15 \%$ by volume each

- Pipe dimensions $0.3 \times 12 \mathrm{~m}$ cast iron

- Transient simulation

- Input velocity and simulation period

$\begin{array}{lc}-1 \mathrm{~m} / \mathrm{s} & 12 \mathrm{~s} \\ -0.5 & 10 \mathrm{~s} \\ -0.1 & 6 \mathrm{~s} \\ -1 & \text { steady state }\end{array}$

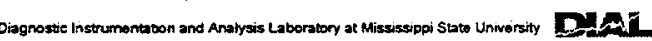

Steady State Results for Velocity and Water Concentration

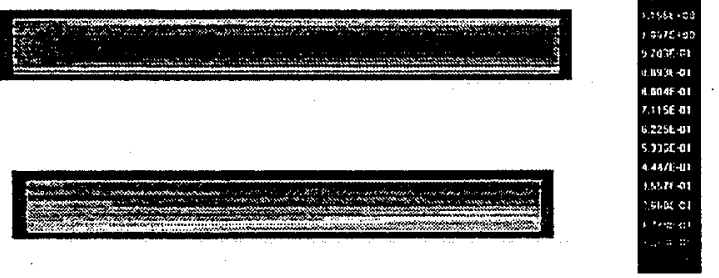

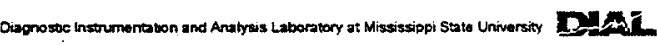

Results of Simulations

- Panel Plots

- Velocity, Carrier, Particle 1, Particle 2

- An initial time of 12 seconds was not sufficient to achieve steady state, flow is in moving bed regime

- Lowering the input velocity results in increased deposition, maximum deposition at $0.1 \mathrm{~m} / \mathrm{s}$

- Increasing flow to $1 \mathrm{~m} / \mathrm{s}$ clears out the deposition and restores a moving bed flow

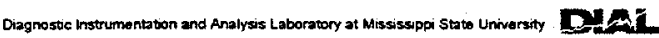

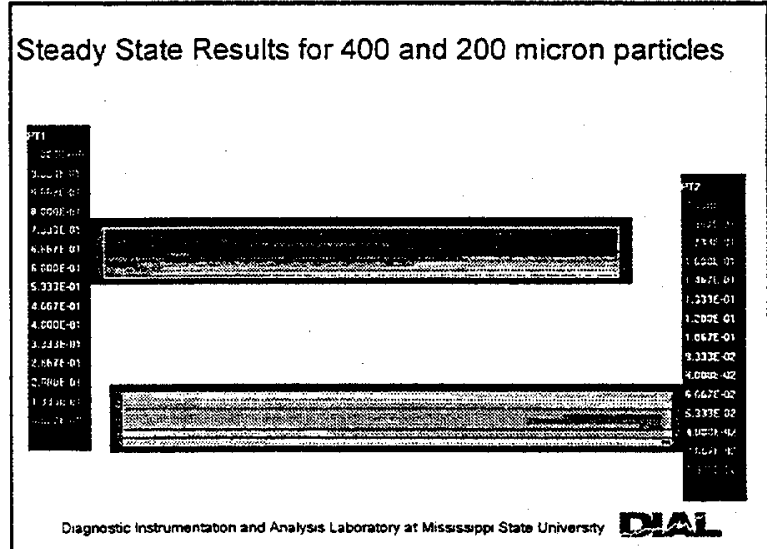


Path Forward

- Develop correlations based on the results of other team members

- Start simulation work for FIU AN-103 Studies

- geometry and grid generation

- code modifications

- module development

- results validation

- Begin Salt Well Pumping Model

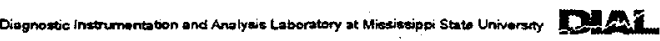




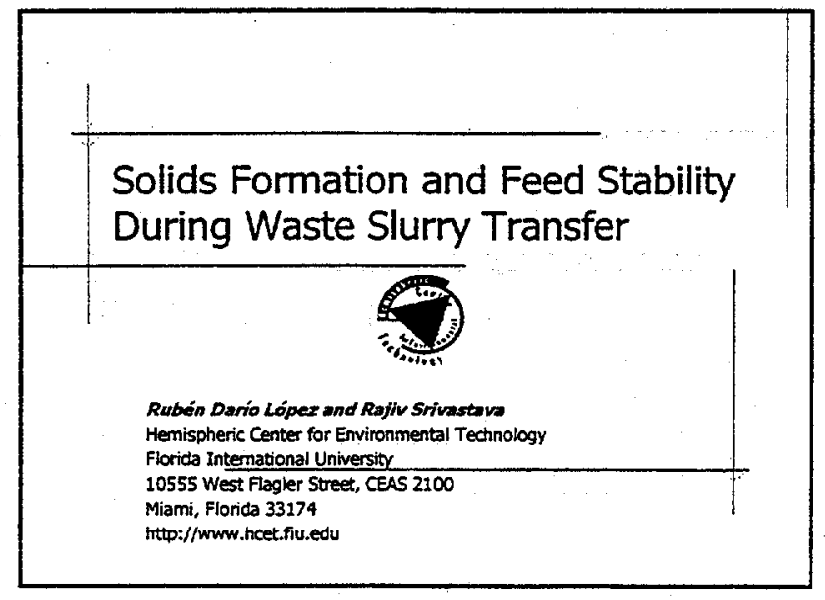

\section{Objective}

- To investigate the effect of temperature and chemical reactions on the slurry transport and stability

- To test the plugging potential of pipelines due to precipitation and crystallization

- To study ways to unplug transfer lines

SALTCAKE DISSOUUTON AND FEED STAEILTT WORKSHOP

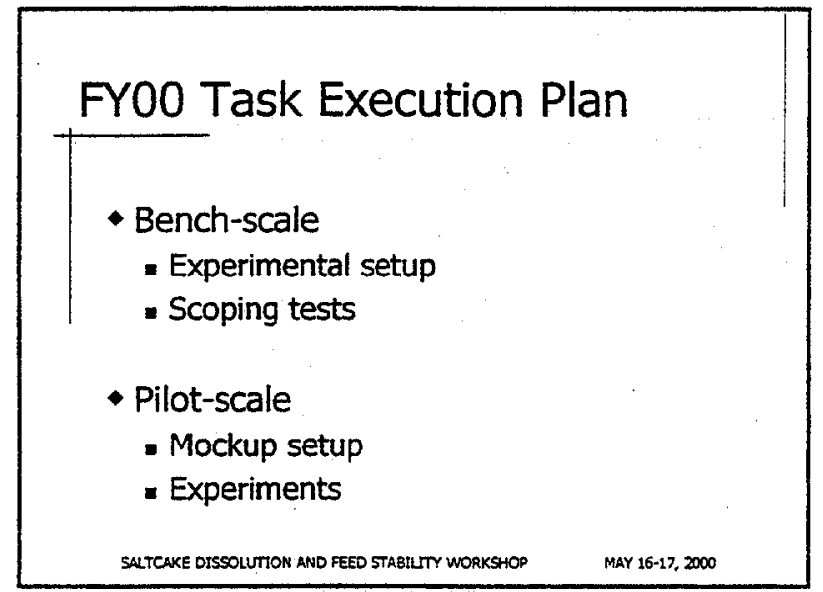

\section{Bench-scale Unit}

- Slurry composition

- Slurry conditioning

- Feed tank with two electrical heaters

- Slurry transfer in 3/8-inch (ID) tubing - Moyno pump

- Plug monitoring

- Time-lapse video recorder

- Process conditions monitoring

- Temperature, flow rate, pressure drop

SALTCAKE DISSOLUTION AND FEED STABILTTY WORKSHOP

Bench-scale Unit
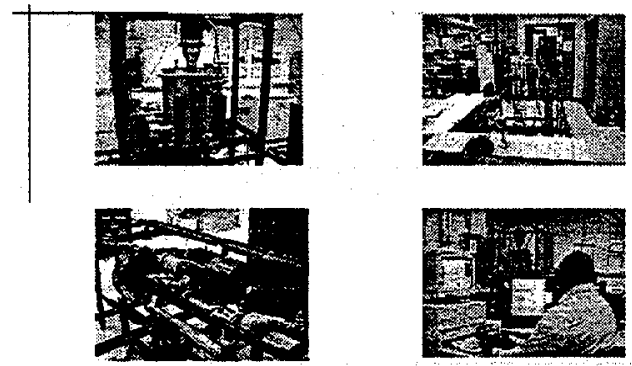

SAITCAKE DISSOLUTION AND FEED STABHITY WORKSHOP

MAY $16-17,2000$

\section{Simulants Tested}

- Hydroxide-phosphate-fluoride system

- $X 1$

- $3 \mathrm{M} \mathrm{NaOH}+0.6 \mathrm{M} \mathrm{Na}_{3} \mathrm{PO}_{4}+0.2 \mathrm{M} \mathrm{NaF}$

$=\times 2$

- $3 \mathrm{M} \mathrm{NaOH}+0.6 \mathrm{M} \mathrm{Na}_{3} \mathrm{PO}_{4}+0.2 \mathrm{M} \mathrm{NaF}+$

$7 \mathrm{M} \mathrm{NaNO}$

- AN 103

- 1.982M NaAlO $+1.103 \mathrm{M} \mathrm{Al}_{2}\left(\mathrm{NO}_{3}\right)_{3} \cdot 9 \mathrm{H} 2 \mathrm{O}+0.148 \mathrm{M}$ $\mathrm{NaCl}+0.692 \mathrm{M} \mathrm{Na}_{2} \mathrm{CO}_{3}+0.061 \mathrm{M} \mathrm{NaF}+2.016 \mathrm{M} \mathrm{NaNO}_{3}$ $+6.744 \mathrm{M} \mathrm{NaOH}+0.031 \mathrm{M} \mathrm{Na}_{3} \mathrm{PO}_{4}+0.028 \mathrm{M} \mathrm{Na}_{2} \mathrm{SiO}_{3}$. $5 \mathrm{H}_{2} \mathrm{O}+0.045 \mathrm{M} \mathrm{Na}_{2} \mathrm{SO}_{4}+49.113 \mathrm{M} \mathrm{H}_{2} \mathrm{O}$

SALTCAKE DISSOUUTON ANO FEED STABUITY WORKSHOP

$\operatorname{MaY} 16-17,2000$ 


\section{Test Matrix}

- Feed tank temperature

$$
\text { . } 50^{\circ} \mathrm{C}
$$

- Test section temperatures

$$
\text { - } 15^{\circ} \mathrm{C}, 40^{\circ} \mathrm{C}
$$

- Flow rates

- Laminar, $\operatorname{Re}<2,300$

- Transition, 2,300<Re<10,000

- Turbulent, Re>10,000

\section{Experimental Observations (X1)}

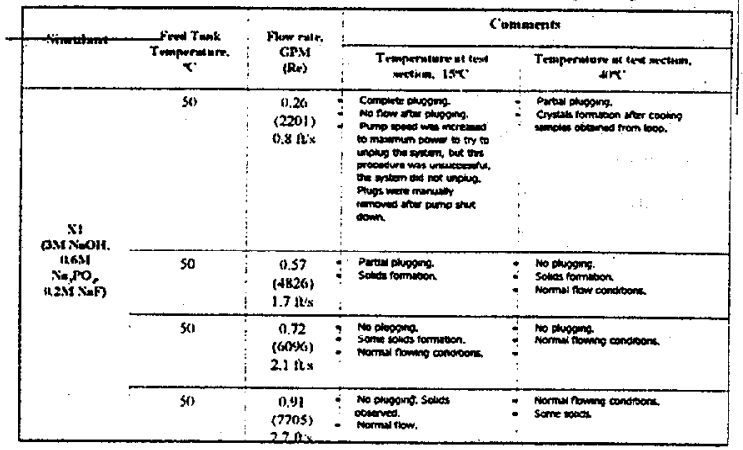

SQLTCAKE DISSOLUTON AND FEED STABILTT WORKSHOP

MAY 16.17, 2000

\section{Experimental Results}

- X1 simulant plugging

- Total plugging at $15^{\circ} \mathrm{C}$ and $v<2.1 \mathrm{ft} / \mathrm{s}$

- Plugs manually removed

- Partial plugging at $40^{\circ} \mathrm{C}$

- System kept running at lower flow rate

- X2 simulant

- Similar to X1, except needie like crystals

- Unplugging achieved by heating system and increasing pump power

- AN 103

- Similar to X2

SALTCAKE DISSOUUTION AND FEED STABHLTY WORKSHOP

$\operatorname{MaY} 16-17,2000$

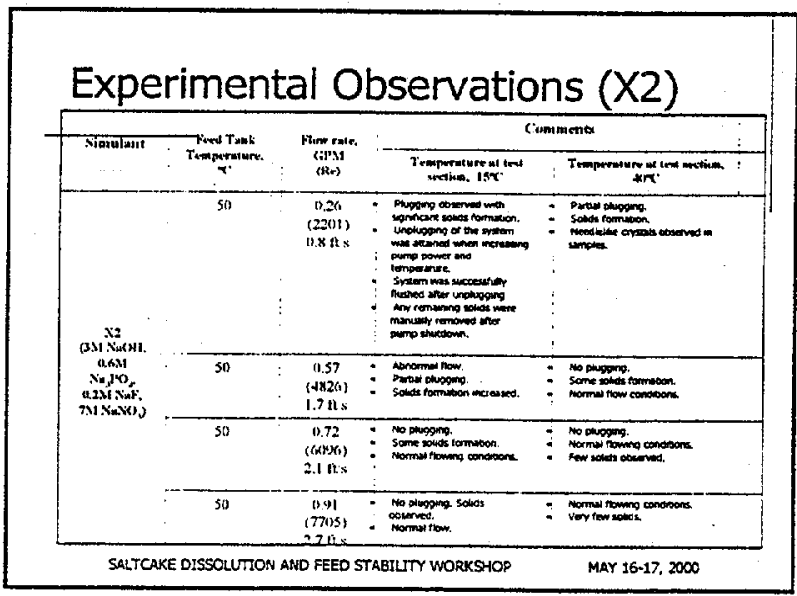

$\mathrm{X} 1$ and $\mathrm{X} 2$ plugging

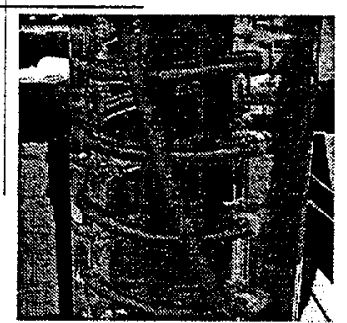

Partial

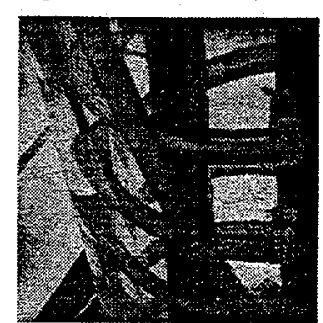

Total
SALTCAKE DISSOLUTION AND FEED STABIITTY WORKSHOP $\operatorname{MaY} 16+17,2000$ 


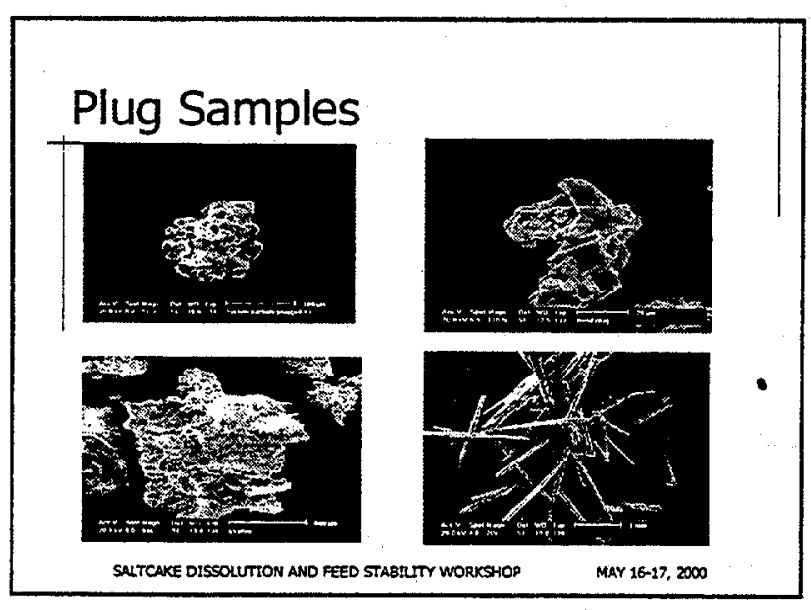

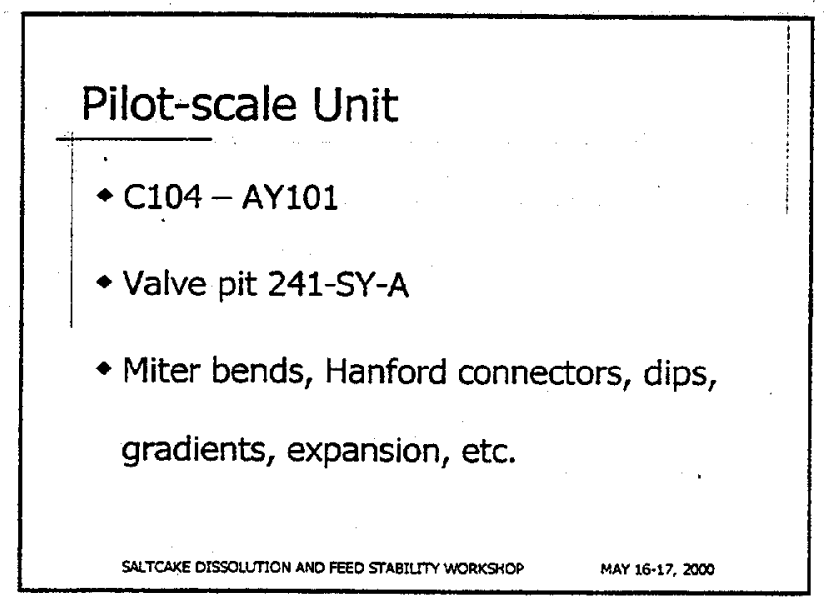

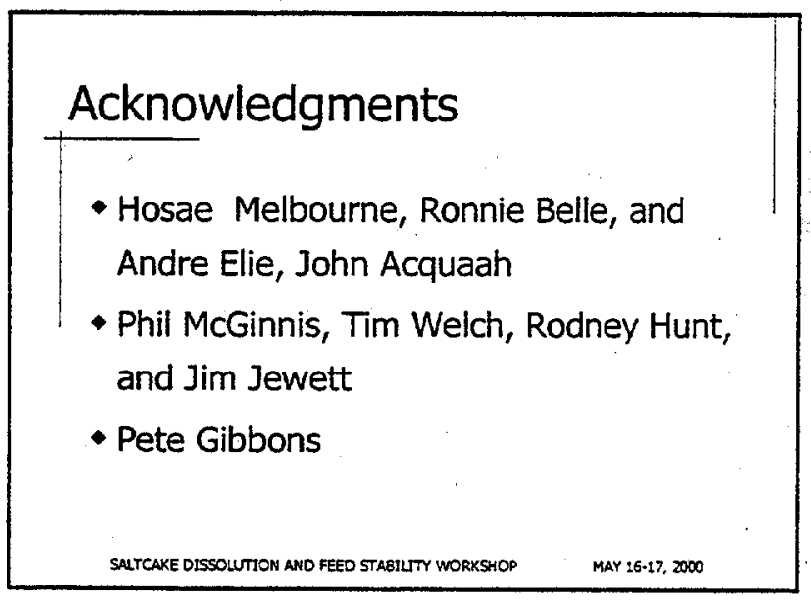




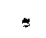




\section{Identification of Future Tests and Benefits}

Tim Welch

Oak Ridge National Laboratory

Salt Dissolution and Feed Stability Workshop

Richland, Washington

May $16-17,2000$
Objective: Maintain Feed Stability -Prevent Pipeline Plugs

- Model waste transfer operations (coupling chemical reaction/precipitation and flow)

- Conduct tests to validate models and determine parameters for transfer without plugging.
Feed Preparation and Transport Tasks

- Solids Formation---Solids formation and dissolution. waste propery data and predictive methods

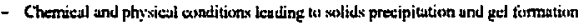

- Viscosity of siurrics

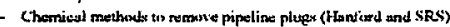

- Precipietedion kirzelizes und preceipitale properties

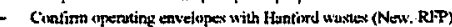

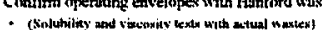

- Feed Stability

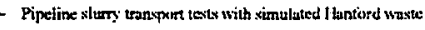

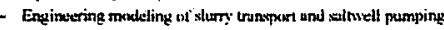

- Saliwell pumping usta with simultuted uasio

- Development of simulited wavte recipes

- Subitily or sumernituna maxtures (Now. RPP)
Feed Preparation and Transport Tasks (continued)

- Sludge Settling

- Effect of shear on settling rates and sediment properties of actual wastes

- Saltcake Dissolution Testing and Solids Characterization - Lab tests with actual saitcake

- ESP code developinent and validation

- Comparison of ESP with literature data

- Comparison of ESP predictions with saltcake dissolution tests

- Expand ESP database to address Hanford saltcake

\section{Solids Formation}

Ensure Thermodynamic Stability-Avoid Supersaturation of Major Components

- Determine chemical operating envelopes for Hanford pipeline transfers

- Includes phosphates, fluoride, nitrate, nitrite, and carbonate

- Measure simuiated waste viscosities

- Identify and characterize solids (PLM. SEM, XRD)
Feed Stability/Waste Transport Chemistry Ensure that Saltcakes and Slurries Can Be Pumped

Pipeline tests with simulated wastes to determine seceptable ranges of

chenvical and transport parmeters to prevent pipeline pluyging

- Bench-scaic tests with simulyted wastes to improve soltwell pumping: reduce plagging and incresse availability

- Measure precipitation kincties and precipitate properties (size. shape. densin.)

- Model transport of slurries and saltcakes usinz computational fluid dynanics code with chemical reaction. population balance.

Evaluate data and transport model results to understand plugging mechanisms and determinc stable regions of chemical-physicaj-lransport parameters.

- Study solids formation in receiving tank from mixed saitcalics 


\section{Benefits From The Feed Stability Tasks}

- Identify potential problems transterring specific wastes

- Provide data and tools to plan and evaluate waste transfers

- Develop a betrer understanding of plugging mechanisms - Plysical

- Chemical

$$
\text { - Flow }
$$

- Improve waste transfer criteria

- Support waste staging

- Support waste transfer operations

- Identify and test improvements in saltwell pumping operations

- Improve understanding of piugging mechanisms

- Improve measurement and control requirements specifications

- Collaboration on modeling, data development, and cvaluation
Topics For Further Discussion

- Slurry flow-loop tests at FIU

- Transfer criteria

- Solids fraction

- Velocity

- Reznoids no

- Test Desisn

- Candidate tanks

- Pipe and jumper yeotsetryilayout

- Modeling

- Viscosity models for "needles"

- Recovery/restart from partial plus 
Appendix B

OFFICE OF RIVER PROTECTION PRESENTATIONS

B-1 



\title{
Overview of Privatization Waste Feed Delivery
}

\author{
By Randy Kirkbride \\ May 15, 2000
}

For the Saltcake Dissolution and Feed

Stability Workshop 


\section{Phase 1 Process Interfaces}

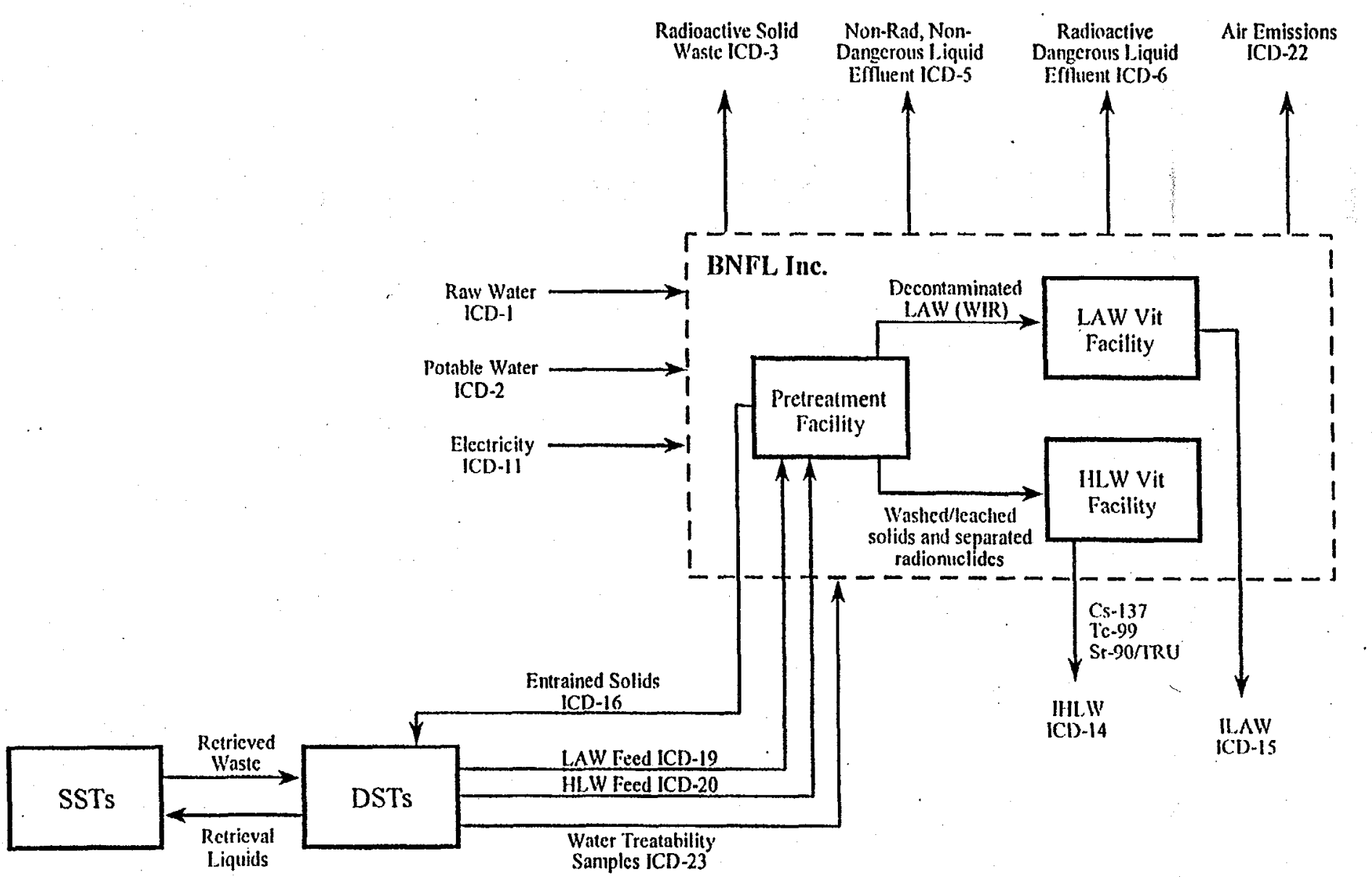

IILW - High Level Wasle

ILAW - Immobilized Low Activity Waste IIHW - Immobilized High Level Wastc LAW - Low Activity Waste

Vit - Vitrification

IR - Waste lncidental to Reprocessing (Per DOE: Order 435.1) 
LOW-ACTIVITY WASTE FEED _SIAGING SEQUENCF CASE 356 PHASE I

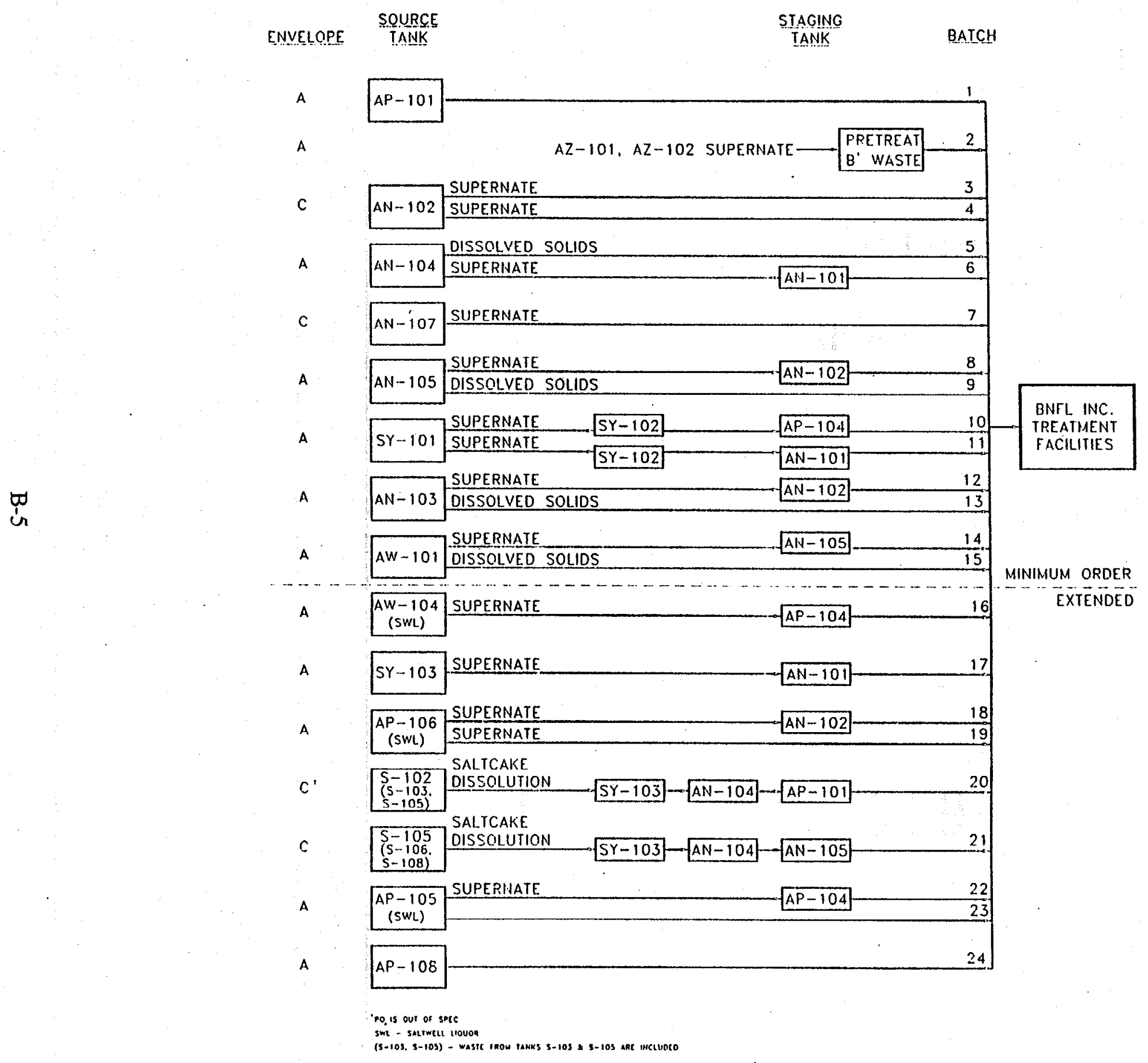


$7 z-101$ EFFICIENCY

GROUP
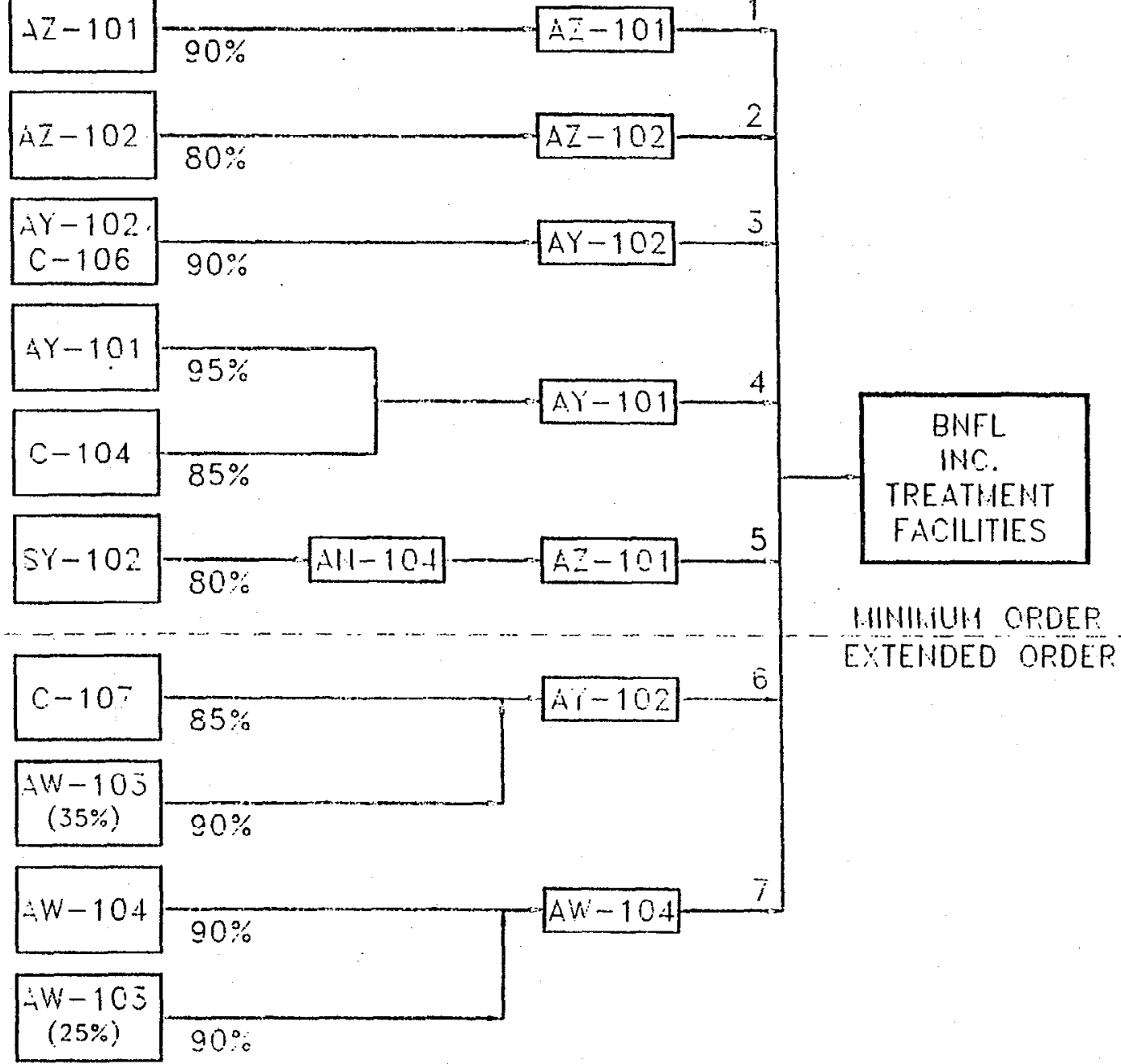

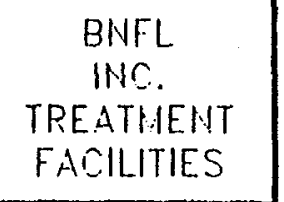

ETETDED ORDEP 


\section{Saltcake Chemistry and Feed Stability}

- Need better understanding of chemistry for:

- AN-104 dissolved salts "sulfate problem"

品 $\quad-$ AN-102/AN-107 residual solids

- HLW slurry compositions

- SST waste blending

- Tank farm system operation 
3 


\title{
Single-Shell Tank Program Single-Shell Tank Waste Retrieval Project
}

\author{
Carolyn Haass \\ Warren Thompson
}

The Conference Center

Richland, Washington

May 16, 2000 


\section{Mission Scope}

- Retrieve waste from initial SSTs to provide waste feed for the treatment (vitrification) system during Phase 1 Privatization ( 4 tanks by 2018 , first tank by 2007)

- Retrieve waste from SSTs to backfill DSTs during Phase 1 Privatization (approximately 15 tanks by 2018 , first tank by 2009)

- Select and demonstrate cost-effective and efficient technologies for waste retrieval, leak detection and response, etc. to support SST waste retrieval

- Implement retrieval processes that allow for SST closure

- Develop the engineering and management foundation to support programmatic and regulatory decisions needed to plan and complete SST waste retrieval (e.g., cost of waste retrieval by tank, risk reduction resulting from waste retrieval, implication of tank waste remaining in tanks) 


\section{SST Current Status}

- Of all tank waste, SSTs contain $\sim 65 \%$ mass, $\sim 70 \%$ long-term radionuclides. 67 of 149 SSTs are known or are suspected to have leaked.

- Other than Interim Stabilization and C-106, no recent retrieval

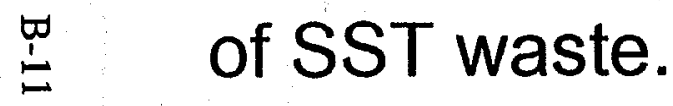

- Proposed work via modified FY 2000 work planning provides solid planning basis; initiates retrieval of SST waste by 2007 (demonstration of salt cake retrieval earlier). 


\section{Proposed Work Targets Key Tanks}

- 58 SSTs contain $\sim 90 \%$ long term radionuclides and $\sim 75 \%$ (26 Mgals) waste

- FY 2000 replanning (BCRs 00-32 and 00-36) initiates retrieval of this key SST waste.

- 52 SSTs contain less than $\sim 1 \%$ long term radionuclides and

$\sim 10 \%$ (4 Mgals) waste

- FY 2000 replanning (BCR 00-25) initiates interim closure activities potentially applicable to these tanks.

- SST baseline is updated accomplishing the above work. 


\section{Drivers for SST Waste Retrieval}

- SSTs are planned as part of Phase 1 Waste Feed Requirements

- 4 SSTs (241-C-104, C-107, S-102, and S-105)

- 1 SSTs will be used for technology demonstrations (241-S103)

- SST retrieval must proceed as soon as DST space becomes available ( FY 2009) to address public concerns on SST waste

- Satisfy RCRA/CERCLA requirements and Tri-Party Agreement commitments for SST waste retrieval and tank farm closure (Major Milestone M-45-00)

- Build credibility to attain the necessary funding commitment and regulatory support to begin and complete the SST waste retrieval and closure mission

- Credibility of Phase 1 will be influenced by Phase 2 planning and agreement on mission requirements and end points 


\section{Technical Foundation}

- In the next few years, ORP needs sound engineering and management foundation for a compliant regulatory path to conduct and complete SST waste retrieval and closure activities which

- Address and reduce program uncertainties

- Allow SST waste retrieval to safely and cost-effectively proceed

- Establish a path for completing the ORP Mission

- Initial engineering must start immediately for SST retrieval for Phase 1 and DST backfill

- Alternatives to Past Practice Sluicing have promise for cost reduction and will be demonstrated prior to deployment 


\section{Technical Approach}

- Retrieve waste from SSTs on a fixed schedule and in sufficient quantity to feed privatized waste immobilization facilities

- Perform tank retrieval with one retrieval campaign -reentering for closure to be avoided - achieve closure requirements with single retrieval effort

- Select and demonstrate SST waste retrieval technologies in time to support design and construction of waste retrieval systems (solutions to the SST waste retrieval problem will require additional technology deployments)

- Implications (health and environmental threat) of tank waste releases to the environment will be an important factor in the development of requirements for SST waste retrieval and tank farm closure activities 


\section{SST Waste Retrieval is Segregated into Three Distinct Phases}

- Phase 1 waste feed requirements

- Backfill of DSTs that are retrieved to provide waste feed during Phase 1 with SST waste

(this waste will be used during the initial years of Phase 2 to meet waste feed requirements.)

- Long-term SST waste retrieval (balance of mission) 


\section{Goals for SST Waste Retrieval}

- Meet Phase 1 waste feed requirements to retrieve SST waste by 2007 by assuming:

- Accelerate retrieval of Tank 241-C-104 into Phase 1 Minimum Order ( $\sim 4$ years)

- Use of past-practice sluicing until alternate technologies are available

- Retrieval of $85 \%$ of the waste from each SST retrieved during Phase 1 , - goal is to achieve closure requirements

- Retrieval leak protection based on graded risk strategy developed under the Retrieval Performance Evaluation (RPE) process and described in the LDMM strategy document

- Plan for SST retrieval to meet balance of mission requirements by:

- Establishing credibility for the life-cycle of the SST Program (technical, cost, and schedule)

- Retrieving waste for Phase II (completion of the balance of mission)

- Linking waste retrieval to tank farm closure activities, including groundwater/vadose zone activities 


\section{Replanning FY 2000 Proposed Work}

- BCR 00-32: Accelerates C-104 sludge (Phase 1 feed material) retrieval 3 years. Initiates preliminary engineering this year.

- BCR 00-25: Initiates C-106 data collection to support "operational closure". Performs SST degradation studies to support SST retrieval planning and prioritization.

- BCR 00-36: Deploys salt cake dissolution technology in SST, readies crawler for Operations training and deployment (both systems required for Phase 1 feed material and DST backfill). 


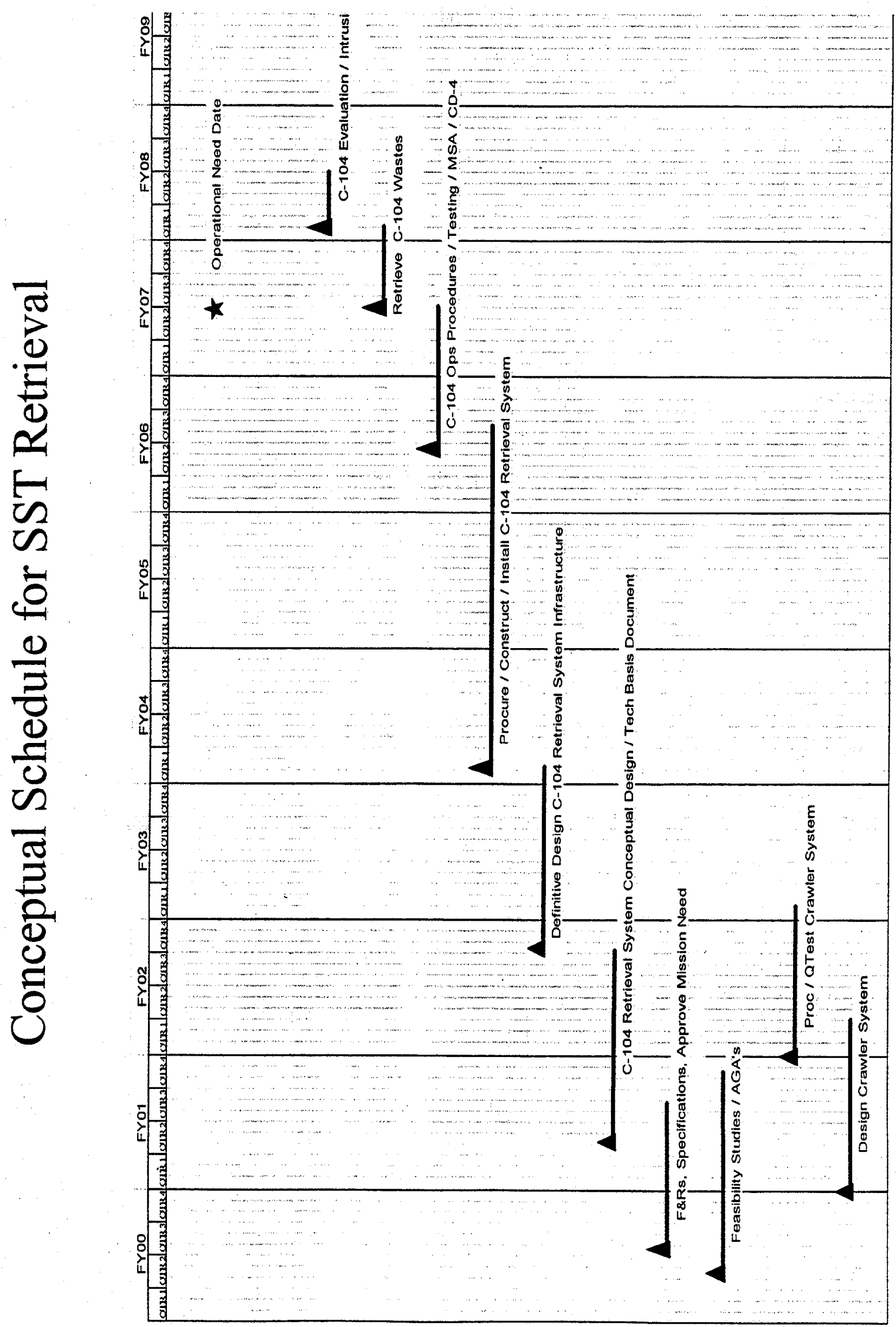




\section{Planned Accomplishments Through FY06}

- Completed S-103 Saltcake Dissolution Retrieval

- Completed Construction of C-104 Retrieval Systems

- Initiated Construction of C-107 Retrieval Systems

- Attained C-106 Interim Closure Status

- In-Process for Interim Closure for Nine Additional SSTs

- Procured and Tested a Crawler Based Retrieval System

- Initiated Conceptual Engineering for S Farm Retrievals

- Initiated Testing for Remaining Systems Configurations 


\section{Expected Results/Outcomes}

- Technologies for SST waste retrieval are available and demonstrated

- Technologies for closure and mitigation of subsurface contamination are known and feasible

- End point requirements are known and bounded

- A credible, defensible and traceable technical, cost, and schedule foundation 


\section{Single-Shell Tank Characteristics and Proposed Work}

\begin{tabular}{|c|c|c|c|c|c|}
\hline $\begin{array}{l}\text { Single Shell } \\
\text { Tanks }\end{array}$ & $\begin{array}{c}\text { Long Term } \\
\begin{array}{c}\text { Radionuclide (LTR) } \\
\text { Inventory }\end{array} \\
\end{array}$ & Tank Integrity & Waste Type & BCR Proposed Work & $\begin{array}{l}\text { DST Backfill and } \\
\text { Phase I Feed }\end{array}$ \\
\hline \multirow{9}{*}{$\begin{array}{l}149 \\
\text { Single-Shell } \\
\text { Tanks }\end{array}$} & \multirow{7}{*}{$\begin{array}{l}58 \text { Tanks } \\
\text { Contain 90\% LTR } \\
\text { in } 25.7 \mathrm{Mgals}\end{array}$} & \multirow{3}{*}{$\begin{array}{l}42 \text { Sound Tanks } \\
\text { Contain } \\
71 \% \text { LTR }\end{array}$} & 24 Saltcake tanks, $42 \%$ LTR, 11 Mgal & $\begin{array}{l}\text { BCR\#36: initiates } S-103 \text { retrieval } \\
\text { preliminary engineering. } \\
\text { BCR\#25: see below }\end{array}$ & 11 tanks \\
\hline & & & 14 Mixed tanks, $26 \%$ LTR, $6 \mathrm{Mgal}$ & $\begin{array}{l}\text { BCR-032 \& BCR\#36: depending } \\
\text { on outcomes in C-104 retrieval and } \\
\text { crawler testing, apply best } \\
\text { technology to these type of tanks. } \\
\text { BCR } \# 25 \text { : see below }\end{array}$ & 4 tanks \\
\hline & & & 4 Sludge tanks, 3\% LTR, 1 Mgal & $\begin{array}{l}\text { BCR-032: C-104 retrieval } \\
\text { preliminary engineering. } \\
\text { BCR } \# 25 \text { : see below }\end{array}$ & 2 tanks \\
\hline & & \multirow{3}{*}{$\begin{array}{c}15 \text { Tanks which leaked } \\
<8000 \text { gals contain } 19 \% \\
\text { LTR } \\
\end{array}$} & 9 Saltcake tanks, $12 \%$ LTR, $5 \mathrm{Mgal}$ & \multirow{4}{*}{$\begin{array}{l}\text { BCR\#36: low water volume } \\
\text { methods - saltcake dissolution and } \\
\text { crawler apply to leaking and } \\
\text { potentially leaking tanks BCR } \# 25 \text { : } \\
\text { see below }\end{array}$} & \multirow{4}{*}{ none } \\
\hline & & & 4 Mixed tanks, $5 \%$ LTR, $\sim 2$ Mgal & & \\
\hline & & & 2 Sludge tanks, $2 \%$ LTR, $<1 \mathrm{Mgal}$ & & \\
\hline & & \multicolumn{2}{|c|}{ I Saltcake Tank which leaked $>8000$ gals contains $\sim$ \% LTR } & & \\
\hline & \multicolumn{3}{|c|}{39 Tanks Contain 9\% LTR in 5.6 Mgals (includes 21 past leaking tanks) } & $\begin{array}{l}\text { Cost data developed in retrieving } \\
\text { the } 58 \text { tanks containing } 90 \% \text { LTR } \\
\text { will help define "economically and } \\
\text { technically achievable" for these } \\
\text { takks } \\
\text { BCR\#25: see below }\end{array}$ & 2 tanks \\
\hline & \multicolumn{3}{|c|}{52 Tanks Contain 1\% LTR in 4.1 Mgals (includes 30 past leaking tanks) } & $\begin{array}{l}\text { BCR-025: data collection } \\
\text { from C-106 supports interim } \\
\text { closure investigations for } \\
\text { tanks with little waste. See } \\
\text { below. }\end{array}$ & 1 tank \\
\hline
\end{tabular}

BCRH25 funds assessments on SST initial conditions, applicable to the deployment of all retrieval technologies. BCRH25 also funds assessments of SST retrieval delays and the impact that has on selection of retrieval methods. 


\title{
Status on Improving Hanford Waste Speciation Modeling Using OLI Software
}

\author{
Albert Hu \\ CH2M Hill Hanford Group Inc. \\ Steve Sandra and Brian Li \\ OLI Systems, Inc.
}

Tank Focus Area Workshop on Saltcake Dissolution and Feed Stability May 16, 2000 at Richland Conference Center, Washington 


\section{Status on Current ESP modeling}

- Application of ESP at Hanford Waste:

1) Calculate the tank waste species at equilibrium;

2) Simulate the waste process.

- Evaluations of ESP for Hanford application indicate that there are inconsistencies between the model predictions and observed analytical results, especially for undiluted waste.

- To perform the tank waste speciation prediction normally takes a day for one tank. Thus it takes over half year continuously to run one calculation for $\mathbf{1 7 7}$ tanks. 


\section{Improve the Accuracy and Efficiency on Hanford Waste Speciation Modeling}

Accuracy: Systematically reconstruct the database to model Hanford waste using the OLI regression utility and validate the limitations of the ESP model for extreme waste conditions.

Efficiency: Develop a window-based code "Hanford Waste Speciation Prediction" that interfaces with the OLI software to customize and automate the modeling efforts. 


\section{Characteristics of Hanford Waste}

\begin{tabular}{|c|c|c|c|c|}
\hline \multicolumn{5}{|c|}{ Global Tank Waste Inventory } \\
\hline \multicolumn{5}{|c|}{ Temperature range: $12-77^{\circ} \mathrm{C}$} \\
\hline \multicolumn{5}{|c|}{ Density: $1.1-1.9 \mathrm{~g} / \mathrm{mL}$} \\
\hline \multicolumn{5}{|c|}{ pH: $11.4-14.8$} \\
\hline Analytes & Total $(\mathrm{Kg})$ & $w t \%$ & Cumulative wt $\%$ & $M($ mole $/ \mathrm{L})$ \\
\hline Water & $1.33 E+08$ & $43.67 \%$ & $43.67 \%$ & 36.45 \\
\hline $\mathrm{NO}_{3}^{-1}$ & $5.19 E+07$ & $17.08 \%$ & $60.75 \%$ & 4.14 \\
\hline $\mathrm{Na}^{+1}$ & $4.77 E+07$ & $15.70 \%$ & $76.45 \%$ & 10.26 \\
\hline OH(TOTAL) & 2.25E+07 & $7.40 \%$ & $83.86 \%$ & 6.54 \\
\hline $\mathrm{NO}_{2}^{-1}$ & $1.24 E+07$ & $4.07 \%$ & $87.93 \%$ & 1.33 \\
\hline $\mathrm{TIC}\left(\mathrm{CO}_{3}^{-2}\right)$ & $9.50 E+06$ & $3.13 \%$ & $91.05 \%$ & 0.78 \\
\hline $\mathrm{Al}^{+3}$ & $8.10 E+06$ & $2.66 \%$ & $93.72 \%$ & 1.48 \\
\hline $\mathrm{PO}_{4}^{-3}$ & $5.69 E+06$ & $1.87 \%$ & $95.59 \%$ & 0.30 \\
\hline $\mathrm{SO}_{4}^{-2}$ & $3.21 E+06$ & $1.05 \%$ & $96.64 \%$ & 0.16 \\
\hline TOC & $1.50 \mathrm{E}+06$ & $0.49 \%$ & $97.14 \%$ & 0.62 \\
\hline $\mathrm{Fe}^{+3}$ & 1.33E+06 & $0.44 \%$ & $97.58 \%$ & 0.12 \\
\hline $\mathrm{Si}^{+4}$ & $1.16 E+06$ & $0.38 \%$ & $97.96 \%$ & 0.20 \\
\hline $\mathrm{F}^{-1}$ & $1.14 E+06$ & $0.37 \%$ & $98.33 \%$ & 0.30 \\
\hline
\end{tabular}




\section{Customized Database}

- Strategy: to study the major species of Hanford Waste such as $\mathrm{NaNO}_{3}, \mathrm{NaNO}_{2}, \mathrm{Na}_{2} \mathrm{CO}_{3}, \mathrm{NaOH}$, then add secondary species like $\mathrm{NaPO}_{4}, \mathrm{NaSO}_{4}, \mathrm{NaF}$ into databank. Then work on the minor/trace species such as $\mathrm{Cr}, \mathrm{Cs}, \mathrm{Sr}$, which were identified to be important to waste operations.

- Methodology: to first establish parameters of the binary electrolyte in the multicomponent, $\mathrm{Na}-\mathrm{NO}_{3}-\mathrm{NO}_{2}-\mathrm{CO}_{3}-\mathrm{OH}-\mathrm{Al}-$ $\mathrm{PO}_{4}-\mathrm{SO}_{4}-\mathrm{F}-\mathrm{Cr}-\mathrm{H}_{2} \mathrm{O}$, chemical system using OLI-modified Bromley electrolyte model ESP, then construct the new parameters for ternary or higher order systems. The newly constructed database will be validated with waste data stage-by-stage. 


\section{Major subsystems: $\mathrm{Na}-\mathrm{NO}_{3}-\mathrm{NO}_{2}-\mathrm{OH}-\mathrm{H}_{2} \mathrm{O}$}

- For example, the major subsystem Na- $\mathrm{NO}_{3}-\mathrm{NO}_{2}-\mathrm{OH}-\mathrm{H}_{2} \mathrm{O}$, the following binary and higher order electrolytes will be studied,

- Binary: $\mathrm{NaNO}_{3}-\mathrm{H}_{2} \mathrm{O}, \mathrm{NaNO}_{2}-\mathrm{H}_{2} \mathrm{O}, \mathrm{NaOH}-\mathrm{H}_{2} \mathrm{O}$,

- Ternary: $\mathrm{NaNO}_{3}-\mathrm{NaOH}-\mathrm{H}_{2} \mathrm{O}$,

- $\mathrm{NaNO}_{2}-\mathrm{NaOH}-\mathrm{H}_{2} \mathrm{O}$,

$\mathrm{NaNO}_{3}-\mathrm{NaNO}_{2}-\mathrm{H}_{2} \mathrm{O}$

- Quaternary: $\mathrm{NaNO}_{3}-\mathrm{NaNO}_{2}-\mathrm{NaOH}-\mathrm{H}_{2} \mathrm{O}$, 


\section{Data Regression On $\mathrm{NaNO}_{3}-\mathrm{H}_{2} \mathrm{O}$}

- Experimental Data (195 data points):

Osmotic Coeff., water activity, and solubility data

Temperature: 0 to $118^{\circ} \mathrm{C}$

Concentrations: $0.1 \mathrm{~m}$ to $22 \mathrm{~m}$

- Determine the Equilibrium constant for

$\mathrm{NaNO}_{3}$ (aq) $=\mathrm{Na}$ (ion) $+\mathrm{NO}_{3}$ (ion)

$\mathrm{NaNO}_{3}$ (ppt) $=\mathrm{Na}$ (ion) $+\mathrm{NO}_{3}$ (ion)

- Determine ESP Parameters for

$\mathrm{Na}$ (ion) and $\mathrm{NO}_{3}$ (ion) interaction. . 


\section{ESP Activity Coeff. Parameters for $\mathrm{Na}_{\text {and }} \mathrm{NO}_{3}$ Interaction}

- $\quad$ Activity $=$ Activity Coeff. $X$ Concentration

- Activity Coeff.

$=$ Long Range $(\mathrm{z}, \mathrm{I})+$ Short Range $\left(\ldots, \mathbf{b}_{\mathrm{ij}}, \mathbf{c}_{\mathrm{ij}} \mathbf{I}, \mathbf{d}_{\mathrm{ij}} \mathbf{I}^{2}, \ldots\right)$

where $x_{i j}=x_{1}+x_{2} T+x_{3} T^{2} \quad(x=b, c$, and $d)$

and ionic strength $I=1 / 2$ Summation $\left(m_{i} z_{i}^{2}\right)$

\begin{tabular}{|c|c|}
\hline \multicolumn{2}{|c|}{ Bromley Parameters for $\mathrm{Na}$ and $\mathrm{NO}_{3}$ interaction } \\
\hline This work & Sterner et al (1996) \\
\hline $\mathrm{b} 1=4.98 \mathrm{E}-3$ & $\mathrm{~b} 1=1.39 \mathrm{E}-3$ \\
\hline $\mathrm{b} 2=6.07 \mathrm{E}-4$ & $\mathrm{~b} 2=8.38 \mathrm{E}-4$ \\
\hline $\mathrm{c} 1=-1.97 \mathrm{E}-3$ & $\mathrm{c} 1=-4.95 \mathrm{E}-3$ \\
\hline & $\mathrm{c} 2=-1.81 \mathrm{E}-5$ \\
\hline & $\mathrm{d} 1=4.19 \mathrm{E}-4$ \\
\hline
\end{tabular}




\section{$\mathrm{K}_{\mathrm{eq}}(\mathrm{ppt})$ of $\mathrm{NaNO}_{3}$}

\begin{tabular}{|c|c|c|c|}
\hline & \multicolumn{3}{|c|}{ KFIT Parameters For $\mathrm{K}_{\mathrm{NaNO}}$ (Solid) } \\
\hline Coeff. ${ }^{1}$ & This work & Public $^{2}$ & Hanford $^{3}$ \\
\hline a & 5.616 & 1.996 & 4.251 \\
\hline $\mathbf{b}$ & -814.48 & -359.78 & -941.95 \\
\hline $\bar{c}$ & $-8.94 \mathrm{E}-03$ & $4.87 \mathrm{E}-02$ & 0.0 \\
\hline d & $1.13 \mathrm{E}-05$ & 4.82E-06 & 0.0 \\
\hline \multicolumn{4}{|c|}{ Note: 'The te mpe rature de pendent coefficie $n t$ in $\log K=a+b / T+c T+d T^{2}$} \\
\hline${ }^{2}$ The ESP & & & \\
\hline \multicolumn{4}{|c|}{${ }^{3}$ Hanford databank based on Sterner et. al., 1996, PNWD-SA-4436, PNNL } \\
\hline & \multicolumn{3}{|c|}{ K-value for $\mathrm{NaNO}_{3}(\mathrm{ppt})=\mathrm{Na}^{+}+\mathrm{NO}_{3}^{-}$} \\
\hline Temp. & This work & Public ${ }^{*}$ & Sterner \\
\hline $0^{\circ} \mathrm{C}$ & 10.81 & 10.97 & 6.34 \\
\hline $25^{\circ} \mathrm{C}$ & 16.66 & 16.66 & 12.34 \\
\hline $50^{\circ} \mathrm{C}$ & 24.26 & 27.07 & 21.66 \\
\hline $75^{\circ} \mathrm{C}$ & 34.03 & 41.07 & 35.08 \\
\hline $100^{\circ} \mathrm{C}$ & $\overline{46.63}$ & 61.49 & 53.24 \\
\hline
\end{tabular}



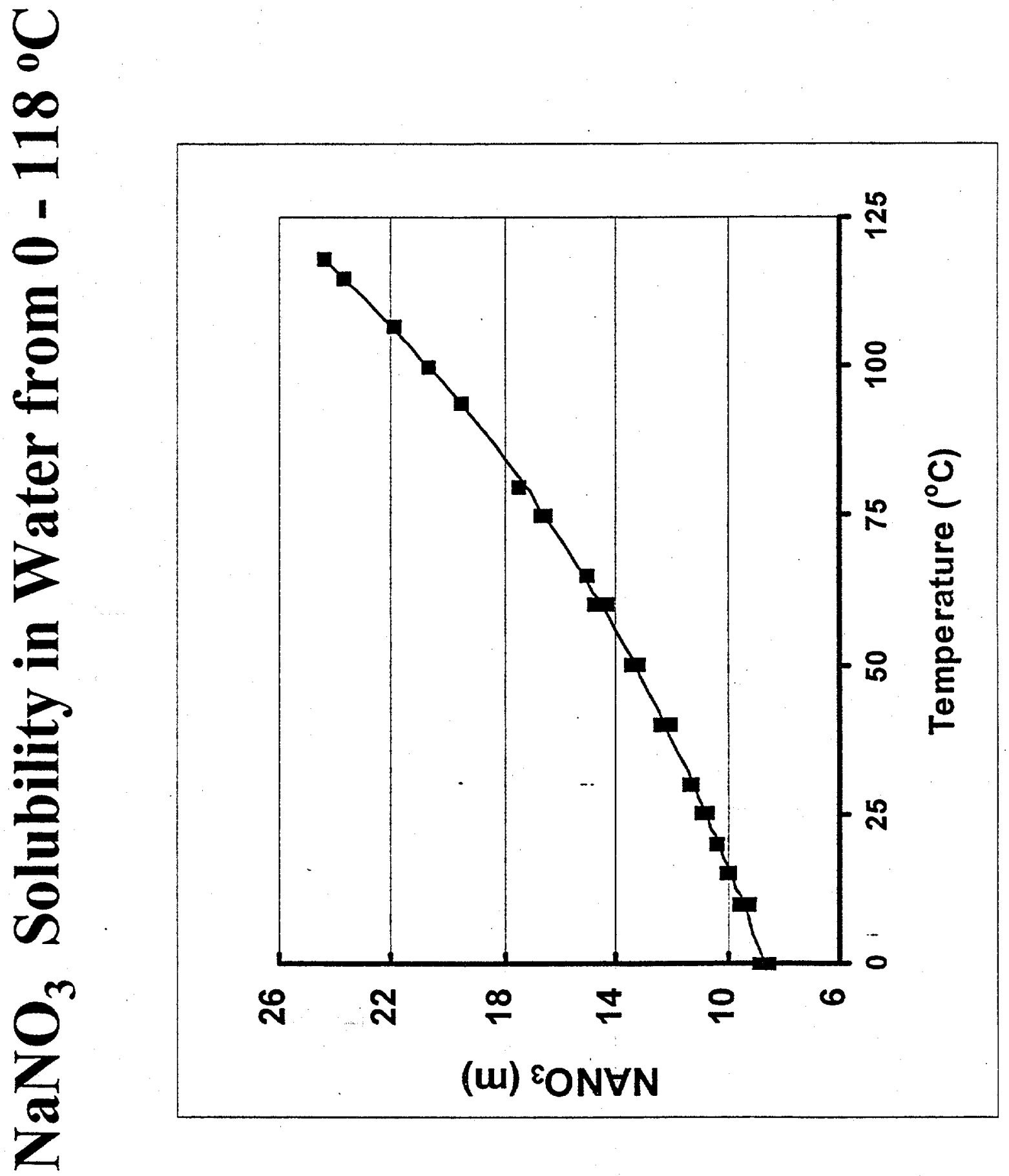

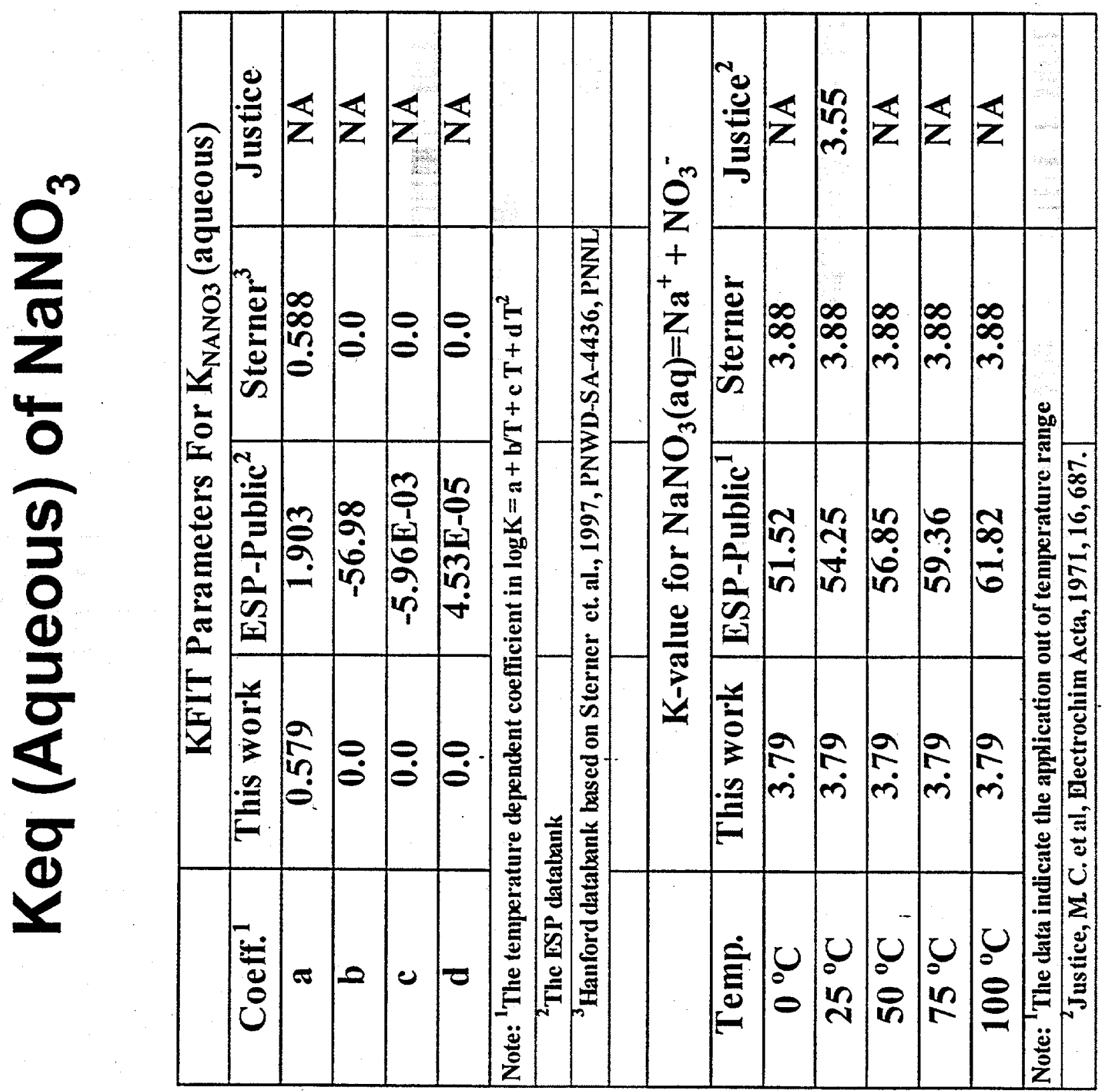


\section{Percent $\mathrm{NaNO}_{3}$ Ion-pair vs Total $\mathrm{NaNO}_{3}$ in Water at Various Temperature}

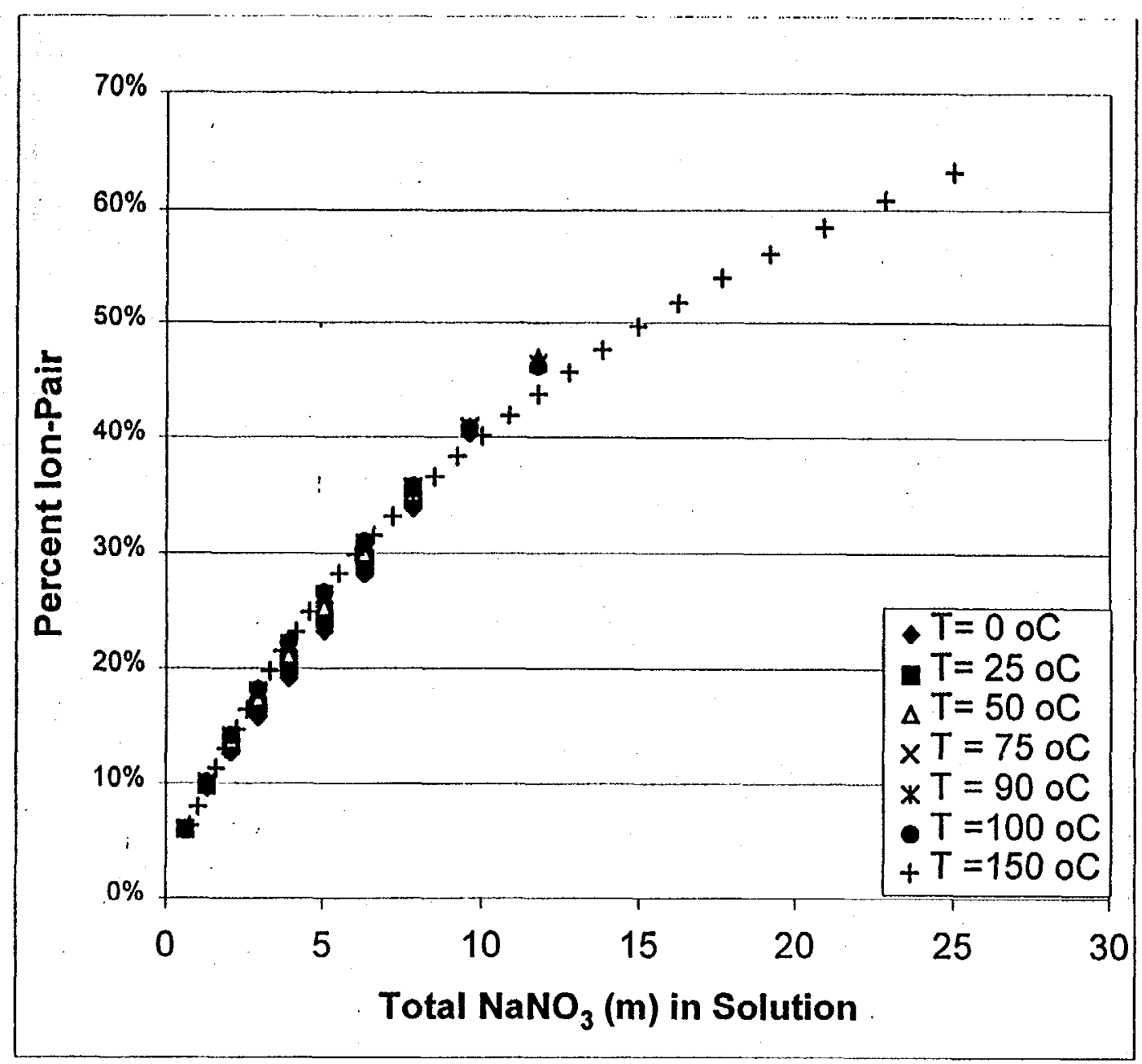



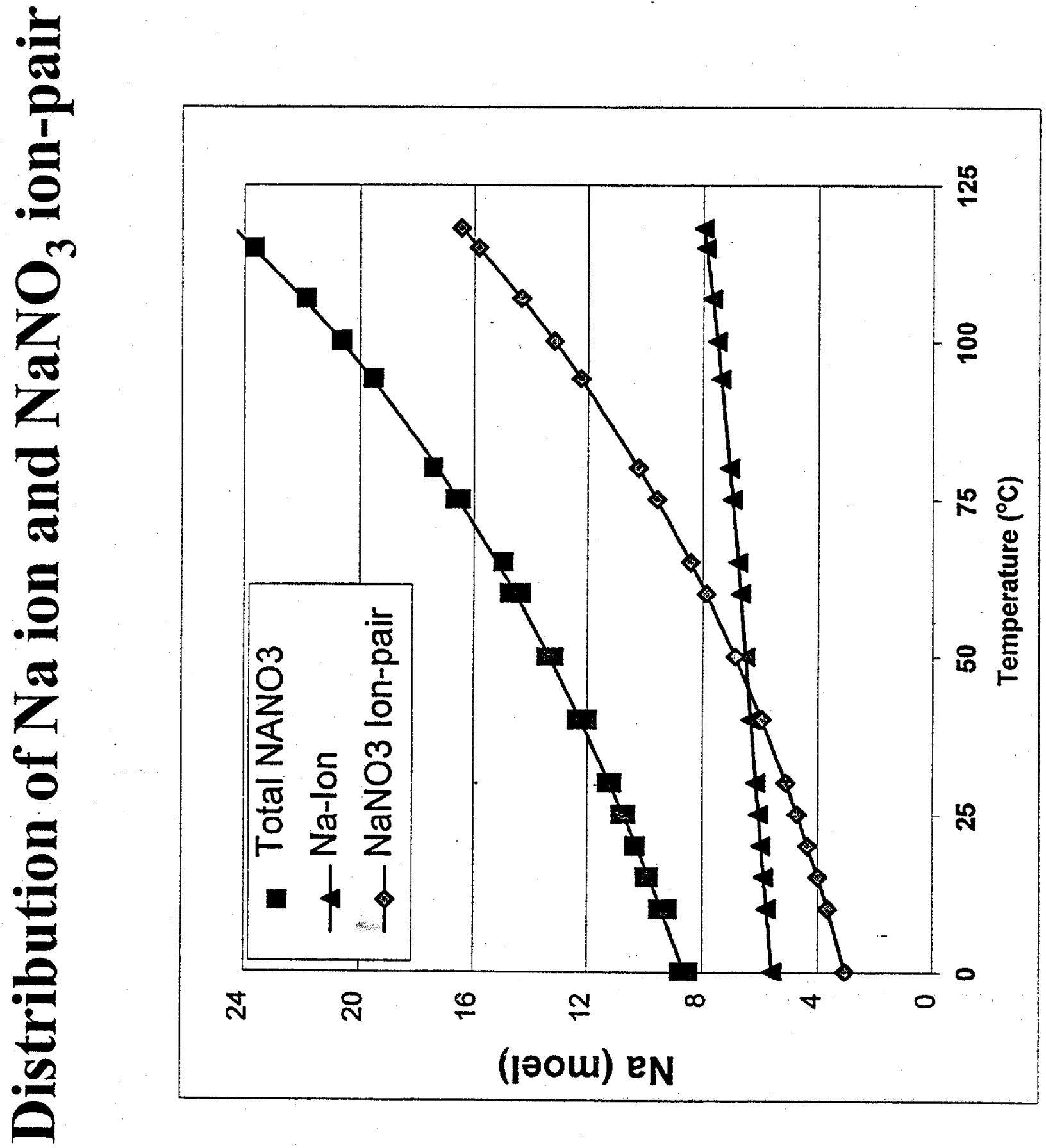


\section{Summary and Discussion of $\mathrm{NaNO}_{3} \cdot \mathrm{H}_{2} \mathrm{O}$}

- This study generated a new set of interaction parameters and equilibrium constants using OLI software, and compared them with the data in Public and Hanford databank.

- In general, the Keq(ppt) agree better with Public for $\mathrm{T}<50{ }^{\circ} \mathrm{C}$, and with Hanford for $\mathrm{T}>50^{\circ} \mathrm{C}$

- The Keq(aq) agree with Hanford and Literature value, while the value is 15 times smaller than Public databank

- The large Keq(aq) value in Public will predict most $\mathrm{NaNO}_{3}$ in water is dissociated and overestimates ionic strength, which will change whole speciation calculations.

- This work shows that $\mathrm{NaNO}_{3}$ in water will only partially dissociate between 5.5 to 7.5 molal at saturate condition from 0 to $100{ }^{\circ} \mathrm{C}$. 


\section{Thoughts: Hydration of $\mathrm{NaNO}_{3}$}

- Aqueous data such as vapor pressure will reflect whether the $\mathrm{NaNO}_{3}$ in water is associated or dissociated because for dissociation the charged ions will trap the polar molecule like $\mathrm{H}_{2} \mathrm{O}$.

- Hydration theory may explain the regression results quantitatively.

- Hydration: an ion in aqueous solution is surrounded by $\mathrm{H}_{2} \mathrm{O}$.

- Hydrated radii (Harris, 1996): 4.5 A for $\mathrm{Na}, 3 \mathrm{~A}$ for $\mathrm{NO}_{3}^{-}, \mathrm{NO}_{2}^{-}, \mathrm{Cl}^{-}$

- Robinson (1948): the hydration number is 3.5 for each $\mathrm{Na}$ and $\mathrm{Cl}$ ion.

- Since $\mathrm{NO}_{3}^{-}, \mathrm{NO}_{2}^{-}$, and $\mathrm{Cl}^{-}$have the same hydrated radii, it is logic to set hydration number as 3.5 to each $\mathrm{Na}$ and $\mathrm{NO}_{3}$ ions. From the regressions, the ratio of moles water to dissociated $\mathrm{Na}$ and $\mathrm{NO}_{3}$ ion per liter is about 4.2 in this work and 4.0 for Sterner et al (1996), which is close to the hydration number of $\mathrm{Na}$ and $\mathrm{NO}_{3}$.

- Possible experiment: FTIR in Aqueous Solution 


\section{On-going and Near Future Work}

- To continue the regression work on $\mathrm{Na}-\mathrm{NO}_{3}-\mathrm{NO}_{2}-\mathrm{OH}-\mathrm{H}_{2} \mathrm{O}$ system

- To study Na-Al-OH-H $\mathrm{H}_{2} \mathrm{O}$ system and the system with $\mathrm{NaNO}_{3}$ and $\mathrm{NaNO}_{2}$ salts.

- Dan Herting's (FDH) data

- Jun Liu's (PNNL) data

- Literature data

- To study the system of $\mathrm{Na}^{-}-\mathrm{PO}_{4}-\mathrm{OH}-\mathrm{H}_{2} \mathrm{O}$ and $\mathrm{Na}-\mathrm{SO}_{4}-\mathrm{OH}-\mathrm{H}_{2} \mathrm{O}$.

- The newly established parameters will be reviewed by OLI, validated with waste data continuously, and documented. 


\section{General Comments on Existing Databanks}

- ESP Public databank need to be customized systematically to characterize Hanford waste.

- Efforts in the Hanford databank (Sterner et al. 1996) provide a good start and guidelines to better characterize the parameters for the databank reconstruction.

- Special databank (MacLean) and other available databank contains information of species identified in Hanford waste but not available in Public and can be evaluated and consolidated to reconstruct the databank. 


\section{Hanford Waste Speciation Prediction (HWSP) Code}

- HWSP is a customized code to speed-up and automate the efforts for modeling Hanford Waste using OLI software

- HWSP code developed in Visual-Basic within MS Excel provides frontend capability to interface OLI thermodynamic code and can be bridged to other engineering calculations such as HTWO modeling.

- Phase I development focused on automating the speciation modeling of the tank waste inventory. The code incorporates all the required user interactive procedures and possible logic/iterations of modeling efforts to get the speciation results in one-keystroke.

- Phase II development will automate process simulations like dilution or leaching. 


\section{Current Status of HWSP}

- The code predicts the species directly with input tank waste inventory, and it can handle five tanks at one time and takes about half hour per tank.

- It provides the choice to reconcile the input data and the choice to optimize the input data to match the $\mathrm{Cr}$, TOC, $\mathrm{pH}$, and $\mathrm{wt} \%$ water data in liquid phase.

- Needs more polishing, feature-adding and validation to work properly and easily. It also requires a better database to understand the issues while developing the logic to automate the simulation. 


\section{Acknowledge}

- Thanks to CHG Retrieval Engineering/Process Development for providing funding.

- Thanks to Graham MacLean, Randy Kirkbride, Ron Orme, James Jewett, Jim Person, Dan Reynolds and Kent Hodgson for their input and useful discussion.

- Thanks to Andy Felmy for providing the experimental raw data and useful discussion. 


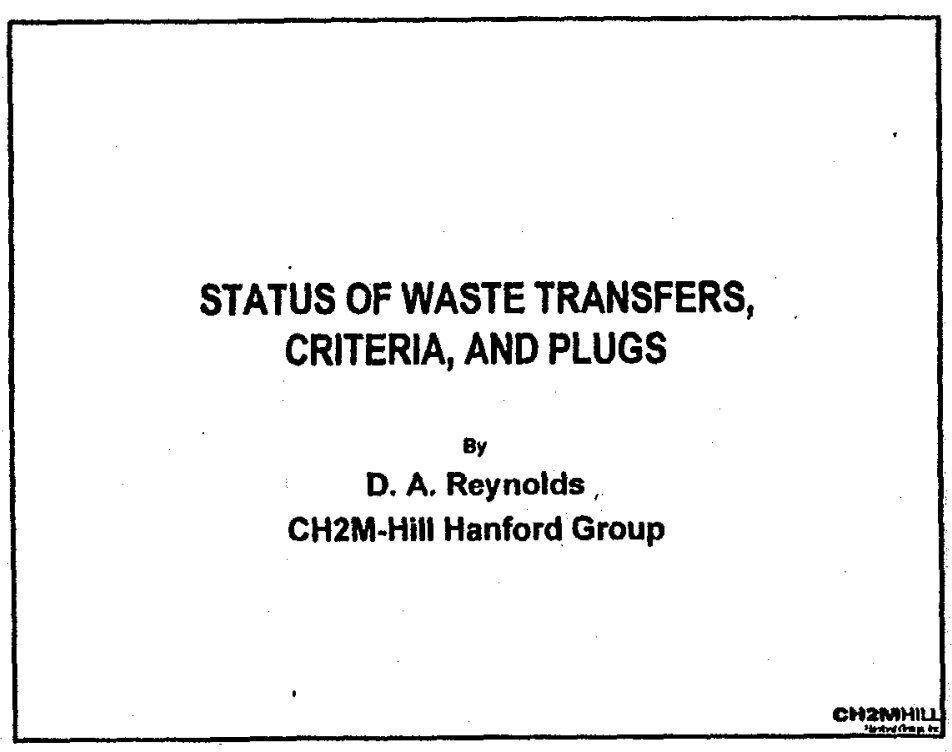

$\ddot{\sigma}$

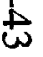

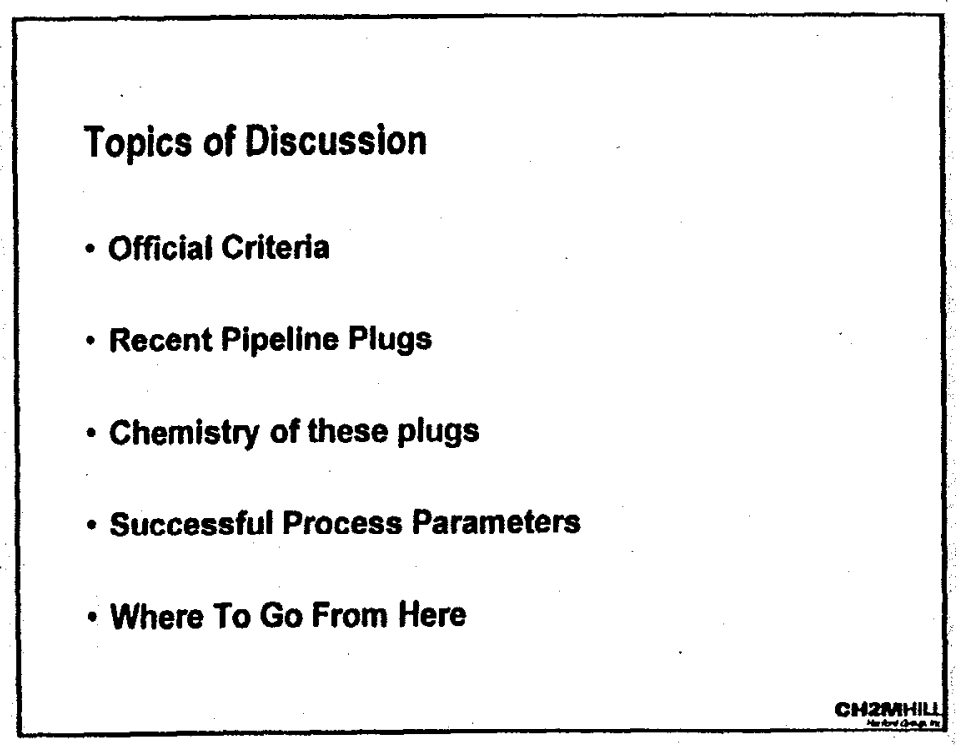

\section{INTRODUCTION}

- Hanford has $\mathbf{5 3 . 7}$ millions of gallons of waste - all has to be moved.

- The solids will be dissolved or slurried to move.

- Currently are removing liquid waste from singleshell tanks (about 1 million gallons per year.)

\section{Current "Official" Criteria}

- Waste Compatibility Program has limits for liquids and slurries of 1.41 specific gravity.

- Cross-site Transfer System has limits for liquids and wt\% solids. Currently only transferring liquids.

- Liquids must stay below 1.35 SPG with less than 30 wt $\%$ solids. 


\section{Recent Plugs}

- There has been three plugs in the last 5 years.

- BY-103

- SX-104

- U-103

\section{SX-104}

- Pumping with ineffective dilution.

- Stopped for a while. Plug formed in unheated jumper on restart.

- Eventually unplugged with hot water flush.

- Improved dilution scheme.

\section{BY-103}

- Was jet pumping without dilution and told to shut off without flushing due to flammable gas concern.

- Some months later the plug was discovered.

- Could move plug about $\mathbf{4 0 0}$ feet from either end.

- Could not attack with chemicals.

- Abandoned the pipeline.
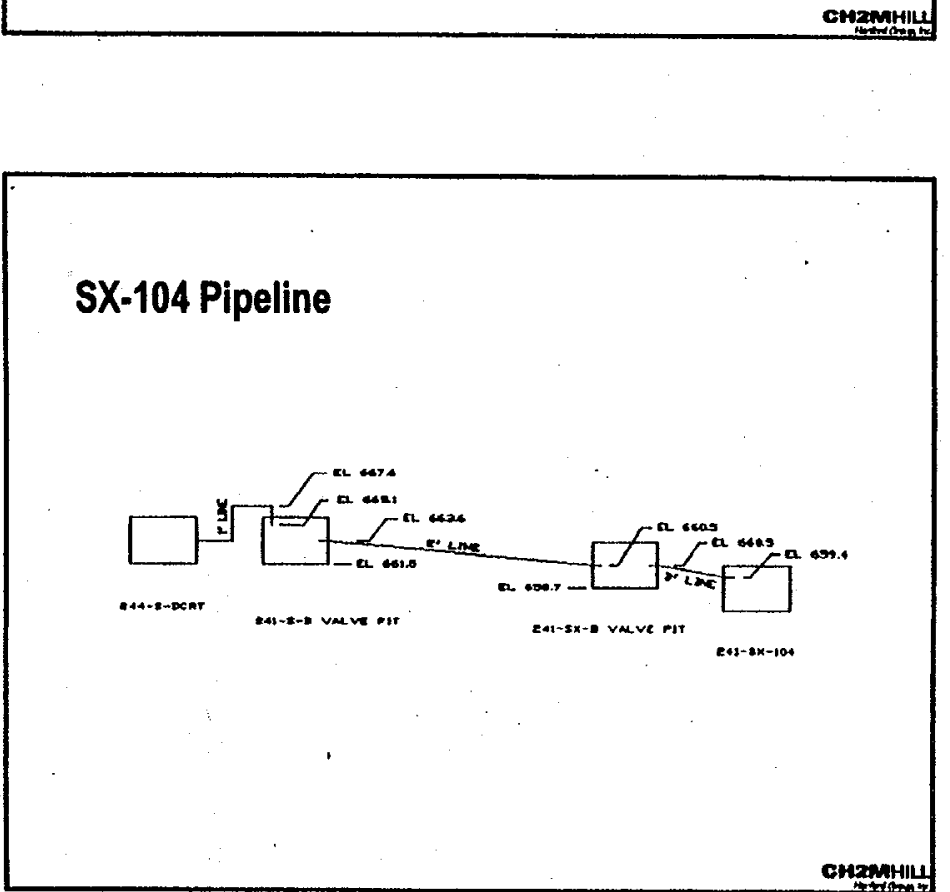


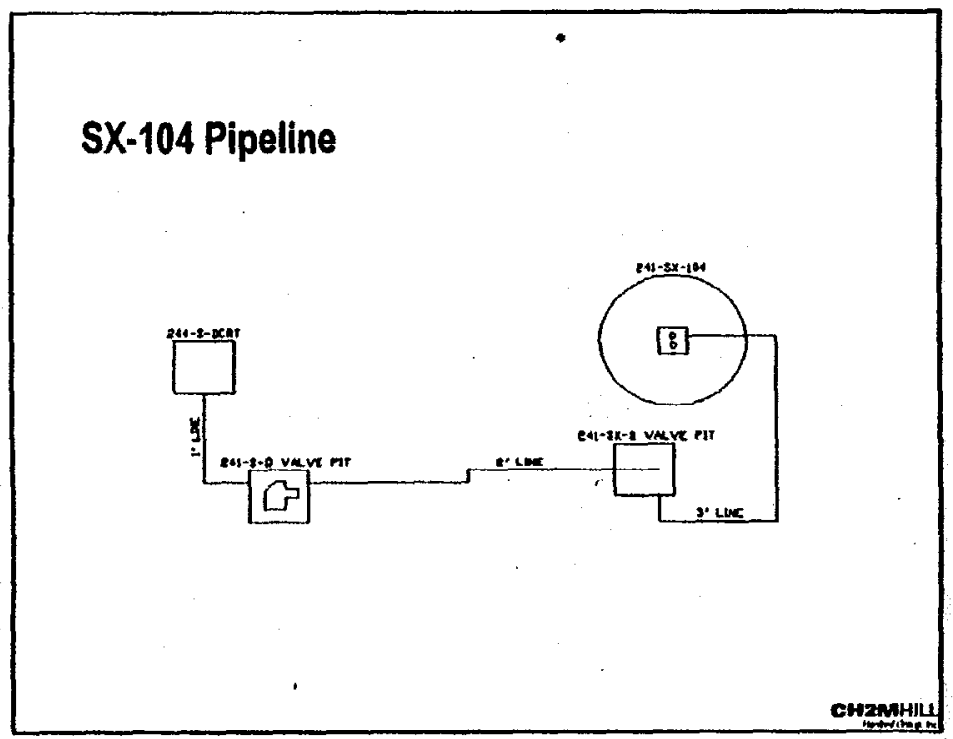

U-103

- Pump stopped. No flush for over 24 hours.

- On restart, a plug formed in non-heat traced jumper.

- Jumper pulled to break plug.

- Currently using the line.

$\Phi$

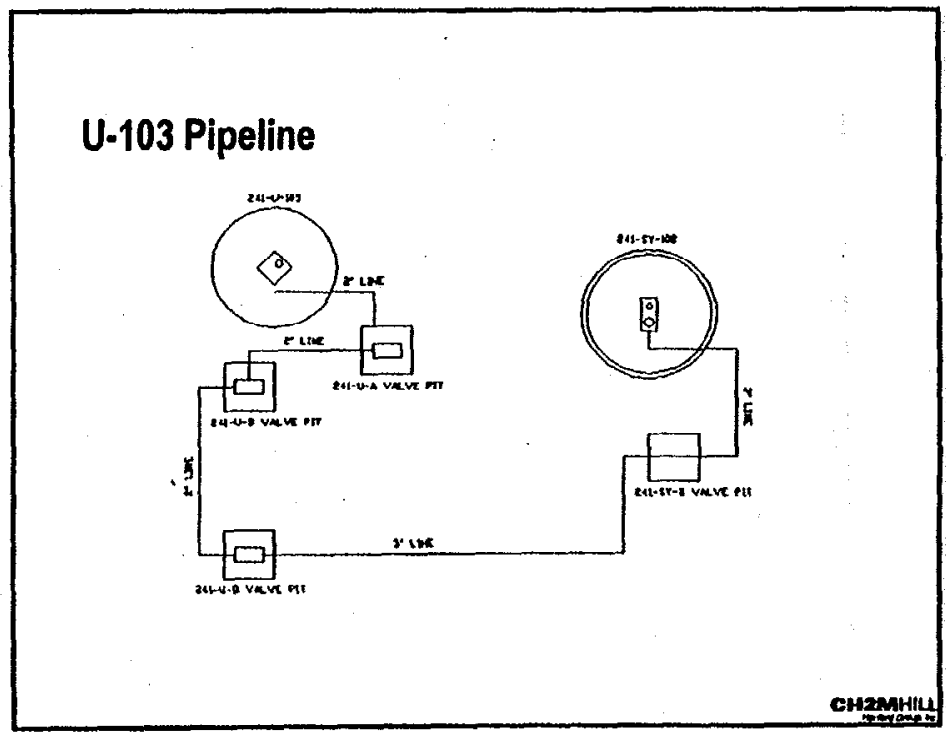

\section{Chemistry of Plugs}

- Liquid from salt cake is at saturation and often warm.

- Sodium phosphate is special problem due to crystal habit, low solubility, and high temperature dependency. 


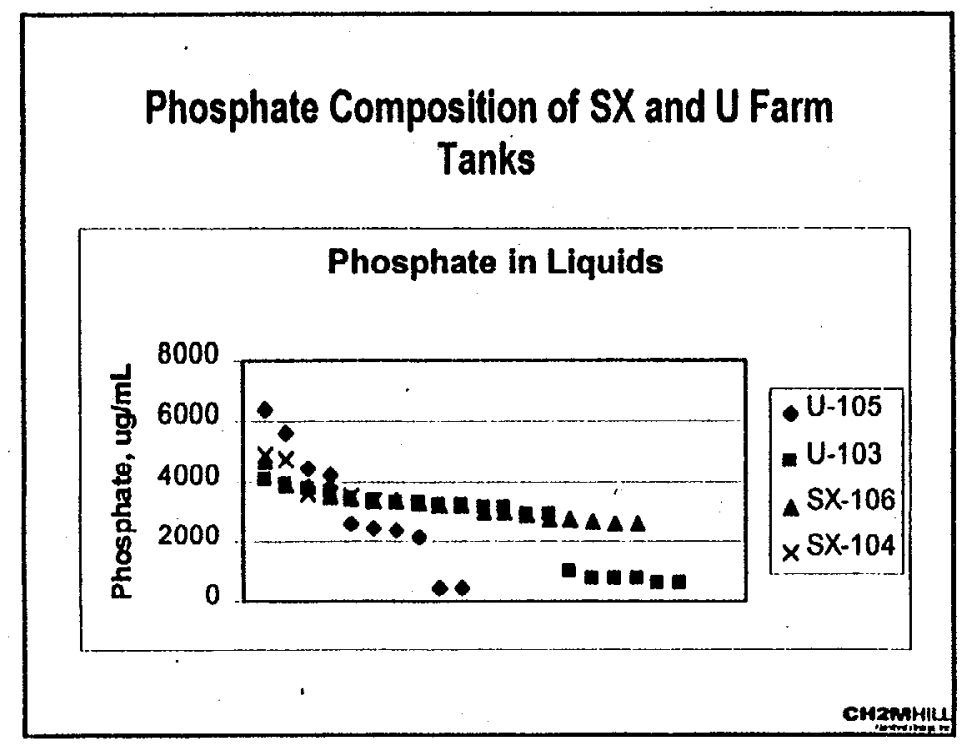

Phosphate Phase Diagram Showing Temperature Dependency

Sodium Phosphate solubility in Water

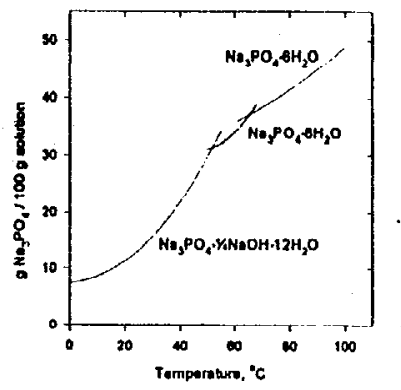

congnum

$\frac{0}{a}$

Photo of Sodium Phosphate

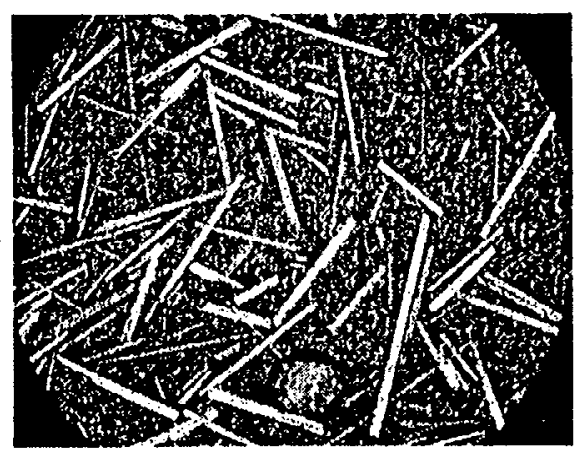

Photo of Sodium Fluoride Phosphate

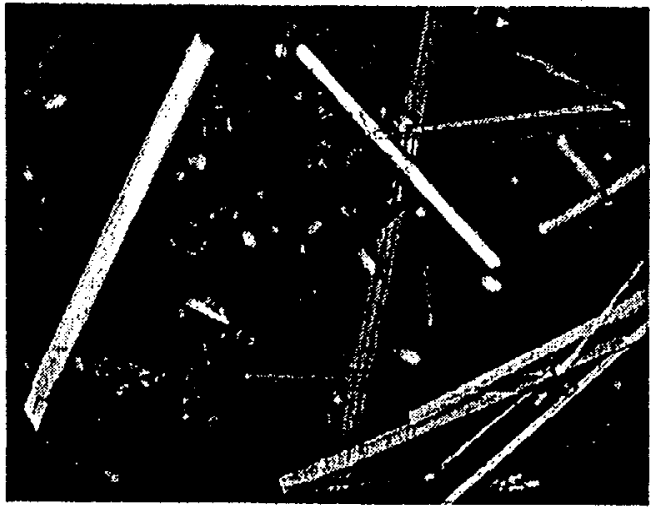



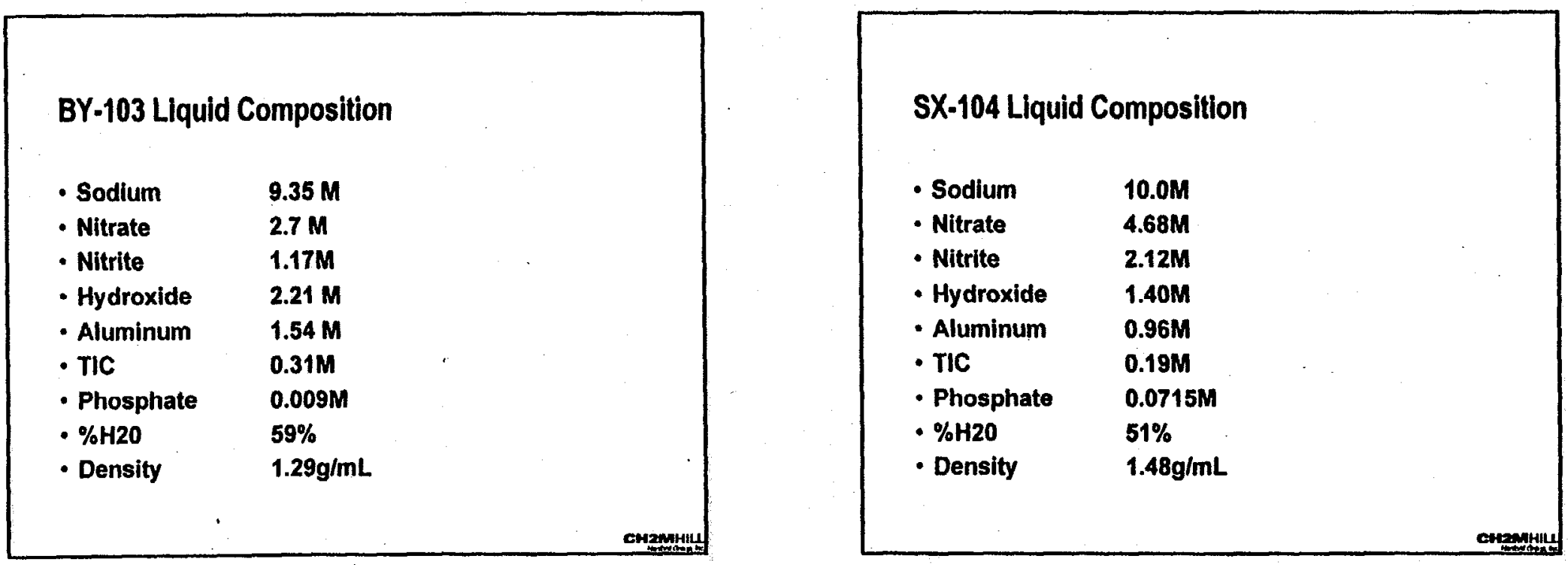

\begin{tabular}{|ll|}
\hline & \\
U-103 Liquid Composition \\
& \\
- Sodium & $10.5 \mathrm{M}$ \\
- Nitrate & $2.8 \mathrm{M}$ \\
- Nitrite & $2.8 \mathrm{M}$ \\
- Hydroxide & $2 \mathrm{M}$ \\
- Aluminum & $1.4 \mathrm{M}$ \\
- TIC & $0.3 \mathrm{M}$ \\
- Phosphate & $0.017 \mathrm{M}$ \\
- \%H20 & $50 \%$ \\
- Density & $1.43 \mathrm{~g} / \mathrm{mL}$ \\
& \\
\hline
\end{tabular}

\section{Successful Dilution Strategies and Flushing}

- 1:1 has worked for dilution

- 1:1 up to $2 \mathrm{gpm}$ of water, then $2 \mathrm{gpm}$ water max

- Flush with 1 line volume

- Flush when pump down for $>2$ hours

- Flush every week

- Currently, flush every 21 days

- Clock reset every time flush

- Assuring heat trace is functional 


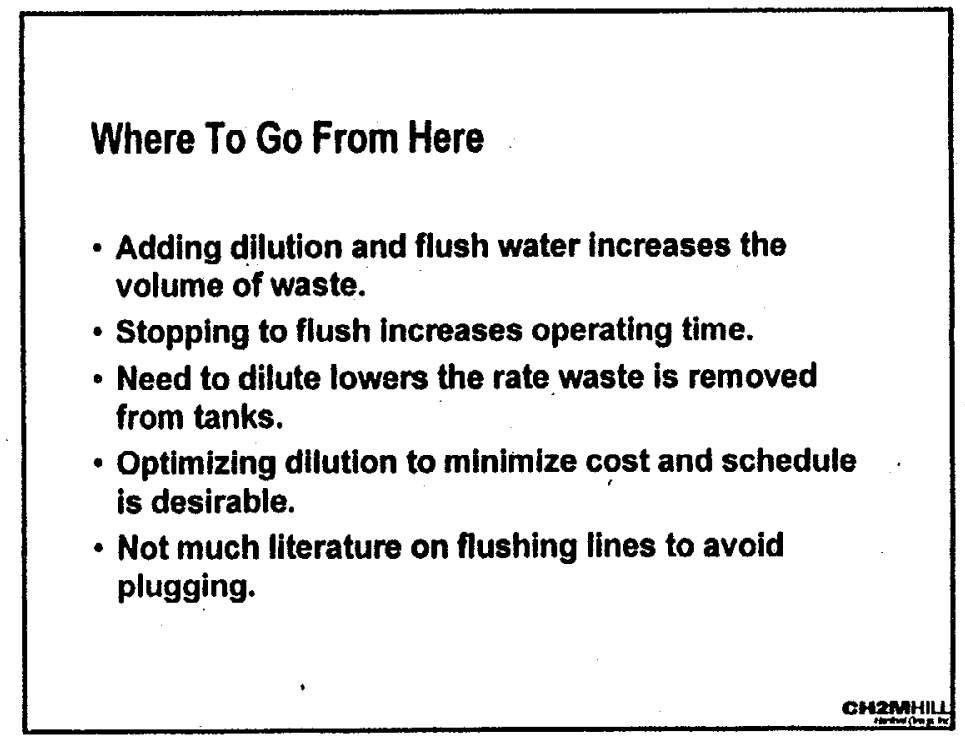

